NBSIR 75-972

\title{
Skid Resistance Measurement Tests at the FHWA Eastern Field Test Center
}

R. W. Kearns and J. F. Ward

Engineering Mechanics Section

Mechanics Division

Institute for Basic Standards

National Bureau of Standards

Washington, D. C. 20234

August - October 1974

Final

Issued July, 1976

Prepared for

Federal Highway Administration Office of Development

Washington, D. C. 



\section{SKID RESISTANCE MEASUREMENT}

TESTS AT THE FHWA EASTERN

\section{FIELD TEST CENTER}

R. W. Kearns and J. F. Ward

Engineering Mechanics Section

Mechanics Division

Institute for Basic Standards

National Bureau of Standards

Washington, D. C. 20234

August - October 1974

Final

Issued July, 1976

Prepared for

Federal Highway Administration

Office of Development

Washington, D. C.

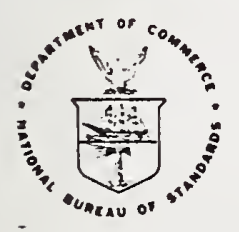

U.S. DEPARTMENT OF COMMERCE, Elliot L. Richardson, Secretary

Edward O. Vetter, Under Secretary

Dr. Betsy Ancker-Johnson, Assistant Secretary for Science and Technology

NATIONAL BUREAU OF STANDARDS, Ernest Ambler, Acting Director 
Federal Highway Administration Policy

The opinions, findings and conclusions expressed in this publication are those of the authors and not necessarily those of the Federal Highway Administration. 
CONTENTS

1. INTRODUCTION

2. PREPARATION, MEASUREMENT AND ADJUSTMENT OF SUBSYSTEMS

2.1 Test Preparations

2.1.1 Auxiliary Test Equipment

2.1.2 Test Tires

2.2 Skid Trailer Weight Distribution

2.3 Tow Vehicle Displacements

2.4 Speed Measuring Subsystem

2.5 Pavement Wetting Subsystem

2.5.1 Flow Rate Measurement

2.5.2 Water Distribution - Static Measurements

2.5.3 Water Distribution - Dynamic Measurements

2.5.4 Wetted Width Measurement

2.6 Force Measuring Subsystem 24

2.6.1 Transducer Excitation Stability 29

2.6.2 Orientation of the Transducer 29

2.6.3 Vertical Load Channel Calibration 29

2.6.4 Traction Channel Calibration 31

2.6.5 On-Board Calibration System Equivalent Values 31

2.7 Suspension Subsystems 31

2.7.1 Tow Vehicle and Trailer Displacements under 33.

Static Traction Load

2.7.1.1 Displacement of the Test Wheel Hub 33

2.7.1.2 Displacement of the Trailer Body 35

2.7.1.3 Displacement of the Trailer Body
Dish Roll Axis Rotation

through Pitch Axis Rotation

2.7.2 Trailer Displacements under Transient Loading 35

2.7.2.1 Effective Coulomb Friction of the 35

Trailer Suspension

2.7.2.2 Effective Spring Rate of the 39

Trailer Suspension

2.7.2.3 Effective Natural Frequencies of the 39

Trailer Suspension

2.7.2.4 Effective Viscous Damping of the Trailer Suspension 
3. THE DYNAMIC SKID RESISTANCE MEASUREMENT OF SELECTED SURFACES AND FARS-IRS CORRELATION

3.1 Surfaces Selected

3.2 Tests Planned

3.3 The Test Matrix

3.4 Tests Accomplished

3.5 Control of Test Variables

3.6 Measurement of Uncontrolled Test Variables

3.7 The Correlation Test Plan

3.8 Test Matrix Results

3.9 Skid Resistance Speed Gradient

3.10 The Correlation Equation

3.11 Use of the Correlation Equation

\section{REFERENCES}

Appendix A. Exploratory Tests of the Dynamic Distribution Gage

Appendix B. The Test Matrix

Appendix C. General Description of the Eastern Area 
TABLES

1. EARS Flow Rates.

2. DDG Data: IRS, $40 \mathrm{mph}(64 \mathrm{~km} / \mathrm{h})$.

3. DDG Data: Comparison of Water Collected with Water Pumped.

4. Wetted Width Measurements.

5. Tests Planned and Accomplished.

6. Test Flow Sequence.

7. Weather during Test Plan Time Periods.

8. Ranking of Possible Sources of Dispersion.

9. Correlation Summary.

A-1 DDG Data: Comparison of Water Collected with Water Pumped, Dry Basin. 


\section{ILLUSTRATIONS}

1. Test tire radial spring rate test setup.

2. Change in tow vehicle hitch height with load.

3. Change in tow vehicle rear wheel radius with load.

4. Radar test of EARS speed system.

5. Simultaneous speed data recorded by the stationary radar and the EARS tow vehicle in motion (fifth wheel).

6. EARS pavement wetting based on 7.5 in $(19.1 \mathrm{~cm})$ wetted width compared with ASTM E274-70 water layer tolerance.

7. IRS flow channel, showing water flow into SDG basin.

8. SDG sight tube array.

9. Static water distribution at $20 \mathrm{mph}(32 \mathrm{~km} / \mathrm{h})$.

10. Static water distribution at $40 \mathrm{mph}(64 \mathrm{~km} / \mathrm{h})$.

11. Static water distribution at $60 \mathrm{mph}(97 \mathrm{~km} / \mathrm{h})$.

12. EARS pavement wetting system test using the DDG.

13. Dynamic distribution. Depth scale based on slot dimensions.

14. Measurement of water trace width after the trailer has passed.

15. Wetted width by delayed measurement on pavement.

16. Arrangement for photography of wetted width.

17. Application of a simulated traction force to a locked test wheel through an air-bearing force plate.

18. EARS wheel transducer linearity - vertical load channel after trailer modifications.

19. EARS wheel transducer linearity - traction channel.

20. Displacement of the test wheel hub due to static traction.

21. Roll displacement of the trailer body due to static traction.

22. Pitch displacement of the trailer body due to static traction.

23. Coulomb damping test response.

24. Axle drop test response.

25. Effective viscous damping envelope.

26. Effect of different damping factors on second-order linear systems. 
27. Location of selected surfaces and pylons at EFTC.

28. Surface temperatures during dynamic testing.

29. Texture of skid resistance surface number 1 .

30. Texture of skid resistance surface number 2 .

31. Texture of skid resistance surface number 3 .

32. Texture of tire wear on surface number 1 .

33. Texture of tire wear on surface number 2 .

34. Texture of tire wear on surface number 3 .

35. IRS results from measurements made at EFTC during single time periods.

36. EARS results from measurements made at EFTC during single time periods.

37. IRS results from measurements made at EFTC during multiple time periods.

38. EARS results from measurements made at EFTC during multiple time periods.

39. Possible tire dispersion calculated from IRS measurements on surface 3 at the EFTC.

40. Possible tire dispersion calculated from IRS measurements on surfaces 1 and 2 at the EFTC.

41. Possible lane dispersion calculated from IRS measurements on surface 3 at the EFTC.

42. Possible lane dispersion calculated from IRS measurements on surfaces 1 and 2 at the EFTC.

43. Possible time period dispersion calculated from IRS measurements on surfaces 1,2 , and 3 at the EFTC.

44. EARS-IRS correlation.

A-1 Dynamic distribution (dry basin).

A-2 IRS operating on the DDG.

A-3 IRS pavement wetting on solid pavement ahead of the DDG grate.

A-4 Severe splashing over the DDG.

C-1 EARS test cycle sequence of events. 



\title{
SKID RESISTANCE MEASUREMENT TESTS \\ AT THE \\ FHWA EASTERN FIELD TEST CENTER
}

August and October, 1974

\begin{abstract}
The measurement of the skid resistance of highways, under wet weather conditions, is part of the Federal Highway Administration (FHWA) skid accident reduction program. To standardize and to improve the precision of the measurements, the program includes national and regional reference systems to which the highway measuring systems may be systematically related. This report describes evaluation tests conducted at the FHWA Eastern Field Test Center (EFTC) which included the use of the Eastern Area Reference System (EARS) and the Interim Reference System (IRS) maintained by the National Bureau of Standards. The performance characteristics of the EARS, its subsystems and a correlation equation between the EARS and the IRS are presented. A method of quantifying sources of dispersion is applied to the measurements made by the IRS on the EFTC reference surfaces. Recommendations for modifications to the EARS, the test procedures, and EFTC facilities are made.
\end{abstract}

Key Words: Accident reduction, skidding; correlation, skid resistance; highway safety; pavement, skid resistance; pavement wetting system; tire-pavement interface forces; wet pavement.

\section{INTRODUCTION}

The measurement of the skid resistance of highways, under wet weather conditions, is part of the Federal Highway Administration (FHWA) skid accident reduction program. Currently, the majority of state highway departments measure pavement skid resistance with lockedwheel skid measurement systems, which are reported to be in substantial compliance with the requirements of ASTM Designation E274-70 [1].* To reduce the variability between measurement results from different designs of systems meeting these requirements and to improve the precision of the measurements made by a given system, FHWA is developing a hierarchial

*Figures in brackets indicate the literature references at the end of this report. 
system for the measurement of pavement skid resistance [2]. At the national level, the FHWA program provides for an interim reference system (IRS) maintained by the National Bureau of Standards (NBS). At the regional level, the program provides for area reference systems (ARS) maintained at FHWA Field Test Centers (FTC). At the state level, skid resistance measuring systems are maintained to inventory and rank the condition of the highways in accordance with their skid resistance. The plan to assure measurement consistancy between the states includes the monitoring and development of test procedures and equipment by NBS to relate the measurements made within the hierarchial system to the national measurement system.

The measurement assurance program for the FTC and ARS includes the periodic evaluation of test facilities and procedures, determination of the performance characteristics of the ARS and its subsystems, measurement of selected reference surfaces maintained at the FTC with the IRS, and correlation of the measurements made by the ARS and IRS. The program also includes the evaluation of new test equipment and procedures, and experimental studies for the development of numerical data, where appropriate, to identify and quantify sources of difference in the skid number measurements. As a result, improvements in procedure and equipment are expected as the program develops with the increased measurement capabilities being transferred to the highway measurement systems at the FTC.

This report describes tests conducted under the direction of NBS personnel at the FHWA Eastern FTC (EFTC) during periods in August and October, 1974.

\section{PREPARATION, MEASUREMENT AND ADJUSTMENT OF SUBSYSTEMS}

Previous results from skid trailer correlation test programs indicated the measurements lacked precision, agreement among trailers using selfwatering systems was poor, and the causes for the differences between trailer measurements was difficult to define [3]. To identify sources of these differences, certain preparations were made and auxiliary equipment and experiments were designed to measure, and intercompare with the IRS, the performance characteristics of the components and subsystems. When conditions were found to be outside the ASTM requirements or conditions were found that would adversely affect the peformance of the total EARS system, adjustments and modifications were made or recommended.

\subsection{Test Preparations}

Auxiliary test equipment and facilities of the EFTC were used to prepare the EARS for test. Test tires were prepared for test. 


\subsubsection{Auxiliary Test Equipment}

Skid resistance is reported in terms of skid number which is determined from the force required to slide a locked test tire at a stated speed in the presence of a water layer applied to the pavement ahead of the test tire, divided by the effective wheel load and multiplied by 100. The thickness of the water layer, the speed and forces at the tirepavement interface are the principal quantities to be measured. To relate these measurements to the national measurement system, auxiliary test equipment was designed using component types which are routinely calibrated in various NBS laboratories.

Two load cells, calibrated to a $0.25 \mathrm{Ibf}(1.1 \mathrm{~N})$ uncertainty in the Engineering Mechanics Section, were utilized in a test fixture to apply simultaneously known traction and load forces to a force plate during its calibration [4]. The force plate was used subsequently to calibrate the force transducer of the trailers (Section 2.6).

A turbine flow rate meter was calibrated, to a 0.06 gpm (0.23 1iters/ min) uncertainty, in the Fluid Meters Section. Calibrations were obtained for the turbine both alone and as part of a digital differential flow rate system having a $0.1 \mathrm{gpm}(0.4$ liters/min) resolution. The system is part of the on-board IRS instrumentation, but is adaptable to measuring the flow rate in the ARS (Section 2.5).

A differential radar speed meter, whose time base was calibrated against the standard frequency and whose radiated frequency is specified to be well within its $0.1 \mathrm{mph}(0.16 \mathrm{~km} / \mathrm{h})$ resolution, is used to record the speed of the system during a skid resistance measurement (Section 2.4).

Other auxiliary equipment includes a voltmeter, calibrated to one millivolt uncertainty by the Electrical Instruments Section; an inflation pressure gage, calibrated to $0.05 \mathrm{psi}$ (345 Pa) uncertainty by the Pressure and Vacuum Section; and an automatic sequential displacement recording system (Section 2.7 ).

\subsubsection{Test Tires}

In preparation for the testing at the EFTC, each of 20 ASTM E501 test tires to be used was mounted on a wheel, balanced, and broken in with a 200 mile $(320 \mathrm{~km})$ drive. In addition, the nominal radial spring rate was determined at NBS. The spring rate value was $1280 \mathrm{lbf} /$ in $(224 \mathrm{kN} / \mathrm{m})$ at 24 psi (165 kPa) inflation pressure undei $10851 \mathrm{bf}(4800 \mathrm{~N})$ load after break in. This value was determined from radial load versus deflection data obtained with the test setup shown in Figure 1 . 


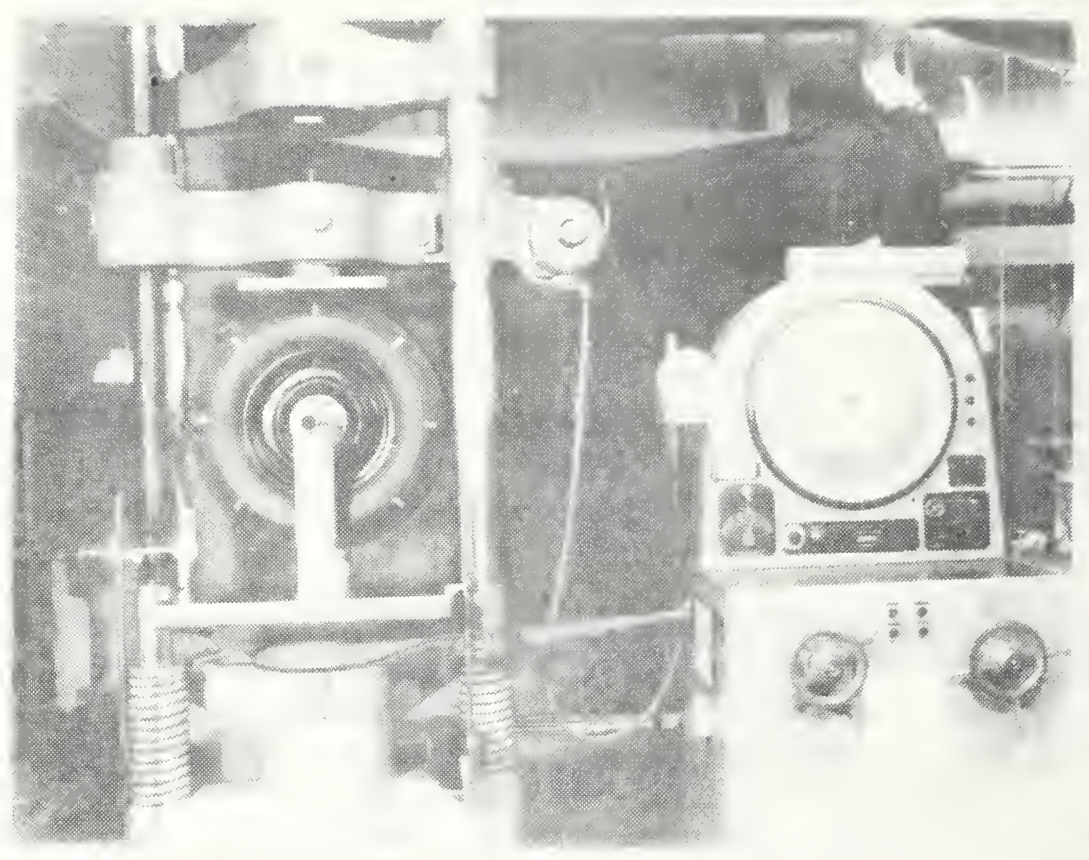

Figure 1. Test tire radial spring rate test setup. 


\subsection{Skid Trailer Weight Distribution}

To measure the static vertical wheel loads of the test trailer, a force plate was placed under each traller tire and a vertical load cell was placed under the hitch. The air bearings of the force plates were inflated, water placed in the trailer hose and the trailer leveled. Readings were then taken simultaneously. The measured weight distribution for the EARS was:

$$
\begin{aligned}
& \text { Driver's side test wheel load }=10991 \mathrm{bf}(4888 \mathrm{~N}) \\
& \text { Passenger's side wheel load }=1084 \mathrm{lbf}(4821 \mathrm{~N}) \\
& \text { Hitch vertical load }
\end{aligned}
$$

Load adjustments to bring the trailer within the desired range of 1080 to $1090 \mathrm{lbf}(4800$ to $4850 \mathrm{~N}$ ) were to be made by EFTC personnel during the planned time period between the subsystem testing and the dynamic skid resistance measurement testing.

\subsection{Tow Vehicle Displacements}

Changes in the tow vehicle hitch height and rear wheel radius were measured as a function of operator and passenger weight and water load. Changes in hitch height affect the skid number measurement in two ways; the vertical load reduction factor is altered and the transducer is rotated such that a component of the vertical load may be measured as traction (Section 2.6). Changes in tow vehicle rear wheel radius change the water pump rate. The results, shown in Figure 2, show that hitch height displacements are much more sensitive to water load than passenger load in this case. The IRS is less sensitive to water load changes than the EARS. Figure 3 indicates the wheel radius changes nearly one percent over the range of a full water load even though dual wheels are used on the EARS.

\subsection{Speed Measuring Subsystem}

The EARS uses separate speed measuring systems for driver aid purposes and for test recording purposes. The driver aid signal was derived from a fifth wheel pulse transducer system on the tow vehicle while the recorded signal was generated by a tachometer generator on the right wheel of the trailer. To avoid confusion and possible error from use of this dual system, a commercial digital-to-analog (D/A) converter was installed so that the recorded speed signal was also derived from the fifth wheel. This recorded signal had a one mile per hour step resolution.

After the above modification, the EARS system (fifth wheel) was adjusted on the measured mile [5] and then checked against the IRS radar system (Fig. 4). The comparative results of a test at about $40 \mathrm{mph}$ $(64 \mathrm{~km} / \mathrm{h})$ are shown in Figure 5. These tests showed the differences between the radar and EARS to be less than $0.5 \mathrm{mph}(0.8 \mathrm{~km} / \mathrm{h})$ at speeds of 20,40 , and $60 \mathrm{mph}(32,64$, and $97 \mathrm{~km} / \mathrm{h})$. 


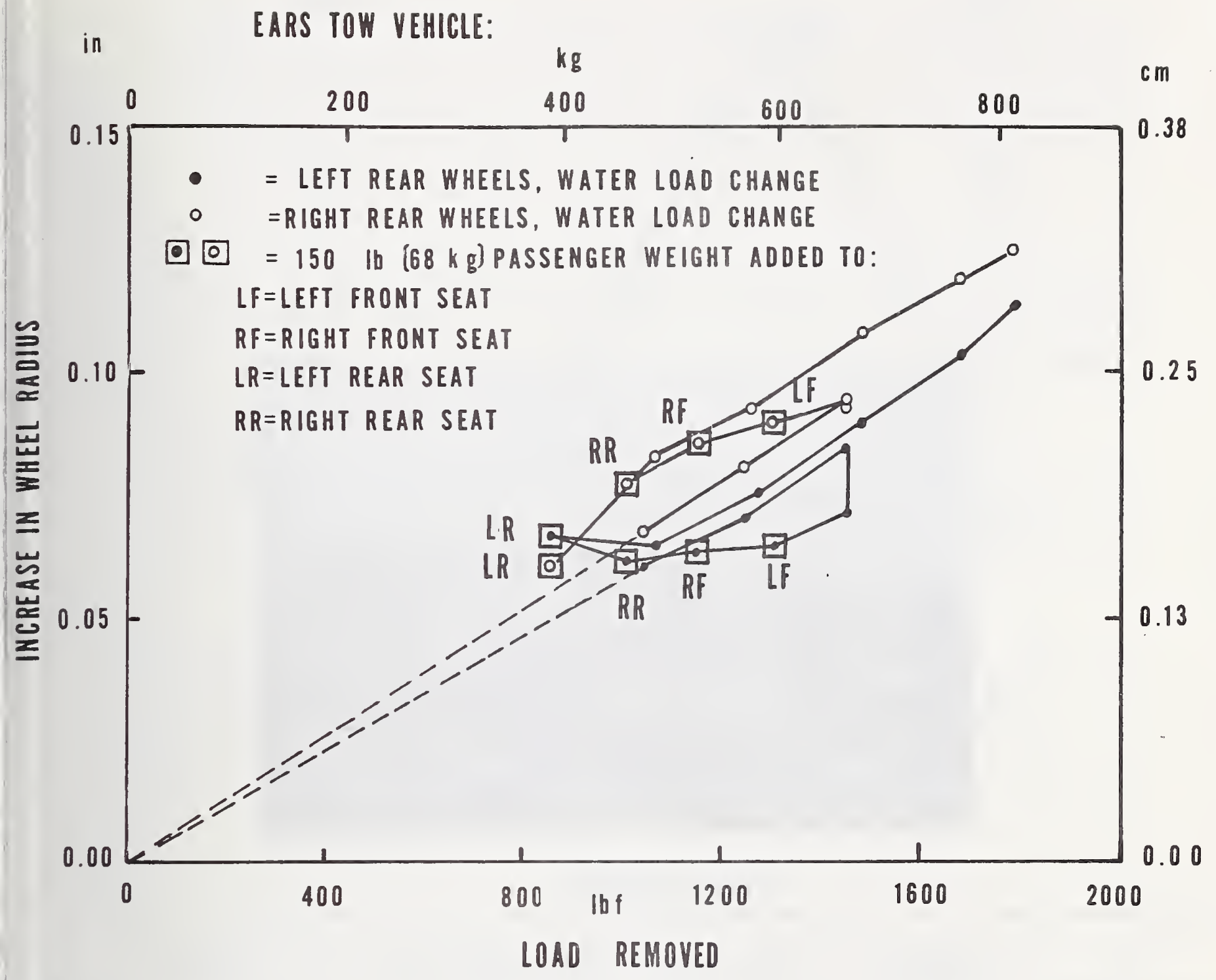

Figure 3. Change in tow vehicle rear wheel radius with load. 


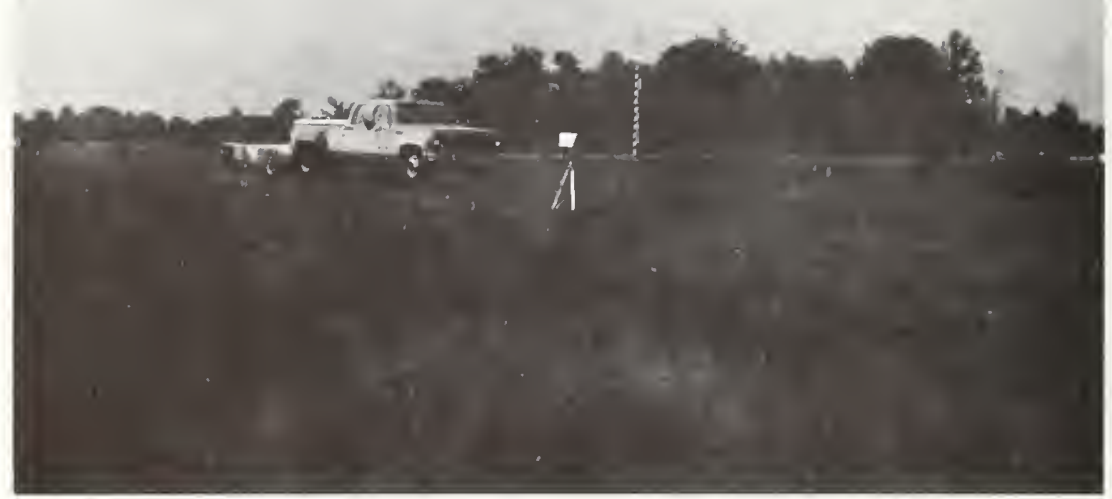

Figure 4. Radar test of EARS speed system. 

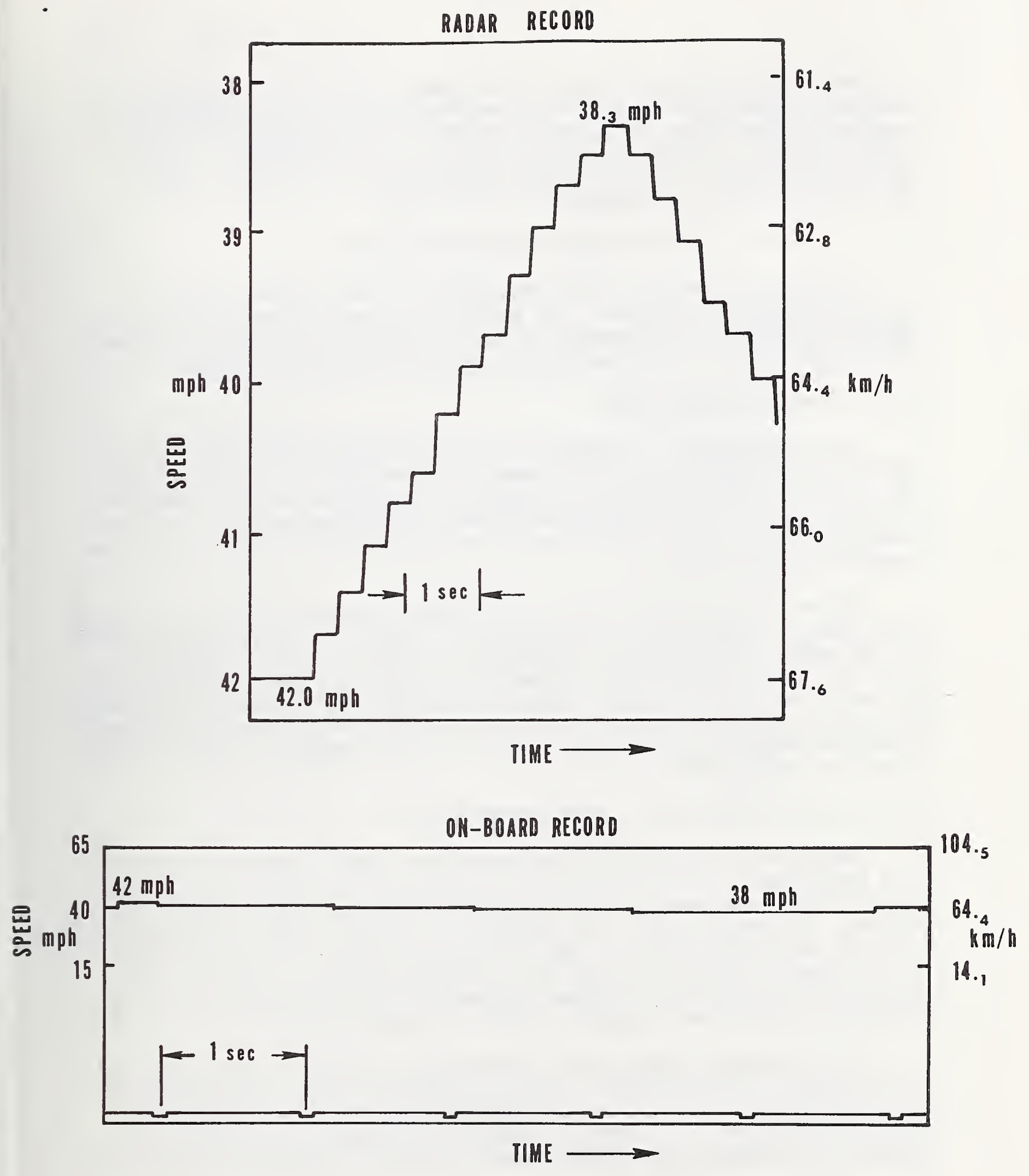

Figure 5. Simultaneous speed data recorded by the stationary radar and the EARS tow vehicle in motion (fifth wheel). 
After these tests, but before the dynamic correlation tests, EFTC personnel reported a malfunction in the D/A converter and temporarily reverted to the tachometer generator system. This system has a resolution of $2 \mathrm{mph}(3.2 \mathrm{~km} / \mathrm{h})(0.88 \mathrm{~mm} /$ division $)$ and the tachometer accuracy was not determined. Speed records obtained with the IRS radar system were used for the data reduction for this report.

\subsection{Pavement Wetting Subsystem}

The pavement wetting system was tested for water flow rate, uniformity of water distribution, and width of the water trace at the tirepavement interface. The dynamic water distribution measurements obtained are considered to be unreliable for reasons to be mentioned later.

\subsubsection{Flow Rate Measurement}

By prearrangement, the EARS water distribution system had been modified to allow replacement of a straight pipe section on the trailer with the flow rate meter pipe section normally installed in the IRS. EARS was also modified to provide valves and pressure measuring ports so that the back pressure of the flow meter could be duplicated when the straight pipe section was reinstalled.

The water distribution pump of the EARS is driven from the tow vehicle drive shaft. Therefore, it was necessary to make the stationary tests with the tow vehicle drive wheels on dynamometer rollers. 'l'he average water flow rate for 75 seconds was determined for simulated vehicle speeds of 20 , 40 , and $60 \mathrm{mph}(32,64$, and $97 \mathrm{~km} / \mathrm{h})$ as measured by the vehicle speedometer. The results, given in Table 1 and Figure 6, show excellent agreement with flow rates based on the value of 7.5 in $(19.1 \mathrm{~cm})$ assumed by EFTC personnel to be the wetted width.

\subsubsection{Water Distribution - Static Measurements}

The objective of static distribution gage (SDG) pavement wetting system measurements is to determine the distribution of water across the width of the water trace at the point where it would contact the pavement surface. The SDG includes a basin divided into equal width slots mounted at floor level (Fig. 7) [6]. The basin is equipped with a sliding cover that is removed during the time that a sample is being collected. When the cover is removed, the incident stream is divided by the slots and displayed in sight tubes arranged to form a bar graph (Fig. 8).

The stationary trailer was positioned with a normal hitch height and with the test tire centered on the basin such that water issuing from the nozzle entered the slots. The tow vehicle drive wheels were placed on dynamometer rollers. To obtain a sample of the water distribution, the wheels were driven at the desired speed with water flowing from the nozzle. 
Table 1 - EARS Flow Rates

\begin{tabular}{ccc}
\hline $\begin{array}{c}\text { Simulated speed } \\
\mathrm{mph}(\mathrm{b})\end{array}$ & $\begin{array}{r}\text { Measured flow rate } \\
\mathrm{gpm}(\mathrm{c})\end{array}$ & $\begin{array}{r}\text { Desired flow rate (a) } \\
\mathrm{gpm}(\mathrm{c})\end{array}$ \\
\hline 20 & 13.5 & 13.5 \\
40 & 27.2 & 27.0 \\
60 & 40.2 & 40.5 \\
\hline
\end{tabular}

(a) for assumed 7.5 in $(19 \mathrm{~cm}$ ) wetted width.

(b) $1 \mathrm{mph}=1.6 \mathrm{~km} / \mathrm{h}$.

(c) $1 \mathrm{gpm}=3.81$ iters $/ \mathrm{min}$. 
$\mathrm{km} / \mathrm{h}$

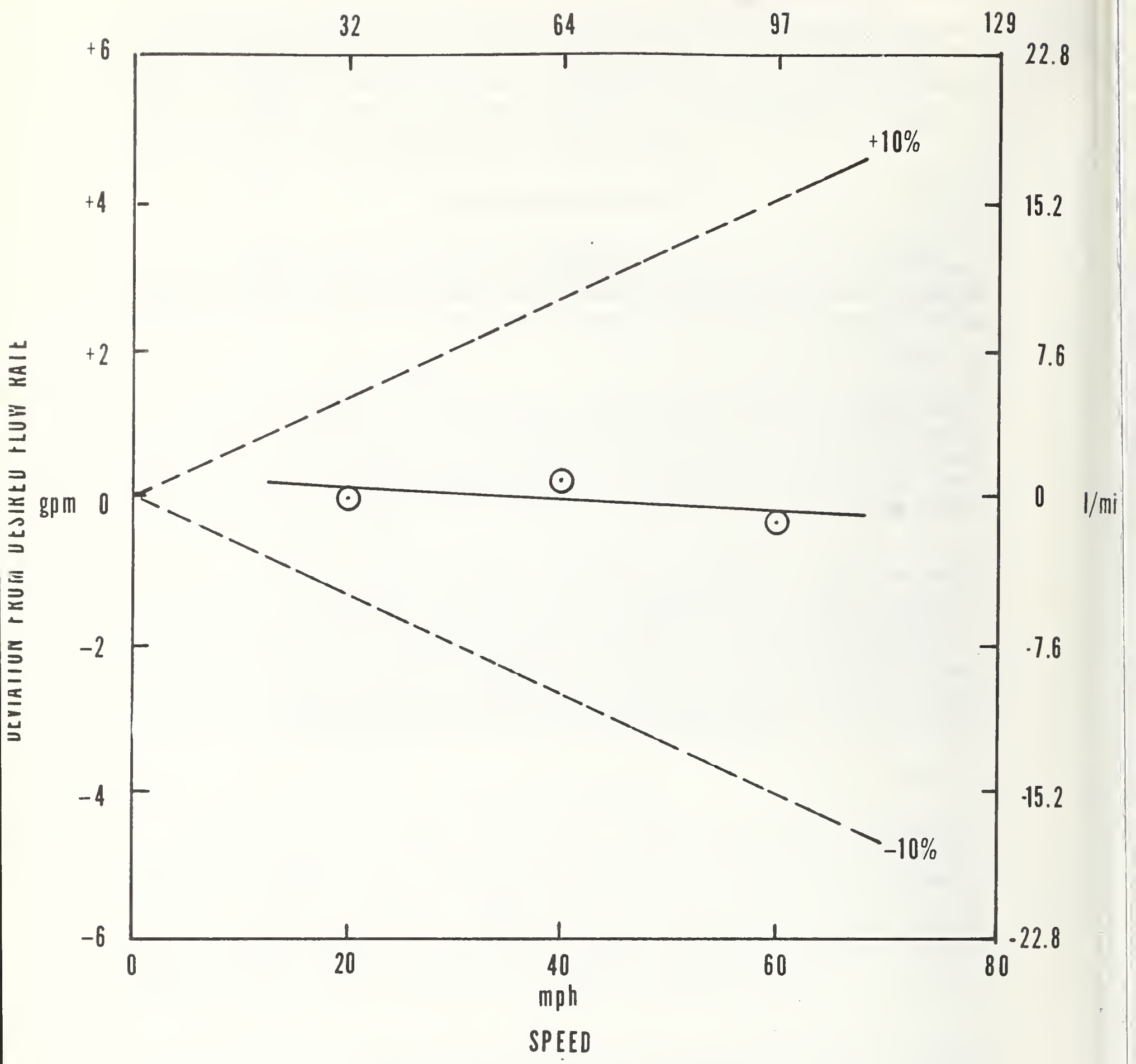

Figure 6. EARS pavement wetting based on 7.5 in $(19.1 \mathrm{~cm})$ wetted width compared with ASTM E274-70 water layer tolerance. 


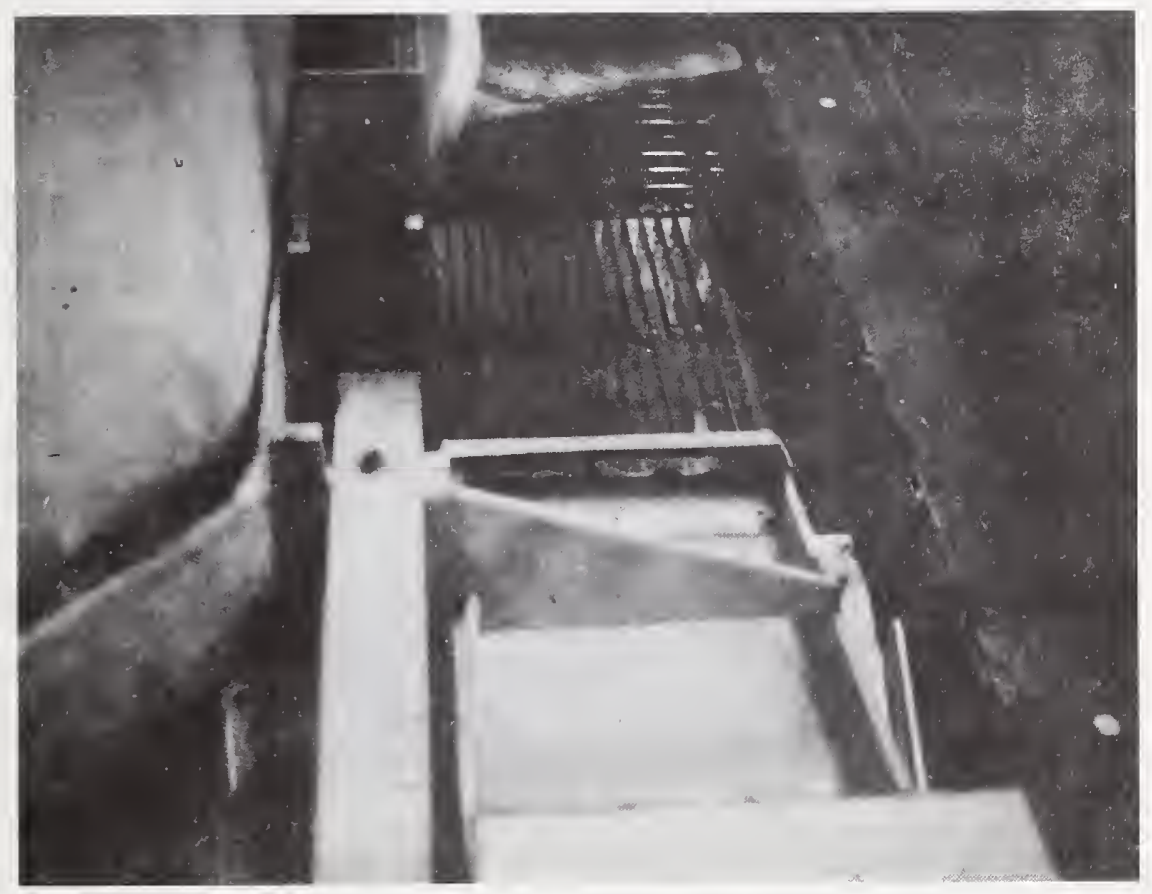

Figure 7. IRS flow channel, showing water flow into SDG basin. 


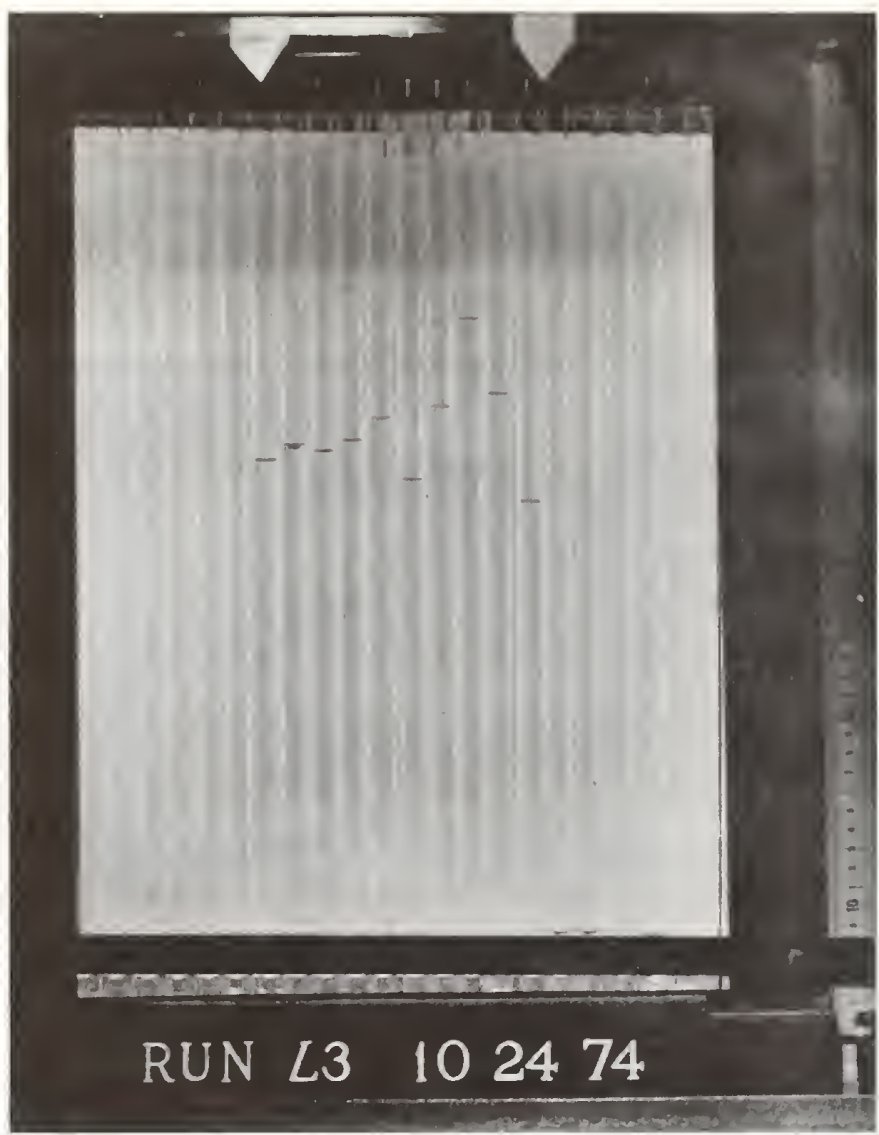

Figure 8. SDG sight tube array. 
The sliding cover was removed until water rose to a predetermined, approximate level in the sight tubes, and then the cover was quickly replaced. The gage size is such that the time required to fill to the predetermined level was comparable to or longer than the duration of a skid test. The relative distribution of water was then noted from the sight tubes.

The location of the test tire relative to the slots filled was noted to check the lateral positioning of the nozzle. The number of slots collecting water was noted as a measure of wetted width at the point of surface contact.

The SDG was not available for NBS to conduct these tests on EARS. The tests were made by EFTC shortly after the evaluation period, and the results were furnished to NBS. These results are shown in Figures 9, 10, and 11 for 20, 40, and $60 \mathrm{mph}(32,64$, and $97 \mathrm{~km} / \mathrm{h}$ ) respectively.

\subsubsection{Water Distribution - Dynamic Measurements}

The objective of dynamic distribution gage (DDG) pavement wetting system measurements is to determine the distribution of water across the width of the water trace at the surface contact line under actual aerodynamic conditions. The DDG consists of an uncovered container mounted flush with the pavement having 20 equal $7 / 8$ in $(2.2 \mathrm{~cm})$ wide slots (Fig. 12). Provisions are made for quickly removing the container to a building where the water in each slot is absorbed with paper towels and weighed. Electrical sensors record the path of the test tire across the slots. In principle, the DDG measurements could show the wetted width (but not at the tire-pavement interface as desired), the alinement of the test tire with the wetted width, the lateral uniformity of the water distribution and the depth of the water layer.

Distributions were determined by EFTC personnel and presented in terms of relative quantity only. However, since the measurements are in terms of the weight of water collected in each gage slot and the slot dimensions are known, we are able to calculate the depth of the water layer. Figure 13 is a typical example of a DDG distribution plotted in terms of depth. Note that the average depth of water collected under the tire is 0.038 in $(.096 \mathrm{~cm})$, surprisingly high since the flow rate had been adjusted in accordance with ASTM E274-70 which leads to an expected depth near 0.020 in $(0.051 \mathrm{~cm})$.

The total water collected during the run represented in Figure 13 was 168 grams (Table 2). From the speed and the flow rate for this run, which were recorded independently, $(39.8 \mathrm{mph}(64.0 \mathrm{~km} / \mathrm{h}), 27.5 \mathrm{gpm}$ (104.5 liters/min)) we calculate that $69.8 \mathrm{~g}$ of water were pumped by the skid system as it travelled 28.2 in $(716 \mathrm{~cm})$, the length of the gage slots. Therefore, the amount of water collected by the DDG was far in excess of the expected amount. 

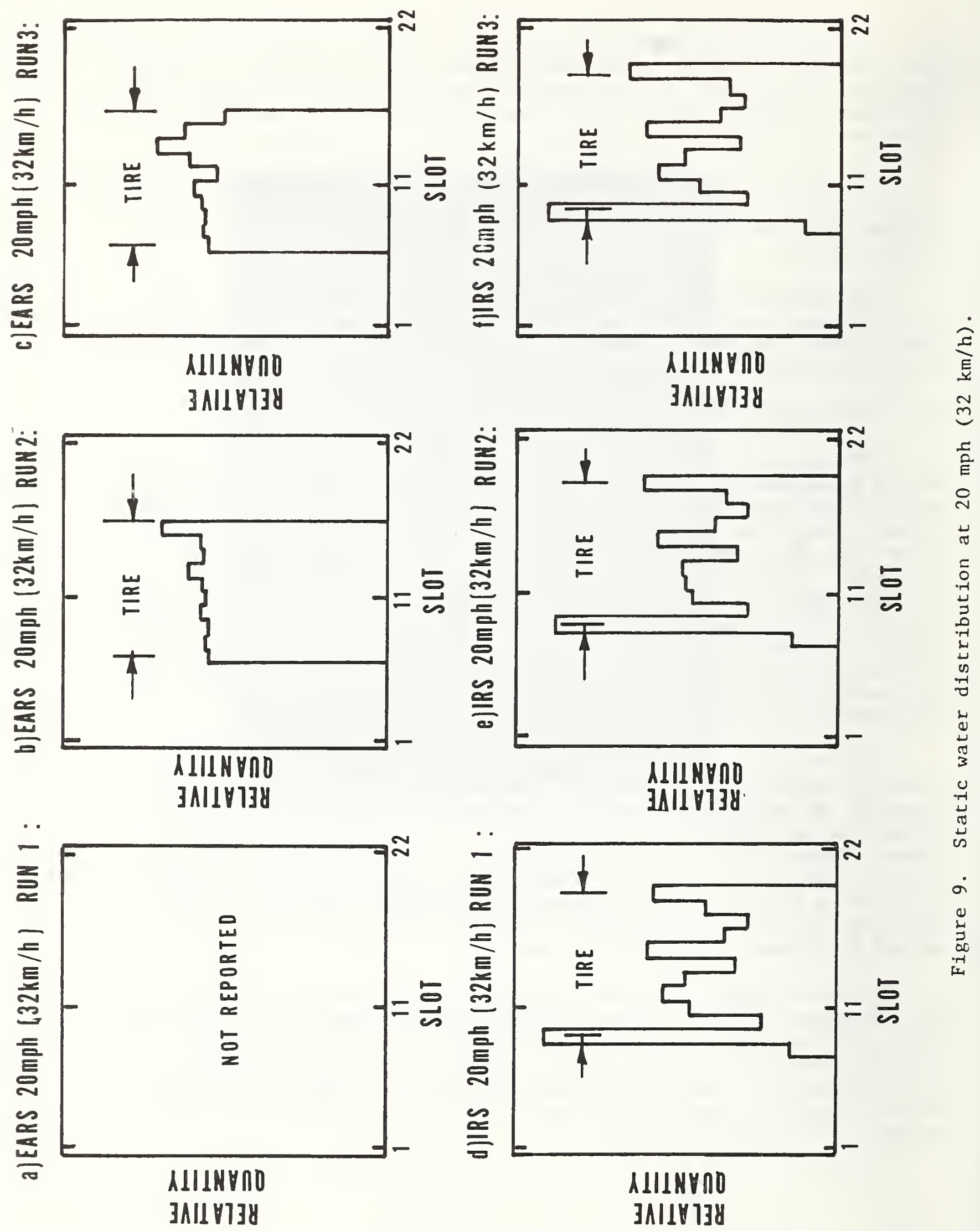

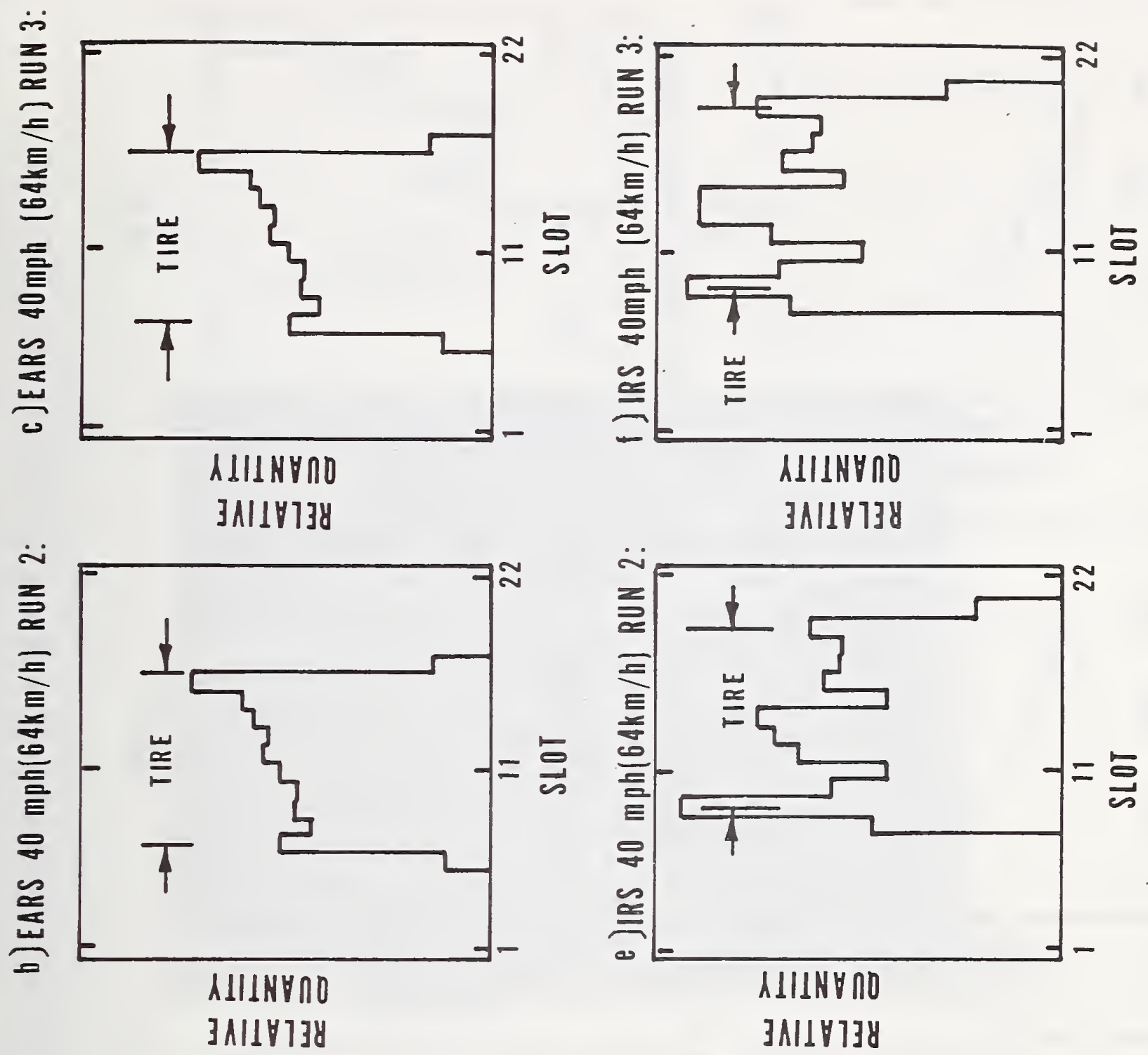

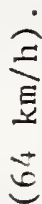
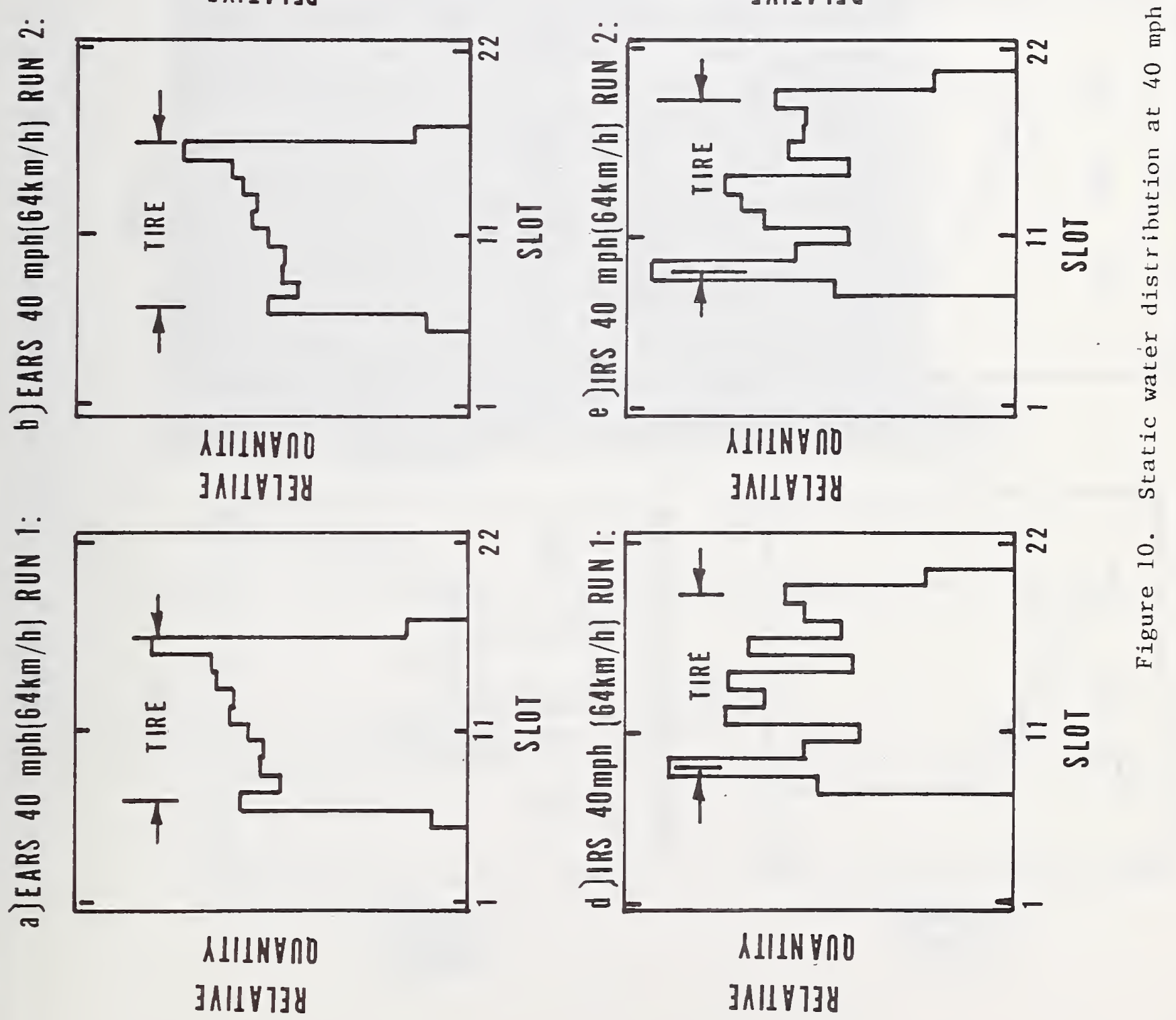

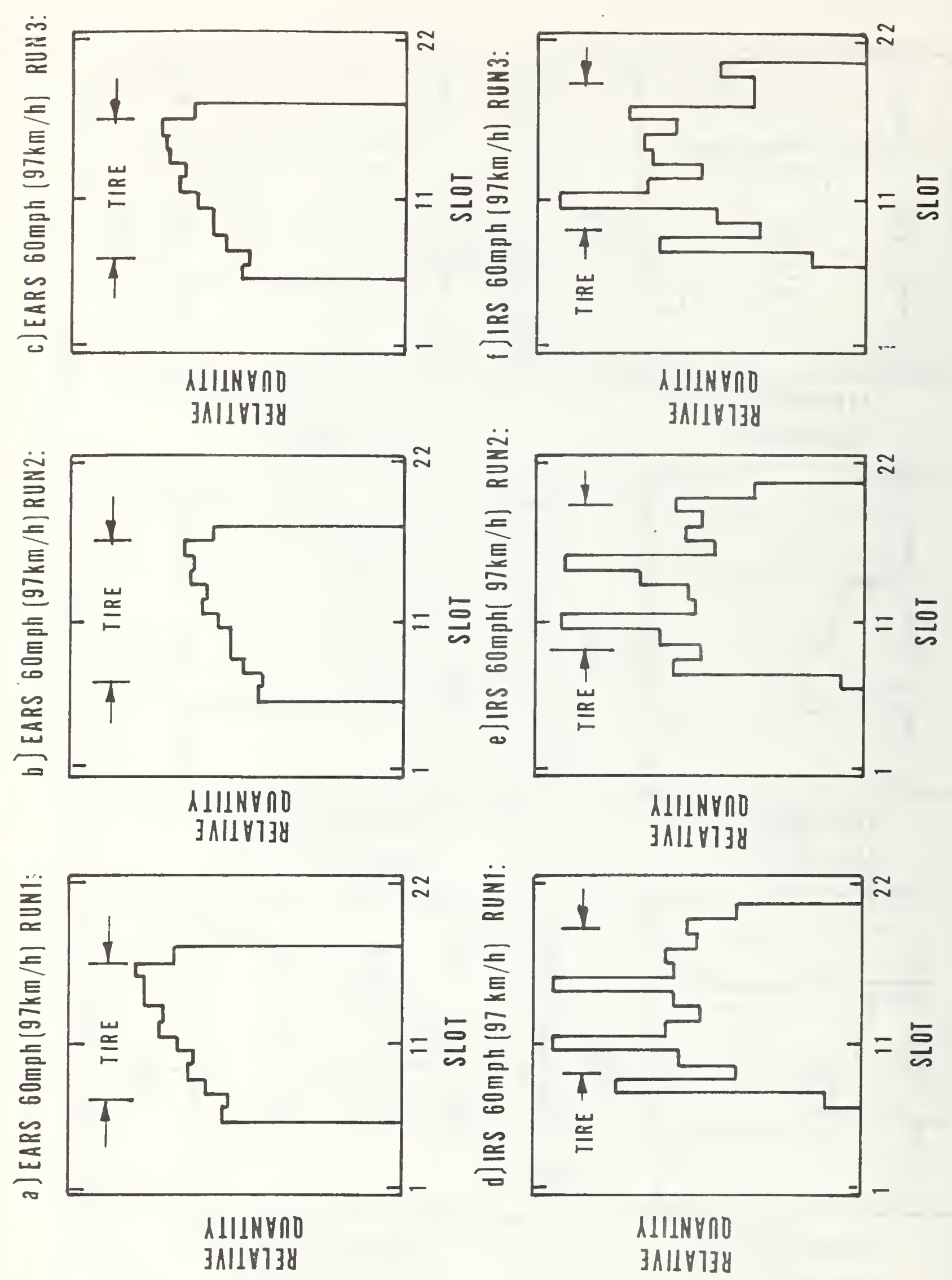


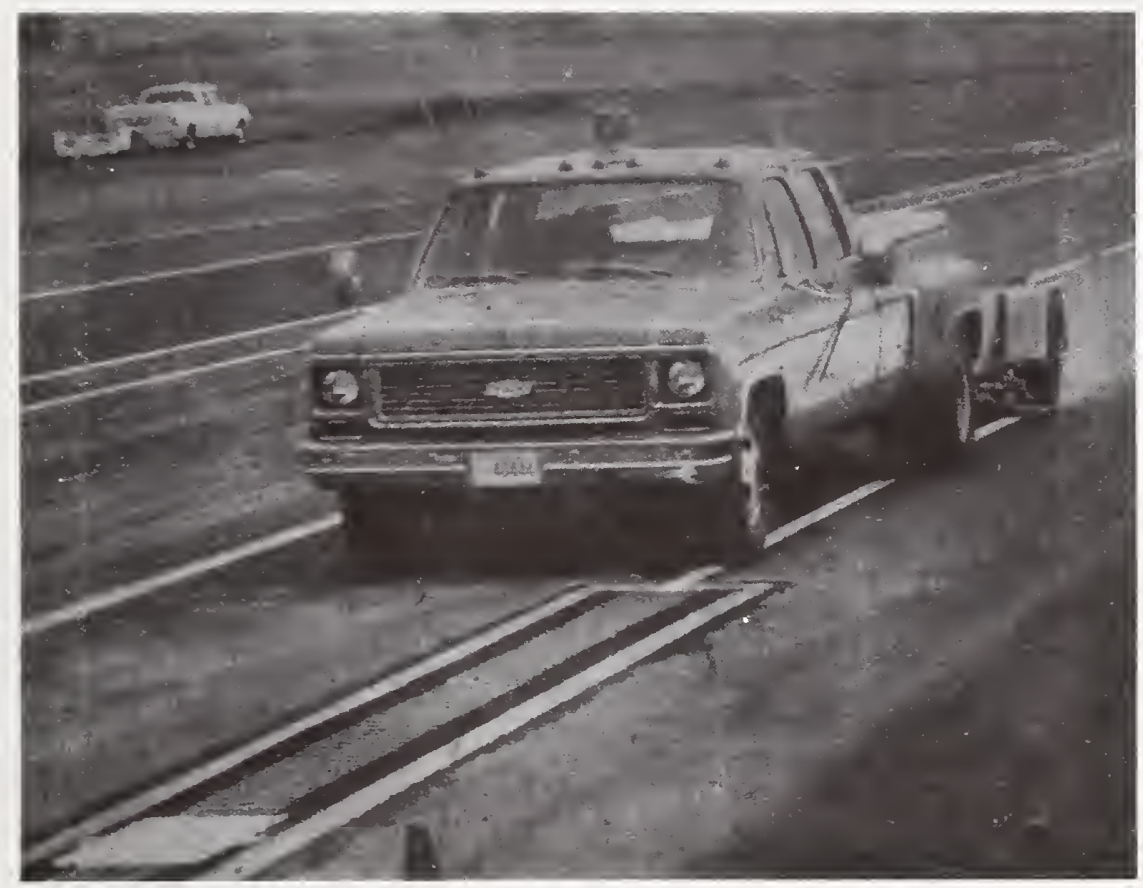

Figure 12. EARS pavement wetting system test using the DDG. 


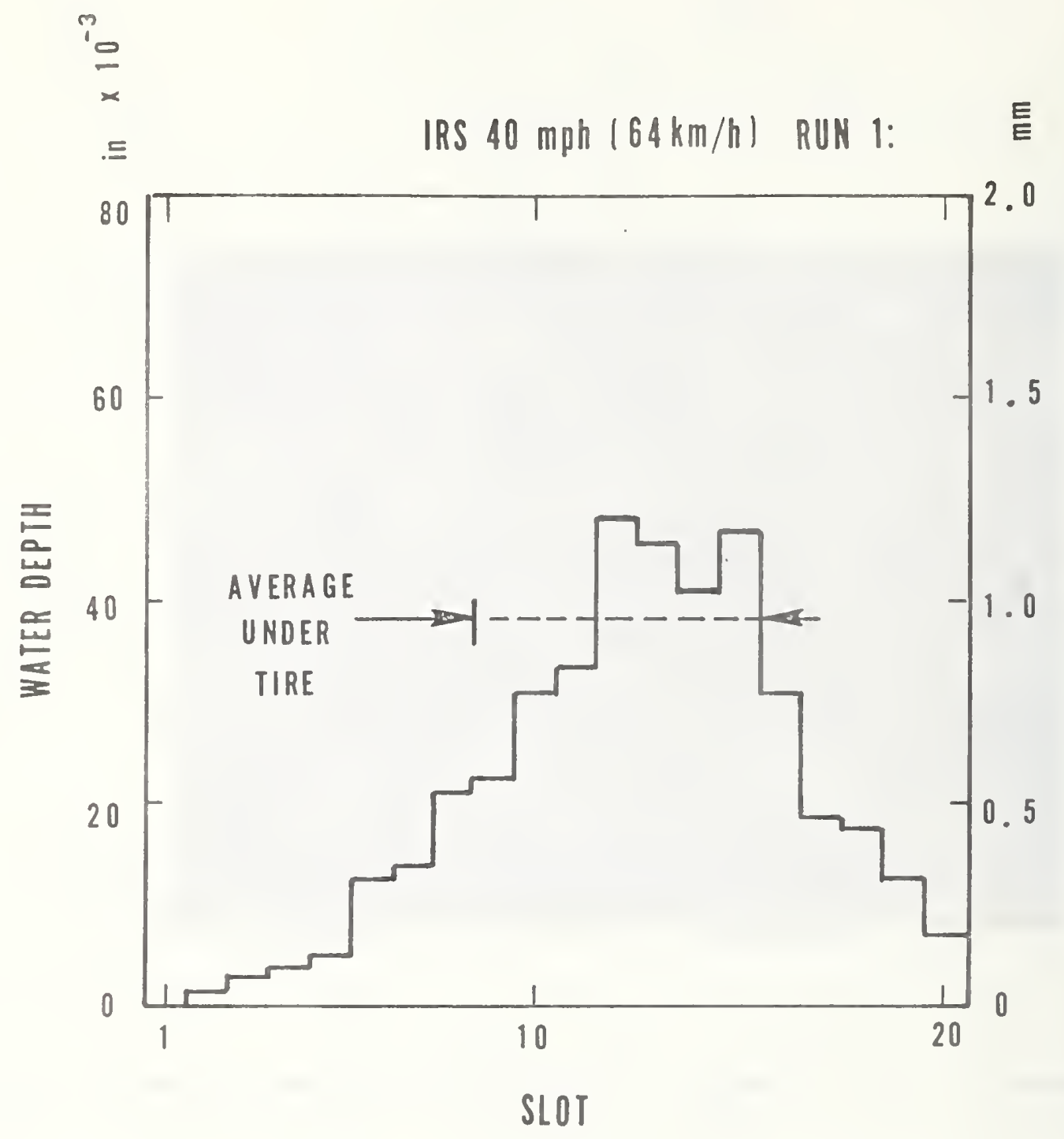

Figure 13. Dynamic distribution. Depth scale based on slot dimensions. 
Table 2 - DDG Data: IRS, $40 \mathrm{mph}$, Run 1

Tire Path: Slots 9 through 15

Slot number

Net weight, grams

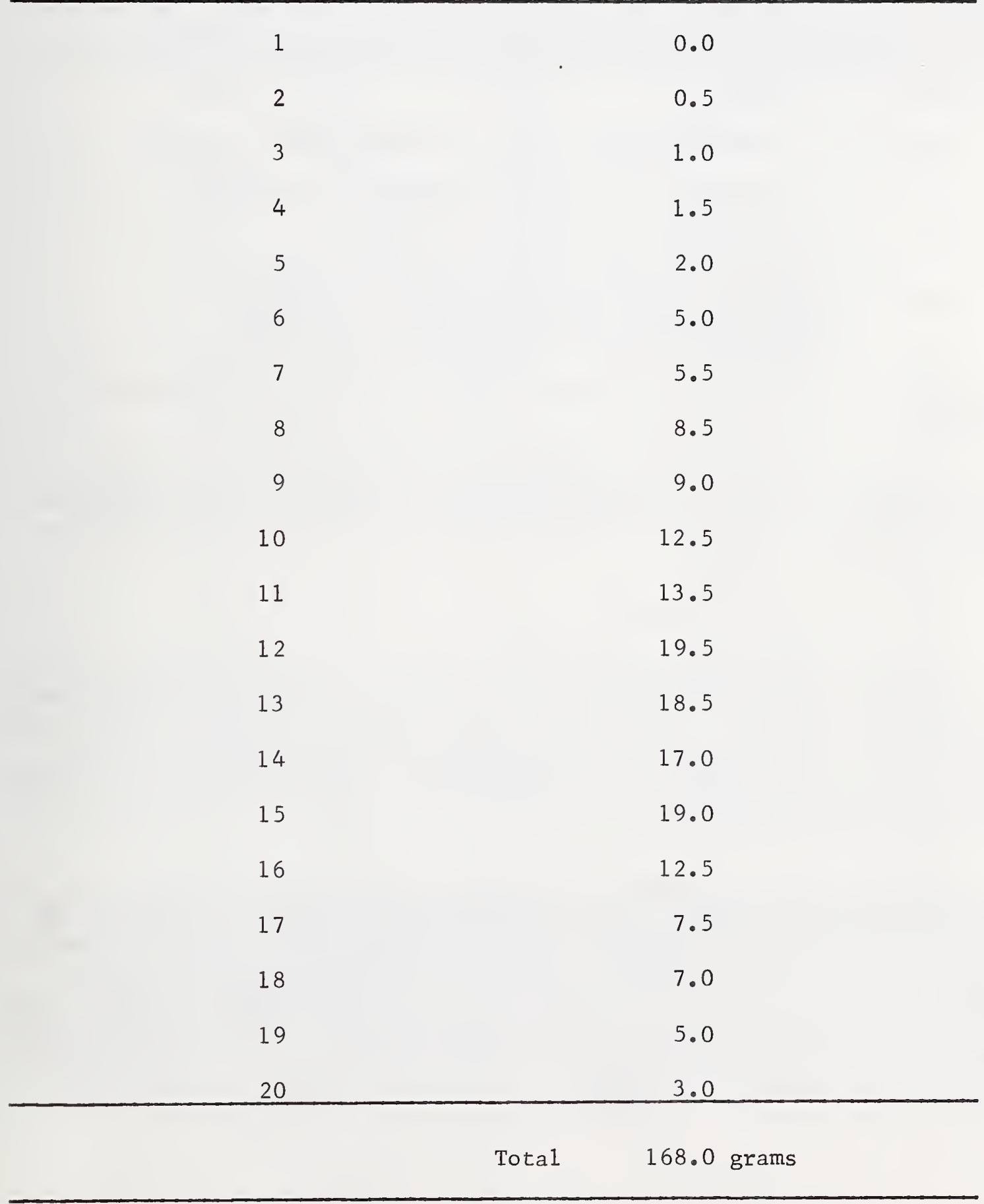


Indication of excess water was typical for all the runs. The discrepant data are summarized in Table 3.

Exploratory tests to determine the reason for these errors were conducted by NBS personnnel. Included was a test for collection efficiency. A graduated cylinder was filled to the 100 millimeter mark. The net weight measured on the balance was $100.01 \mathrm{~g}$. The water was distributed among the slots of the gage in the DDG lane outside. The gage was then brought into the control center and the slot contents were absorbed and weighed as in a normal test. The elapsed time for weighing was 15 minutes. The amount of water weighed was $95 \mathrm{~g}$. This test indicates that the excess water collected was associated with the dynamic collection process rather than the measurement of the water.

Further tests indicated the sources of excess water include:

a) water remaining from prior DDG tests was splashed from beneath the grate and basin.

b) the fog or cloud of mist following in the path of the test wheel continued to be collected after the skid trailer had passed the basin.

The results of these additional exploratory tests are discussed in Appendix A.

In view of the fact that the DDG sample includes a large quantity of water entering the gage by uncertain paths, the results of this test cannet be considered a valid measurement of the water distribution and are not given in this report.

\subsubsection{Wetted Width Measurement}

To lay the desired water film thickness, the flow rate must be adjusted as a function of the width of the water trace at the leading edge of the tire-pavement interface. The various ways of measuring wetted width include using SDG and DDG distribution widths, measuring the water trace on the pavement after the passage of the skid trailer, and photographing the pavement from the moving trailer showing the water trace width at the position of the interface of the tire.

Each measurement technique has known sources of error. Width readings of both distribution gages do not include the spreading that begins when the water contacts the pavement. The SDG reading does not include dynamic effects. Water traces laid down on pavement and measured after trailer passage contain an increment of width due to spreading which necessitates an assumption about the width at the time of passage. Measurement of photographs of the wetted width from the moving skid trailer involves the use of geometry to account for changes in scale with distance from the camera. At this point, an optimal camera arrangement has not been prepared. 
Table 3 - DDG Data: Comparison of Water Collected with Water Pumped

\begin{tabular}{|c|c|c|c|c|c|}
\hline $\begin{array}{l}\text { Speed, } \\
\text { mph (a) }\end{array}$ & Uni & & $\begin{array}{c}\text { Collected, } \\
\text { grams }\end{array}$ & $\begin{array}{c}\text { Pumped, } \\
\text { grams }\end{array}$ & $\frac{\text { Collected }}{\text { Pumped }}$ \\
\hline 20 & EARS, & run & 86.27 & $68.2(b)$ & 1.26 \\
\hline 20 & EARS, & run 2 & 79.59 & $68.2(b)$ & 1.17 \\
\hline 20 & EARS, & run 3 & 76.52 & $68.2(b)$ & 1.12 \\
\hline 20 & IRS, & run 1 & 70.0 & 65.0 & 1.08 \\
\hline 20 & IRS, & run 2 & 71.0 & 64.5 & 1.10 \\
\hline 20 & IRS, & run 3 & 89.0 & 64.7 & 1.38 \\
\hline 40 & EARS, & run 1 & 102.5 & $68.4(b)$ & 1.50 \\
\hline 40 & EARS, & run 2 & 106.0 & 68.4 (b) & 1.55 \\
\hline 40 & EARS, & run 3 & 115.5 & 68.4 (b) & 1.69 \\
\hline 40 & IRS, & run 1 & 168.0 & 69.8 & 2.41 \\
\hline 40 & IRS, & $\operatorname{run} 2$ & 168.0 & 69.0 & 2.43 \\
\hline 40 & IRS, & run 3 & 196.0 & 69.8 & 2.81 \\
\hline 60 & EARS, & run 1 & 96.00 & 68.5 (b) & 1.40 \\
\hline 60 & EARS, & run 2 & 97.11 & 68.5 (b) & 1.42 \\
\hline 60 & EARS, & run 3 & 107.81 & $68.5(b)$ & 1.57 \\
\hline 60 & IRS, & run 1 & 150.5 & 71.0 & 2.12 \\
\hline 60 & IRS, & run 2 & 180.0 & 71.3 & 2.52 \\
\hline 60 & IRS, & run 3 & 158.5 & 70.4 & 2.25 \\
\hline
\end{tabular}
(a) $1 \mathrm{mph}=1.609 \mathrm{~km} / \mathrm{h}$.
(b) Computed. 
In this evaluation, the span of slots collecting water during the SDG tests at $40 \mathrm{mph}(64 \mathrm{~km} / \mathrm{h})$ was used as a measure of wetted width. The resolution of the measurement is limited by the slot width, 5/8 in $(1.6 \mathrm{~cm})$.

Measurements from the pavement were performed with the test wheel extended beyond the water trace (Fig. 14). The pavement wetting outlet remained in its normal position. This arrangement was chosen to minimize the change of the aerodynamic disturbance of the trace and the disturbance due to the tire running in the water trace. Three measurements were made of each trace with increasing delay times to allow extrapolation back to the moment of passage (Fig. 15). Uncertainties in the use of this method include measurement between the indistinct boundaries of the spreading trace and the validity of linear extrapolation.

A high speed movie camera was installed temporarily on the IRS trailer with a downward view of the water trace opposite the extended test tire (Fig. 16). Photographs were obtained from which the wetted width could be estimated in relation to objects of known size. Preliminary tests of this method show promise. No tests using this method were made with EARS.

The measurements obtained by these methods are presented in Table 4.

None of the methods used to measure wetted width during these tests is considered satisfactory. The SDG measurements represent a trace width before the tire-pavement contact line while the measurement on the pavement can occur only after the test vehicle has passed. These values can therefore best be considered as lower and upper bounds on the correct value. The development of the photographic method might be expected to provide a better wetted width measurement.

\subsection{Force Measuring Subsystem}

The transducer of the force measuring system is located in-board from the wheel, on the axle, remote from the force it is to measure at the tire-pavement interface. This force at the interface is equivalent to a moment and a force acting along vectors in three-dimensional space with respect to the centroid of the transducer. Displacements occurring within the system may alter these vectors. Many effects due to these displacements are accounted for by using the tow vehicle and trailer system as a fixture while calibrating the transducer "in situ". Vertical load and traction forces are measured at the tire-pavement interface by means of an air-bearing force plate and calibration box. A locked test wheel is shown on a force plate during such a test in Figure 17. However, effects, such as the transverse force at the tire-pavement interface and the yawing orientation of the trailer usually present during skid testing are not accounted for by this test. Displacements of the interface are larger when the tire is "hot" as in a running condition. The tests described here were conducted with the tire at room temperature. 


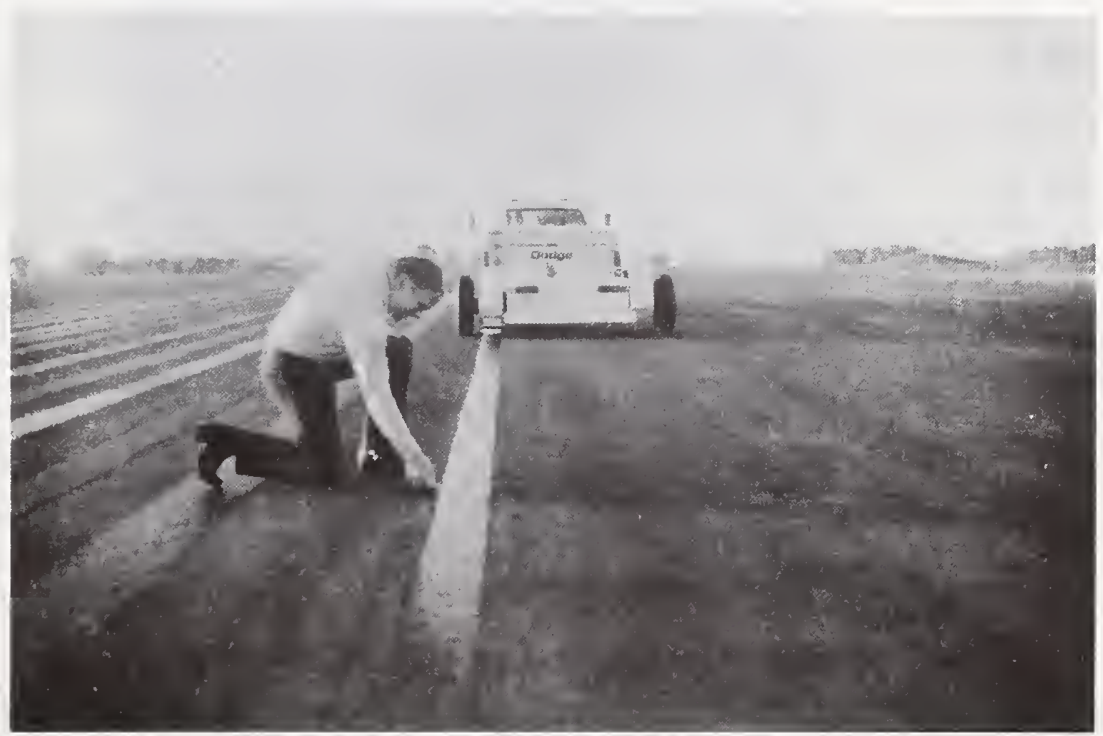

Figure 14. Measurement of water trace width after the trailer has passed. 


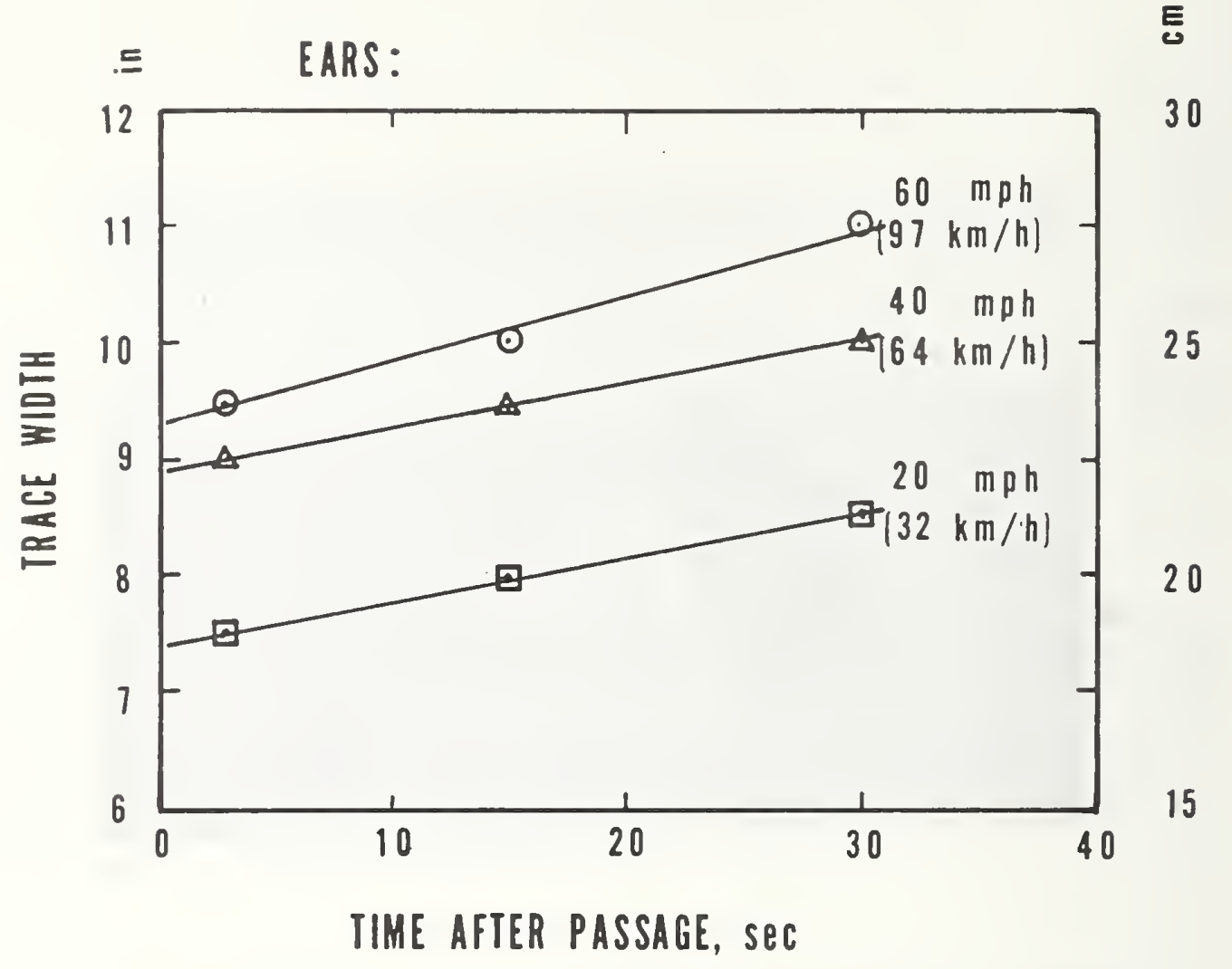

Figure 15. Wetted width by delayed measurement on pavement. 


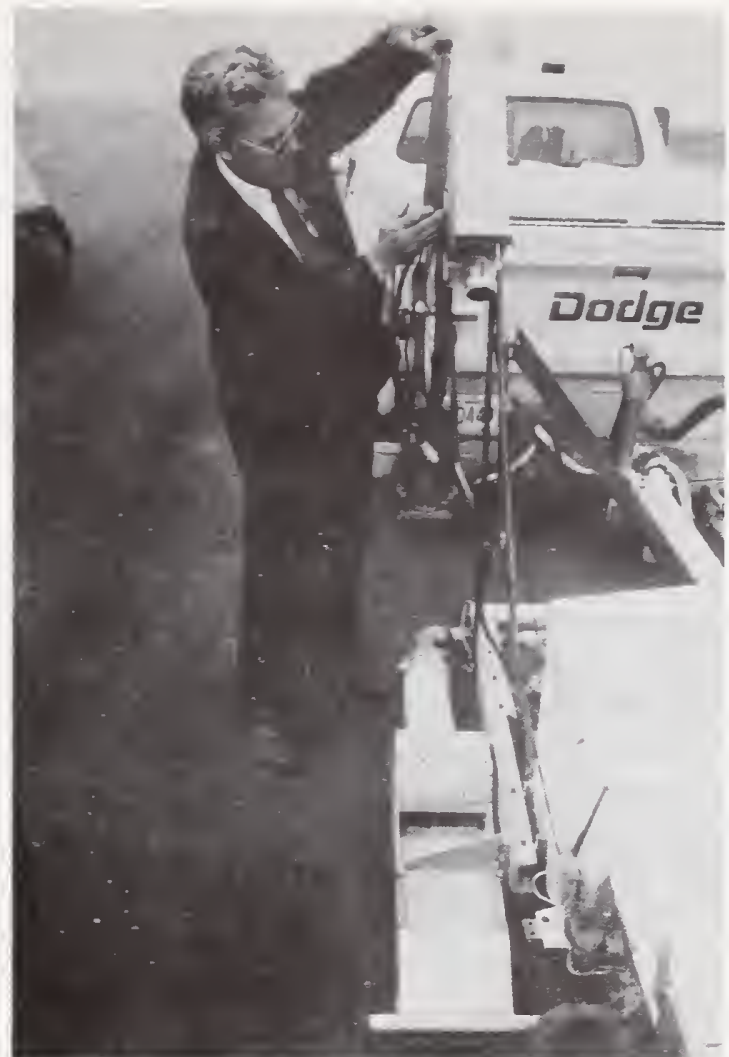

Figure 16. Arrangement for photography of wetted width.

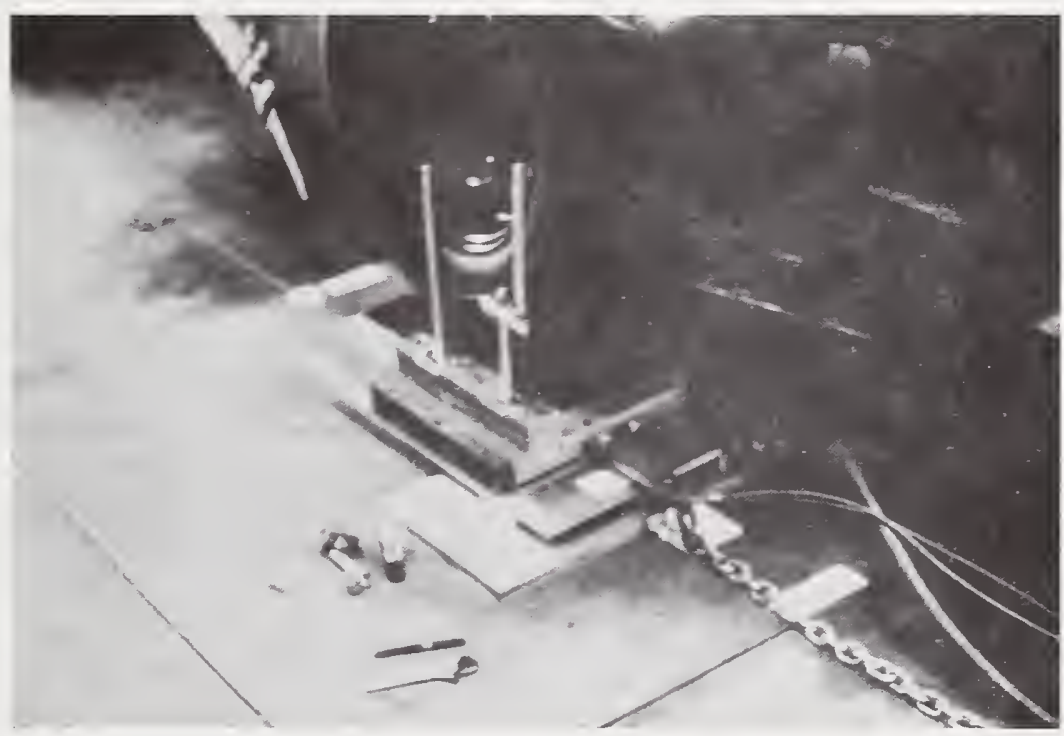

Figure 17. Application of a simulated traction force to a locked test wheel through an air-bearing force plate. 
Table 4 - Wetted Width Measurements

\begin{tabular}{|c|c|c|c|c|}
\hline $\begin{array}{l}\text { Speed } \\
\text { mph (a) }\end{array}$ & Unit & $\begin{array}{r}\text { Flow rate, } * \\
\text { gpm (b) }\end{array}$ & Method & $\begin{array}{r}\text { Wetted width, } \\
\text { in (c) }\end{array}$ \\
\hline 20 & EARS & 13.5 & SDG & 6.2 \\
\hline 20 & EARS & 13.5 & Pavement & 7.4 \\
\hline 20 & EARS & 13.5 & Photo & -- \\
\hline 20 & IRS & 14.5 & SDG & 7.5 \\
\hline 20 & IRS & 14.5 & Pavement & 8.7 \\
\hline 20 & IRS & 14.5 & Photo & 7.6 \\
\hline 40 & EARS & 27.1 & SDG & 7.5 \\
\hline 40 & EARS & 27.1 & Pavement & 8.9 \\
\hline 40 & EARS & 27.1 & Photo & --- \\
\hline 40 & IRS & 29.0 & SDG & 8.1 \\
\hline 40 & IRS & 29.0 & Pavement & 8.9 \\
\hline 40 & IRS & 29.0 & Photo & 8.9 \\
\hline 60 & EARS & 40.2 & SDG & 7.5 \\
\hline 60 & EARS & 40.2 & Pavement & 9.3 \\
\hline 60 & EARS & 40.2 & Photo & $\ldots$ \\
\hline 60 & IRS & 43.5 & SDG & 8.8 \\
\hline 60 & IRS & 43.5 & Pavement & 10.4 \\
\hline 60 & IRS & 43.5 & Photo & 9.9 \\
\hline
\end{tabular}

*Nominal values.
(a) $1 \mathrm{mph}=1.6 \mathrm{~km} / \mathrm{h}$.
(b) $1 \mathrm{gpm}=3.81$ iters $/ \mathrm{min}$.
(c) 1 in $=2.54 \mathrm{~cm}$. 


\subsubsection{Transducer Excitation Stability}

The EARS uses a transducer containing two Wheatstone strain-gage bridge sensors. The bridge excitation from the on-board power supply was measured. The load channel excitation voltage was $10.016 \mathrm{dc}$ volts and the traction channel excitation was $10.025 \mathrm{dc}$ volts. There was no meaningful ac voltage viewable on the 0.05 volt $/ \mathrm{cm}$ scale of an oscilloscope. There was no change in these values as the engine speed was increased from idle.

\subsubsection{Orientation of the Transducer}

The transducer measures a load and a traction component of force. To reduce the effects of any cross-axis misalignment, the hitch height was changed until the removal and application of the static vertical load had a minimal effect on the traction channel output. This condition occurred with 11-7/8 inches between a level surface and the bottom of the welded flange under the trailer hitch assembly. A change of 0.1 in $(0.2 \mathrm{~cm})$ in this measurement is discernable with the on-board traction instrumentation. This orientation was maintained for these tests and should be maintained during trailer use.

\subsubsection{Vertical Load Channel Calibration}

The EARS trailer (with the left test wheel resting on the force plate) was alined with the tow vehicle. A weight of $150 \mathrm{lb}$ (68 $\mathrm{kg}$ ) was placed in each seat of the tow vehicle. (A weight is removed whenever a person occupies a seat during testing). The hitch height was set for the proper transducer orientation. The vertical load at the test wheel was varied over a range from about $100 \mathrm{lbf}(445 \mathrm{~N})$ to about $1450 \mathrm{lbf}$ $(6450 \mathrm{~N})$. Since the EARS was not compatible with the IRS vertical load air cylinder, the load at the test wheel was reduced by lifting the trailer axle with a floor jack. The vertical load at the test wheel was increased by stacking sand bags on top of both sides of the trailer symmetrically. A force plate test was conducted using the on-board amplifiers of the EARS for the transducer load signal and the amplifiers of the IRS for the force plate load signal. The outputs of the vertical channels of the force plate and transducer were recorded point-by-point on the $X$ and $Y$ axes of an $X-Y$ recorder respectively. During the initial tests, the recorded values were nonlinear at loads above 1100 lbf ( $4900 \mathrm{~N}$ ). A series of tests were conducted which revealed that the problem was in the EARS transducer or its mount. EFTC personnel found that the trailer fender, when the new larger E501 test tires were used, interfered with the transducer-axle-tire assembly when the higher forces were applied to the trailer body. Modifications were made to provide fender clearance and new springs of the same type were substituted in the trailer suspension system. After these modifications, the vertical load test was repeated, showing linear results within $15 \mathrm{lbf}(67 \mathrm{~N})$ and negligible hysteresis (Fig. 18). 


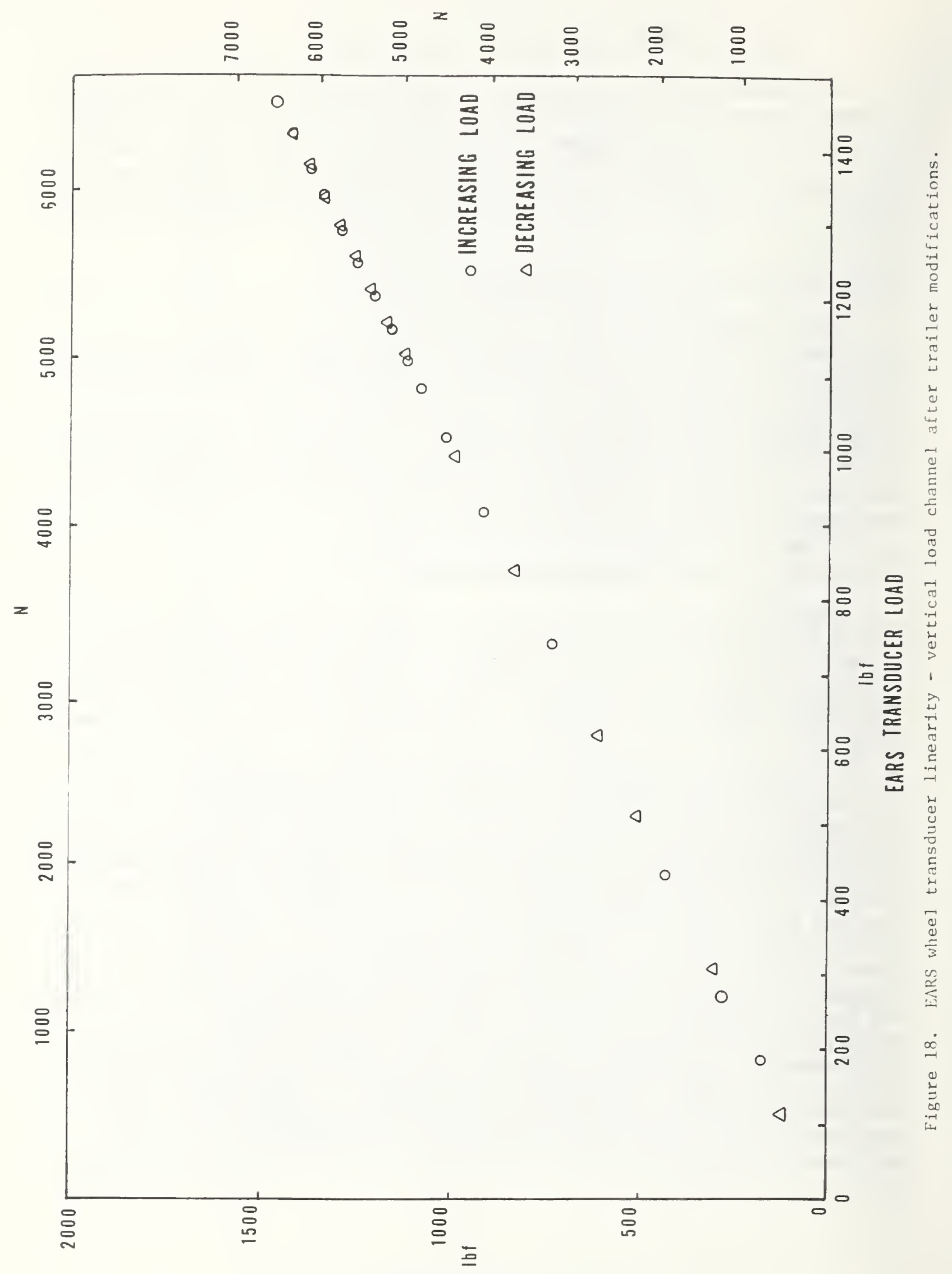

0401 3187d 3980S 


\subsubsection{Traction Load Channel Calibration}

The trailer was alined with the standardized tow vehicle. A weight of $150 \mathrm{lb}(68 \mathrm{~kg}$ ) was placed in each seat of the tow vehicle. The hitch height was set for the proper transducer orientation. A force plate traction test was conducted using the on-board amplifiers of the EARS for the transducer traction signal and the amplifiers of the IRS for the force plate traction signal. The results were plotted point-bypoint on an external $\mathrm{X}-\mathrm{Y}$ recorder. The transducer was linear within 10 Ibf ( $45 \mathrm{~N}$ ) under an increasing load as shown in Figure 19. During the decreasing load portion of the test, the test wheel brake slipped sufficiently to abort the test. In repeat tests, the slippage occurred again. Further investigation revealed that the brake hvdraulic fluid was leaking back to the reservoir such that the reservoir pump had to be energized every 55 seconds to maintain the brake pressure. However, the pump is automatically de-energized when the test brakes are applied in the EARS, and therefore, does not turn on during a force plate test. EFTC personnel repaired the leak at a later date after receipt of new parts. A hysteresis curve was not completed. However, numerous tests on the same model of transducer have shown negligible hysteresis.

\subsubsection{On-Board Calibration System Equivalent Values}

To adjust the gain and offset of the transducer instrumentation, two known values are required for each channel. EFTC procedures use no load for one of the values and a resistor, shunting the transducer bridge circuit for the other value to simulate known forces. The equivalent force values with the bridge circuits shunted were found to be 1081 Ibf $(4808 \mathrm{~N})$ for the vertical load channel and $501 \mathrm{lbf}(2228 \mathrm{~N})$ for the traction channel.

\subsection{Suspension Subsystems}

The measurement of pavement skid resistance at normal traffic speeds is a dynamic test. While data reduction is to occur during a period of steady state friction, the fact is that transient oscillations dominate the entire trace. Trailer motions introduce transient dynamic forces into the system and vice versa. The effective dynamic characteristics of the suspension subsystems need to be measured and reported in analytical form in order that dynamic analyses of the system can be performed for comparison with experimental results and for use in design parameter studies. Further, measurements made by systems of similar or even the same design differ. Consequently, in an attempt to document the dynamic characteristics that might affect measuring performance and account for these differences, the effective spring rates, natural frequencies, Coulomb and viscous friction of the suspension systems were determined. Measurements of certain static displacements were also made as the traction force at the tire-pavement interface was increased to approximately $800 \mathrm{lbf}(3560 \mathrm{~N})$ and then decreased to zero. 


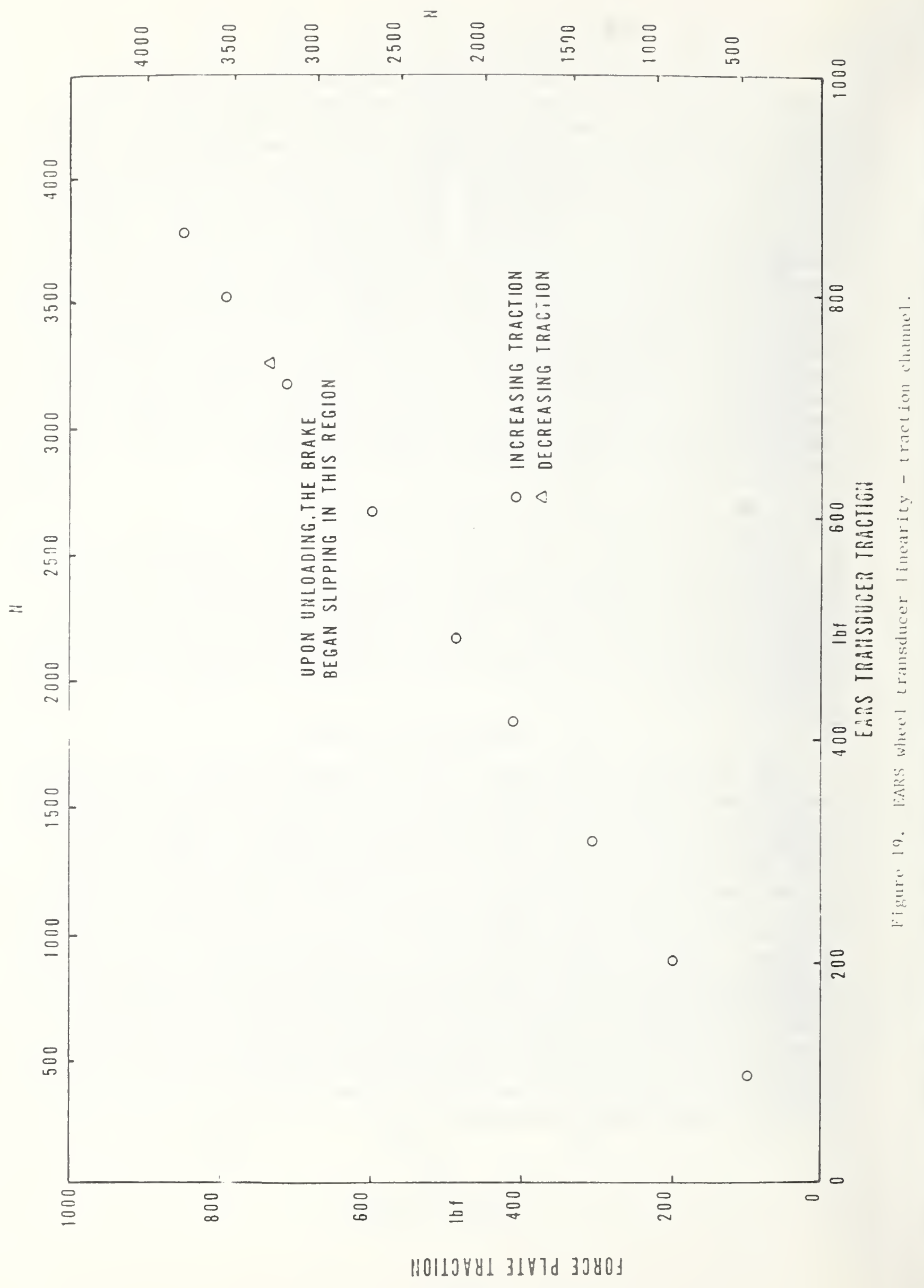


The dynamic characteristics of the trailer suspension system were obtained while the trailer was connected to a ball hitch on a stationary fixture. The displacements of the trailer test wheel under static load were measured with the trailer alined and connected to the tow vehicle with the tow vehicle drive wheels and trailer test wheel locked. Consequently, part of the motion occurring under traction force is due to motion between the ball hitch and the tow vehicle tire-pavement interface.

These suspension system tests were conducted in August 1974. The test program plan utilized the month of September for system modifications before the dynamic correlation tests occurred in October. As reported in Section 2.6, to eliminate a nonlinearity in the vertical load channel, the fenders were raised and the suspension springs were replaced. It was learned later that trailers of this design subsequently manufactured and used with the larger E501 test tires only required the raising of the fender to correct the nonlinearity. The suspension springs in the EARS were replaced with the same type having the same spring rate (Section 2.7.2.2).* The dynamic characteristics reported here were measured prior to the modification and are proportional to the square root of the spring rate, but allowance for a four percent difference in spring rate changes the values by only two percent.

Since optimum design values have not been demonstrated at this time, results from some tests conducted on the IRS are presented with those of the EARS for intercomparison purposes.

\subsubsection{Tow Vehicle and Trailer Displacements under Static Traction Load}

\subsubsection{Displacement of the Test Wheel Hub}

The test wheel hub moves back due to static traction loading. This displacement is the resultant of motions throughout the system. Tow vehicle tire and suspension deflections, trailer suspension deflections, and trailer yaw contribute.

The component of hub displacement along the direction of the initial alinement of the tow vehicle and trailer was measured with respect to the floor. The measured displacements for the EARS and the IRS are plotted in Figure 20. The displacement sensor at the EARS hub went off scale near $400 \mathrm{lbf}(1780 \mathrm{~N})$ traction, however, the slope below $4001 \mathrm{bf}(1780 \mathrm{~N})$ suggests that the displacement at 800 lbf $(3560 \mathrm{~N})$ may have been larger than the corresponding displacement of the IRS hub. At 800 lbf (3560 N) the IRS hub was displaced 0.72 in $(1.8 \mathrm{~cm})$ to the rear.

*Information regarding springs was obtained from $\mathrm{K}$. J. Iaw, Inc. in a letter dated December 16, 1975. 


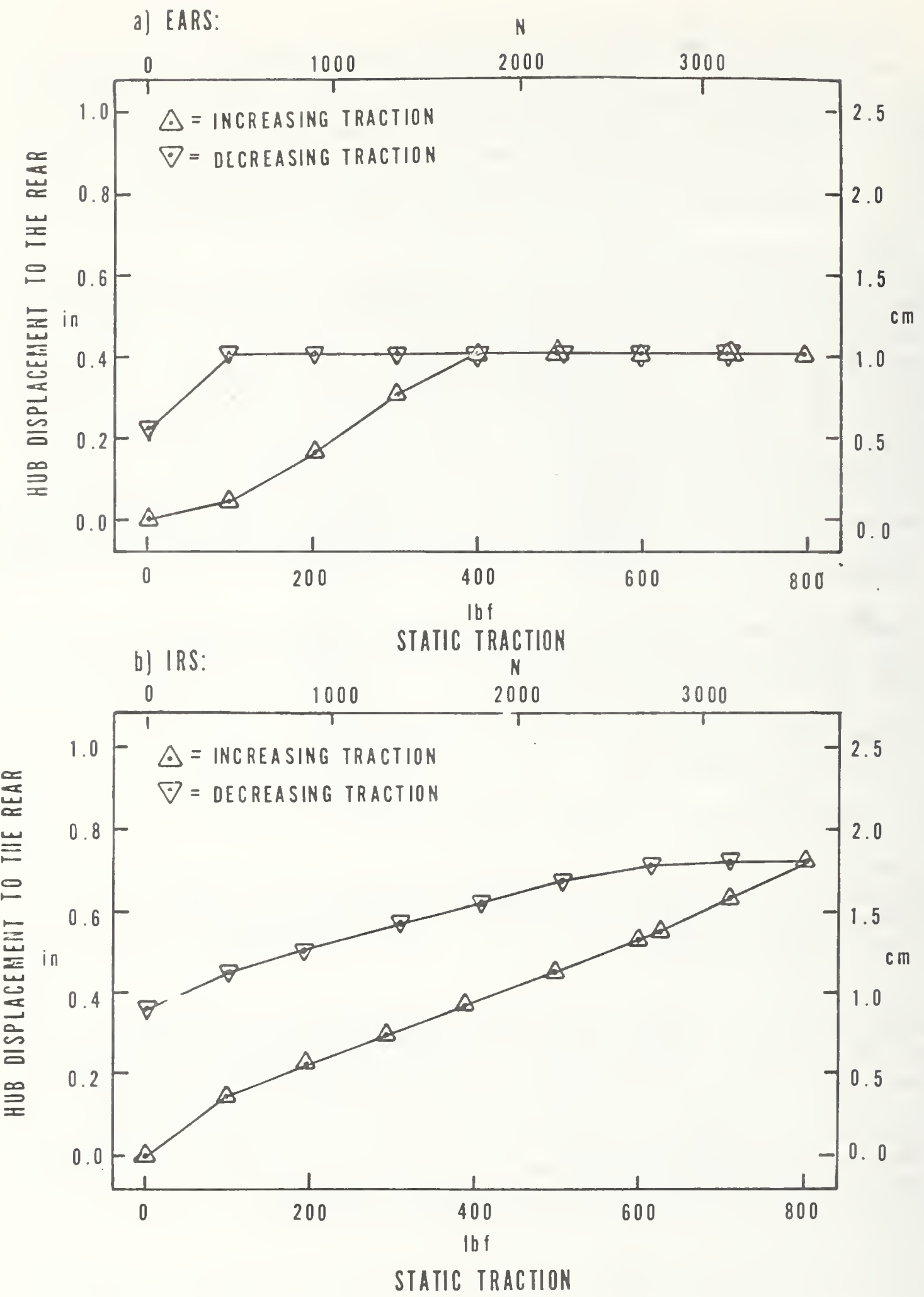

Figure 20. Displacement of the test wheel hub due to static traction. 
2.7.1.2 Displacement of the Trailer Body Through

Roll Axis Rotation

The body of a two wheeled skid trailer may roll about a longitudinal axis during skid testing. The suspension and tires of the trailer respond to asymmetric forces developed by test wheel traction loading.

Roll displacement due to static traction loading was measured with respect to the floor by two sensors applied vertically to the back corners of the trailer body. Lateral separation of the sensors was 46 in $(117 \mathrm{~cm})$.

The EARS and IRS responded quite differently (Fig. 21). At 800 1bf $(3560 \mathrm{~N})$ static traction loading, the EARS trailer body fell 0.35 in $(0.89 \mathrm{~cm})$ on the left (test wheel) side and rose 0.62 in $(1.6 \mathrm{~cm})$ on the right side corresponding to a roll axis rotation of 72 minutes of arc. At the same loading the IRS trailer body rose 0.05 in $(0.12 \mathrm{~cm})$ on the left (test wheel) side and rose 0.04 in $(0.10 \mathrm{~cm}$ ) on the right side corresponding to a roll axis rotation of 0.7 minutes of arc.

\subsubsection{Displacement of the Trailer Body Through Pitch Axis Rotation}

The average of the displacements measured by the two trailer body roll sensors represents the vertical displacement of the center of the trailer body at the rear with respect to the floor. This, combined with the vertical displacement measured by a third sensor at the trailer hitch, yields trailer body pitch. The pitch displacements for the EARS and the IRS are plotted in Figure 22. The longitudinal separation of the front and rear sensors was 137 in $(348 \mathrm{~cm}$ ).

At 800 lbf $(3560 \mathrm{~N})$ static traction loading, the EARS trailer body rose 0.01 in $(0.02 \mathrm{~cm})$ at the hitch and rose 0.14 in $(0.35 \mathrm{~cm})$ at the rear corresponding to a pitch axis rotation of three minutes of arc. At the same loading the IRS trailer body fell 0.07 in $(0.18 \mathrm{~cm})$ at the hitch and rose 0.05 in $(0.13 \mathrm{~cm})$ at the rear corresponding to a pitch axis rotation of three minutes of arc.

\subsubsection{Trailer Displacements under Transient Loading}

\subsubsection{Effective Coulomb Friction of the Trailer Suspension}

To enhance the measurement of the Coulomb friction in the suspension, the shock absorbers were temporarily disconnected. Vertical load at the tire-pavement interface and the displacement between the trailer body and axle were measured versus time after the trailer was lifted at the rear bumper and dropped abruptly. The measurements are shown in Figure 23 where the linear decay of amplitude is a measure of the Coulomb friction. The Coulomb friction associated with one wheel was determined to be $9.41 \mathrm{bf}$ $(41.8 \mathrm{~N})$. 
a) EARS:

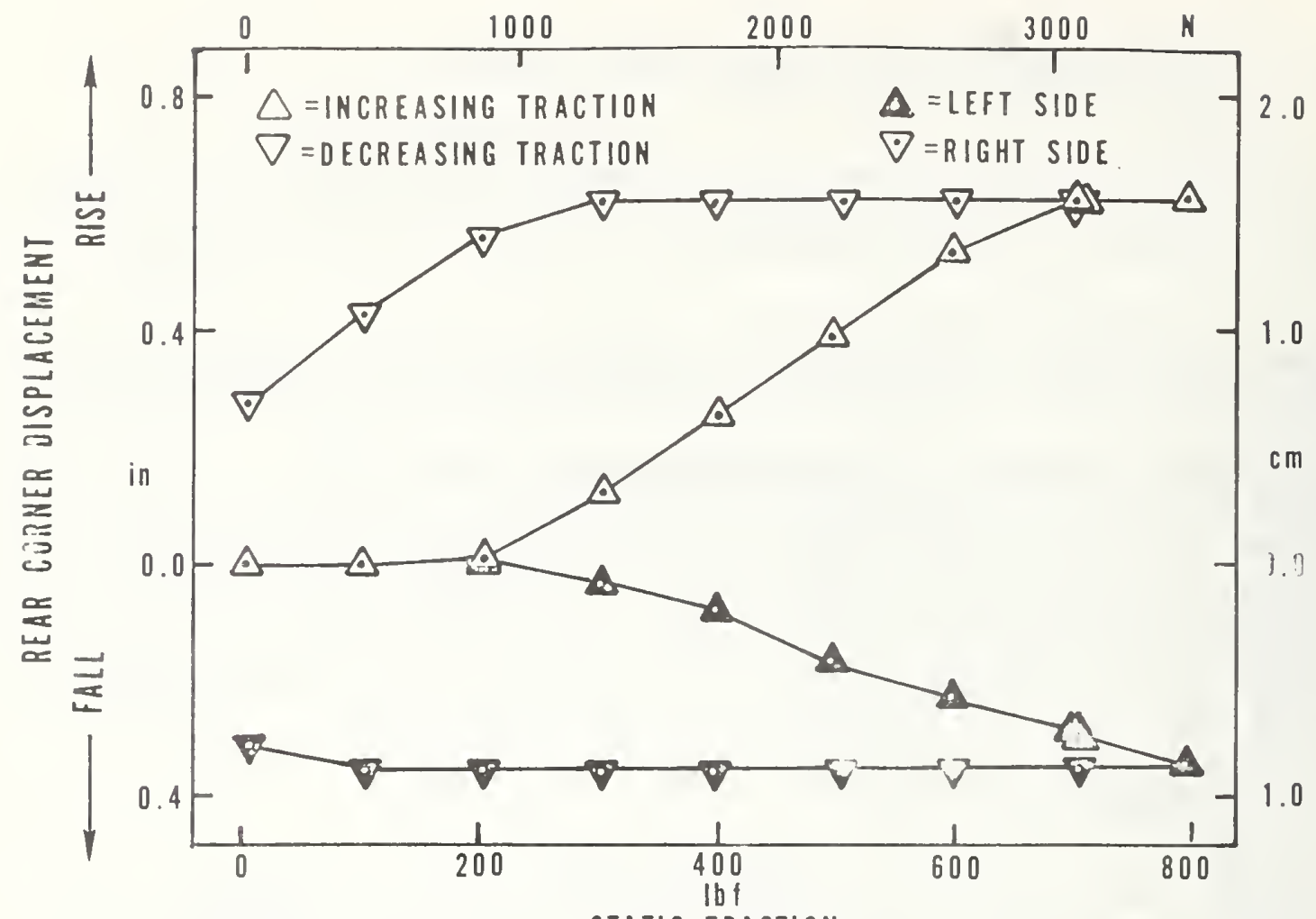

b) IRS:

STATIC TRACTION

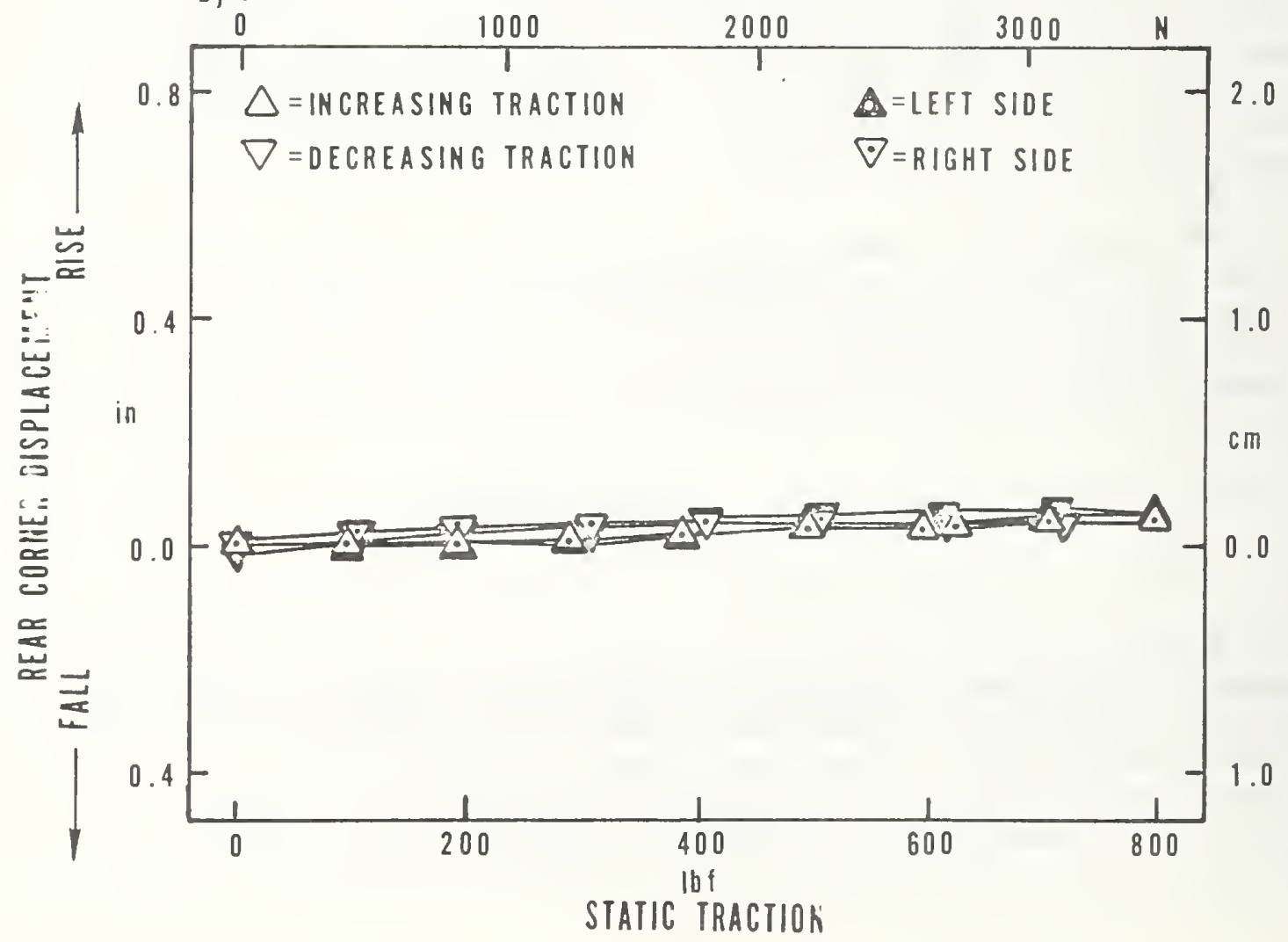

Figure 21. Roll displacement of the trailer body due to static
traction. 


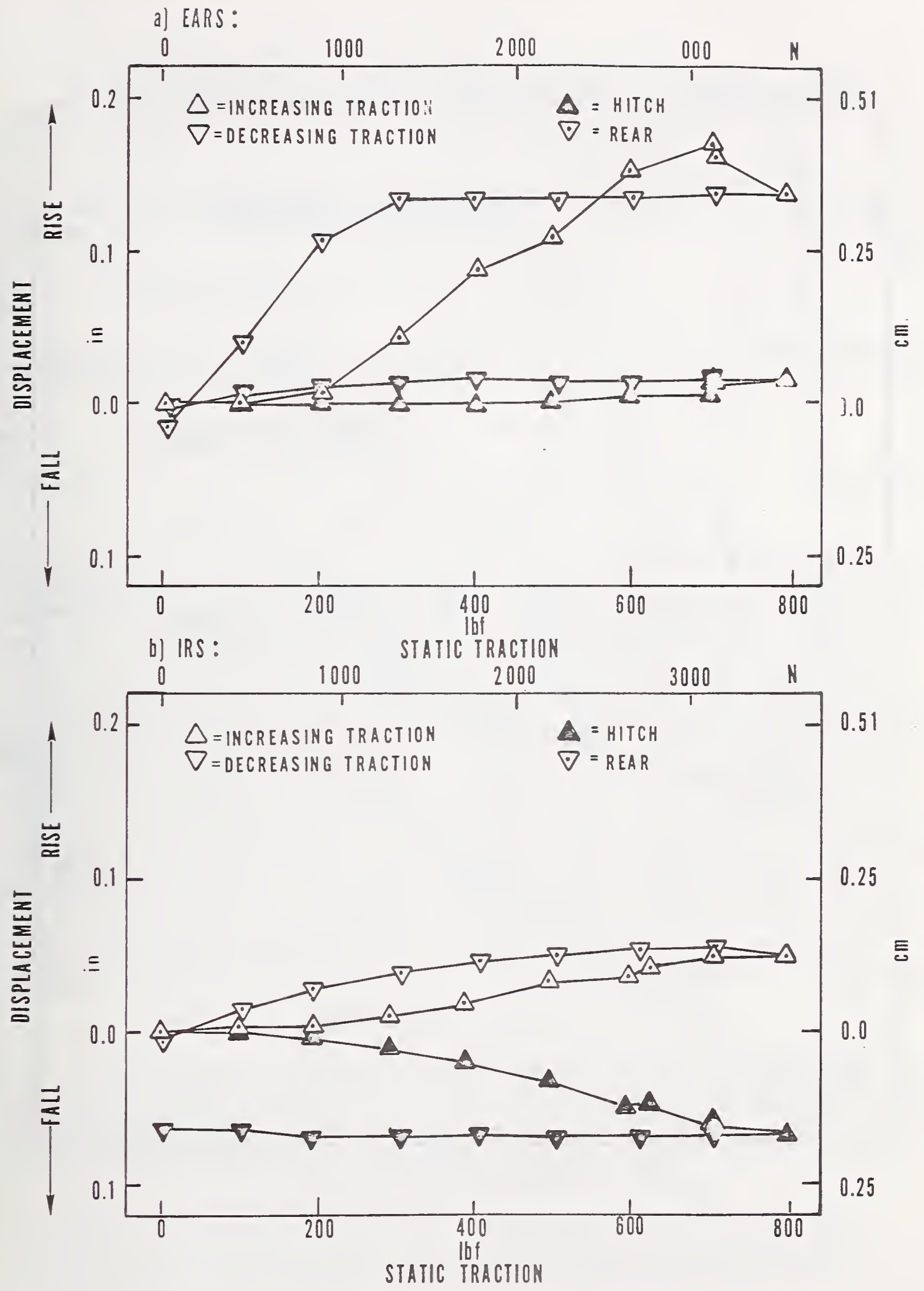

Figure 22. Pitch displacement of the trailer body due to static traction. 


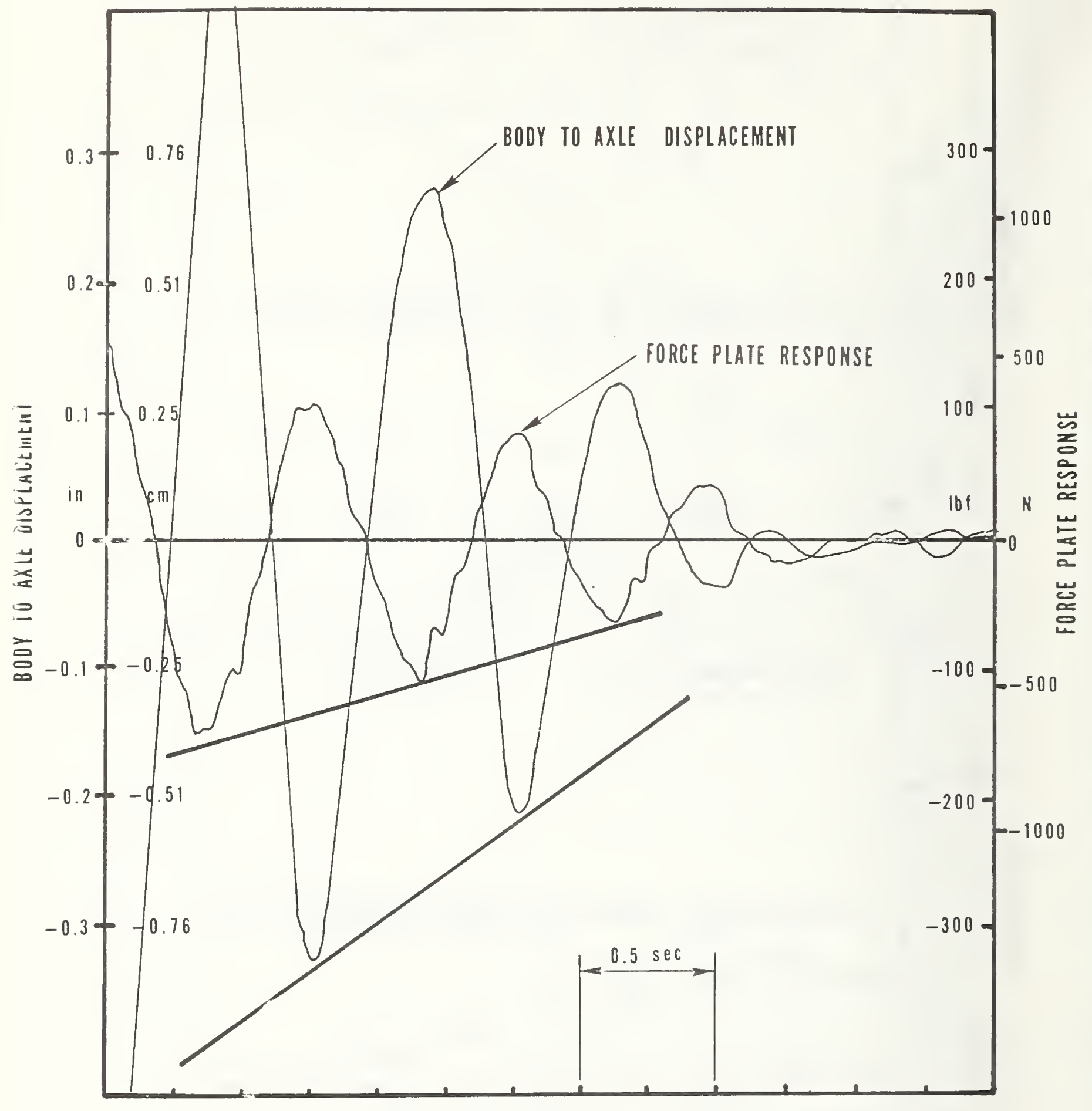

Figure 23. Coulomb damping test response. 
2.7.2.2 Effective Spring Rates of the Trailer Suspension

In the above test, the change in force and displacement from their equilibrium values is a measure of the spring rate. The body-to-axle spring rate was determined to be $3501 \mathrm{bf} / \mathrm{in}(61000 \mathrm{~N} / \mathrm{m})$.*

With the body-to-axle and tire spring rate known (Section 2.1.2) the body-to-pavement effective spring rate was determined to be $2751 \mathrm{bf} / \mathrm{in}$ $(48000 \mathrm{~N} / \mathrm{m})$.

\subsubsection{Effective Natural Frequencies of the Trailer Suspension}

There are two significant natural frequencies of the EARS skid trailer since there are two degrees of freedom:
a) the body can rotate in a vertical plane about the hitch, and
b) the axle can rotate in a vertical plane about its trailing arm hinge.

There is a mode of operation associated with each degree of freedom. Each mode may be produced independently by starting the system oscillation under the proper initial conditions. There are two dynamic tests which are easy to conduct which approximate the independent modes such that the measurement of each natural frequency is enhanced. The first test is to raise the trailer by the rear bumper and to drop it abruptly. With this initial condition, an oscillation occurs where the angular displacement of the body and axle trailing arm are out of phase. In this mode, the low frequency is enhanced as shown in Figure 23. The low undamped natural frequency is measured to be 1.3 hertz. The second test is to raise the trailer at the axle and to drop it abruptly. With this initial condition, an oscillation occurs where the angular displacement of the body and axle trailing arm are in phase. In this mode, the high frequency is enhanced as shown in Figure 24. The high undamped natural frequency is measured to be 12.7 hertz. After the transient decays to where there is no further relative movement in the suspension, the oscillation of the trailer on the tires persists since there is little damping in the tires. The natural frequency of the trailer on the tires at this low amplitude is 3.1 hertz.

\subsubsection{Effective Viscous Damping of the Trailer Suspension}

To estimate the effective amount of viscous damping in the system, the shocks were connected and the bumper drop test repeated. The response is shown in Figure 25. Since the transient is now damped by both the Coulomb and viscous friction, the damped envelope is shown redrawn to account for the Coulomb friction occurring in each cycle.

* Subsequent to the replacement of the suspension springs this test was repeated. When the force amplitude was $44 \mathrm{lbf}$ (196 N) the displacement was 0.125 in corresponding to a body-to-axle spring rate of $350 \mathrm{lbf} / \mathrm{in}$ (61 $000 \mathrm{~N} / \mathrm{m})$. 


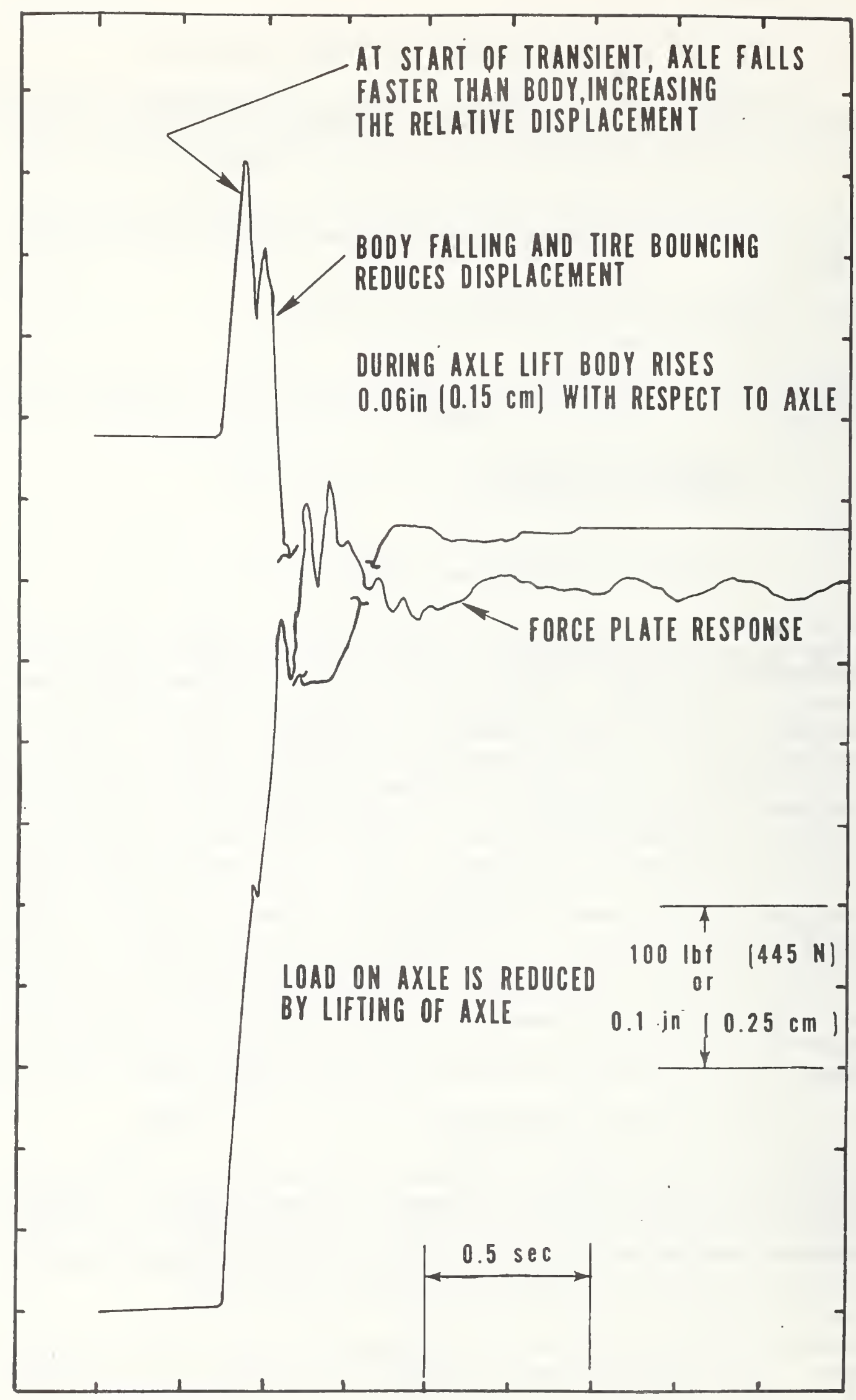

Figure 24. Axle drop test response. 


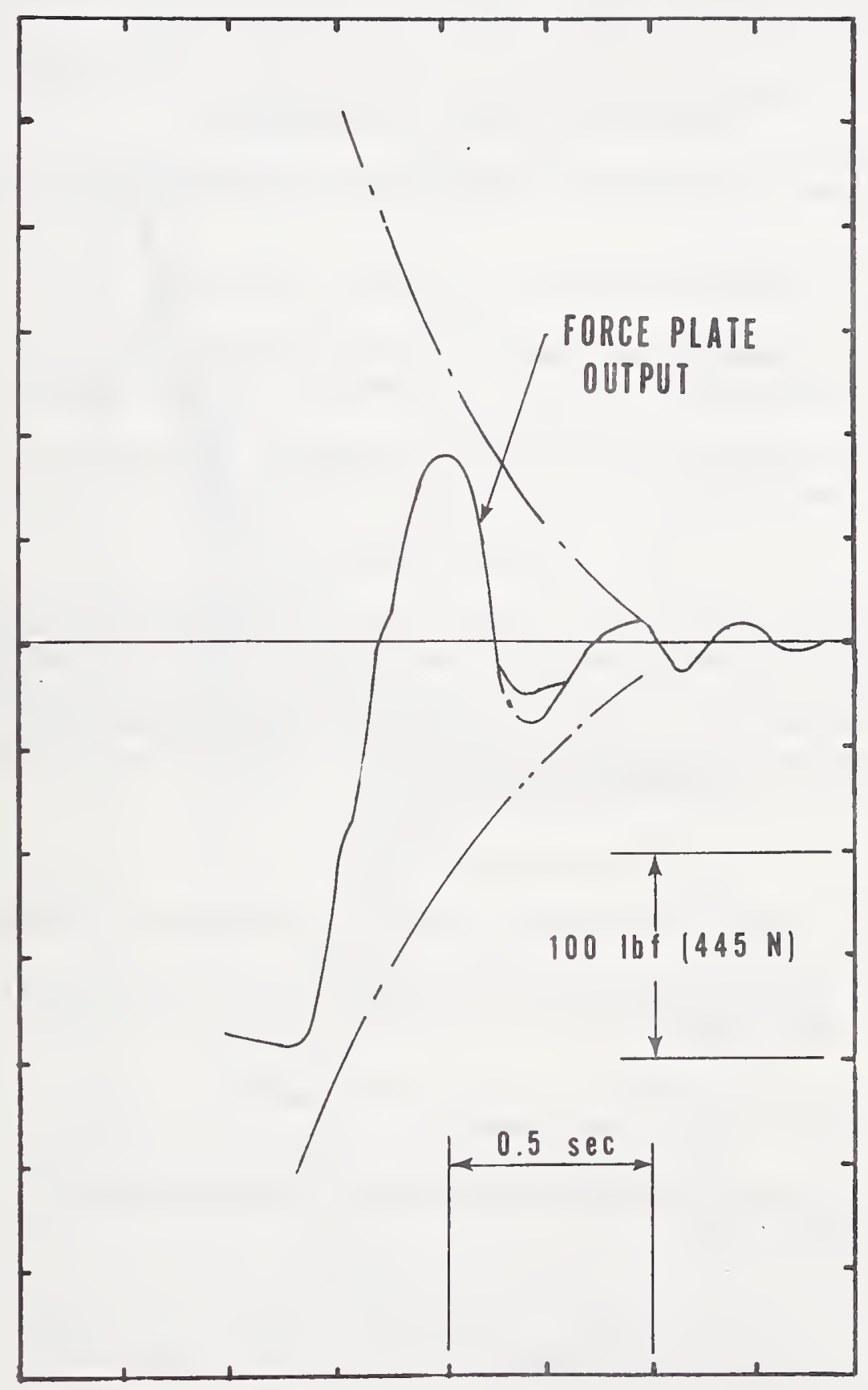

Figure 25. Effective viscous damping envelope. 
A nondimensional plot for estimating damping in systems represented by a differential equation of second degree is shown in Figure 26 [10]. As drawn, the response envelope (Fig. 25) is approximated by a 250 lbf $(1100 \mathrm{~N})$ drop test, with a first overshoot of $130 \mathrm{lbf}(580 \mathrm{~N})$ and a second overshoot of $65 \mathrm{lbf}(290 \mathrm{~N})$. Comparing these results with the family of curves in Figure 26, the effective damping factor, $\zeta$, is approximately 0.2. Another way of estimating the amount of damping present is to measure the rate of decay of oscillation using the logarithmic decrement. This calculation also indicates a damping factor of 0.2 .

\section{THE DYNAMIC SKID RESISTANCE MEASUREMENT OF SELECTED SURFACES AND EARS-IRS CORRELATION}

The purpose of the dynamic skid resistance measurement test program was:

a) to measure selected surfaces at the EFTC,

b) to measure the consistency and precision in the measurements of both the EARS and the IRS, and

c) to correlate the degree of match in the measurements between the IRS and the EARS.

\subsection{Surfaces Selected}

The surfaces selected were a $100 \mathrm{ft}(30.5 \mathrm{~m})$ longitudinal section of lanes 1 through 7 of surfaces identified as 1, 2, and 3 at the EFTC. So that the reduced data would all be within the same $100 \mathrm{ft}(30.5 \mathrm{~m})$ section at all test speeds, pylons were set out where the operator would start the automatic test sequence for each test speed. The locations of the selected surfaces and pylons are shown in Figure 27.

\section{2 Tests Planned}

The test program is designed to yield the following information:

a) skid resistance, $\mathrm{SN}$, of a surface as a function of test speed,

b) skid resistance - test speed gradient, $\theta$, as a function of test speed,

c) variability in SN with choice of time period for the test,

d) variability in $\mathrm{SN}$ with choice of test tire, and

e) variability in SN with choice of lane within the surface. 


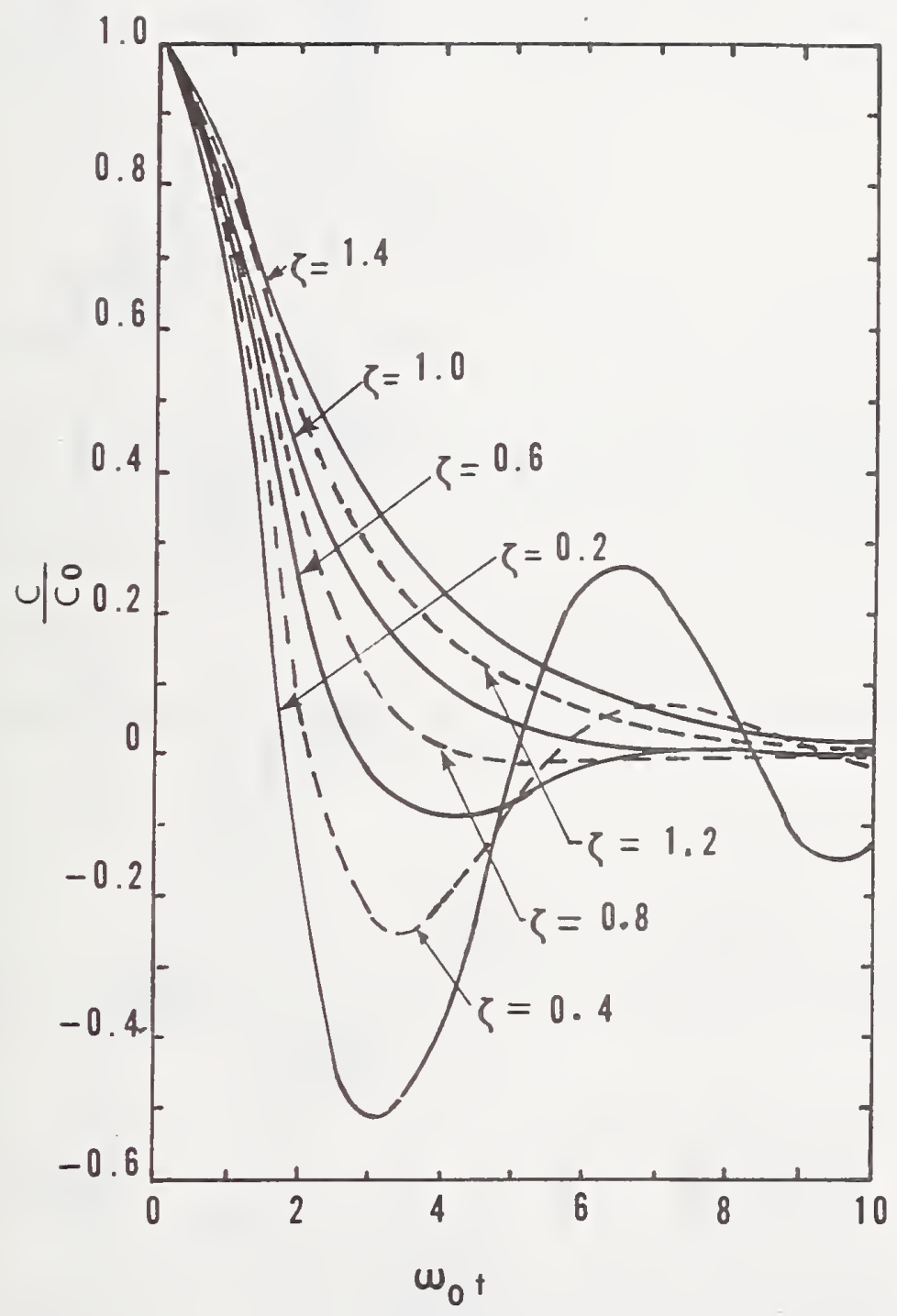

Figure 26. Effect of different damping factors on second-order linear systems. 


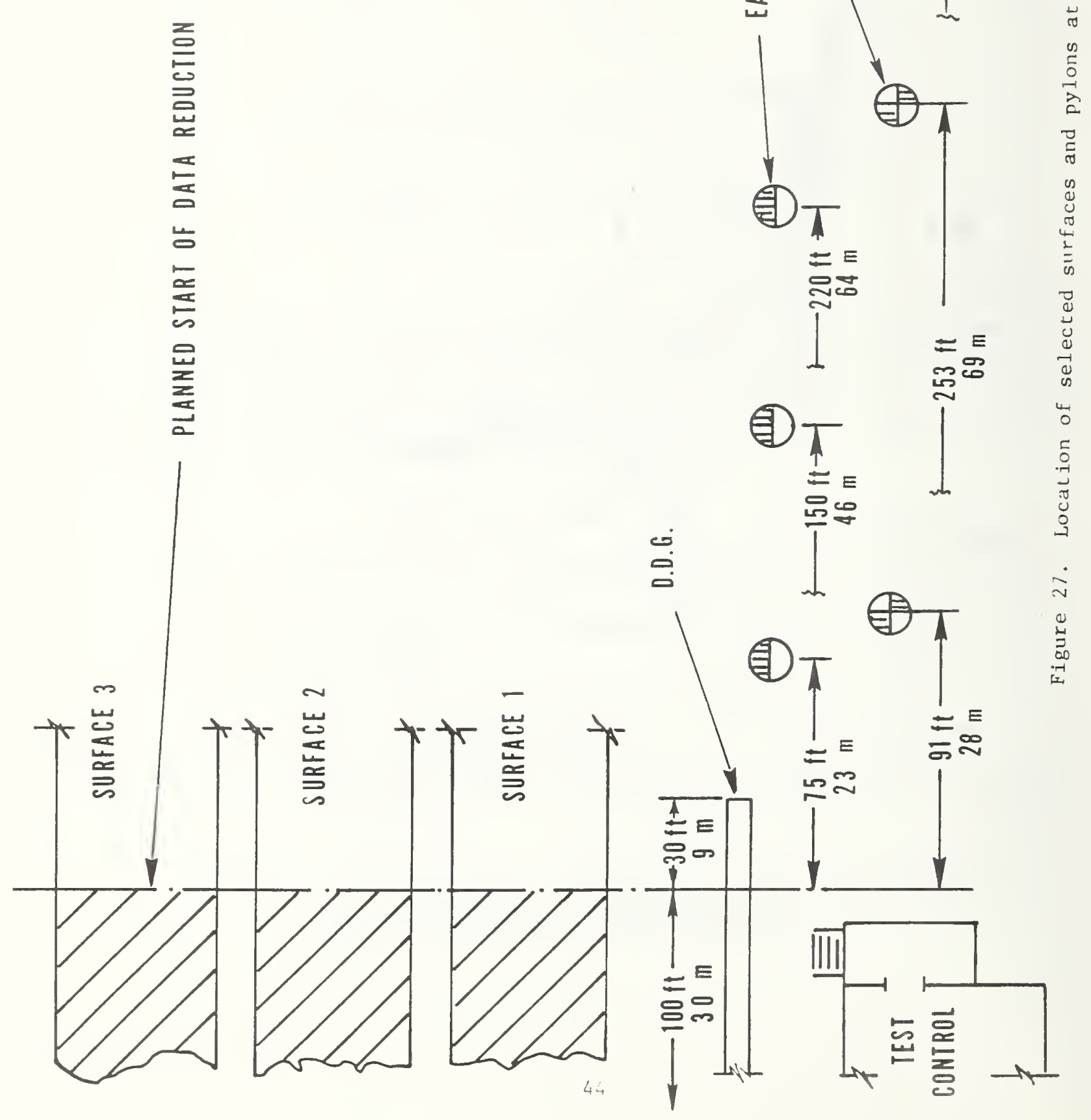


The test plan included the control of the following operating variables:
a) hitch height,
b) inflation pressure of the test tire,
c) inflation pressure of the tow vehicle rear tires,
d) inflation pressure of the shock absorbers,
e) surface cleanliness,
f) surface degree-of-dryness,
g) test speed, and
h) water flow rate.

The test plan included the measurement of the following uncontrolled variables:
a) weather,
b) surface temperature,
c) test tire lock-up position, and
d) test tire tread depth.

The planned test program is contained in Table 5.

The test sequence within each time period is given in Table 6 . In general, at least two tests are conducted in other lanes before a test is repeated in a given lane. At a spacing of 20 minutes between tests, a minimum of one hour is allowed for the surface to dry before measuring the lane again [7].

\subsection{The Test Matrix}

A subdivision of the test plan consists of the following test matrix:

Time Period

Surface

\begin{tabular}{|c|c|c|c|c|c|c|c|}
\hline \multirow[b]{2}{*}{ Speed } & \multicolumn{7}{|c|}{ Tires } \\
\hline & A & B & $\mathrm{C}$ & D & $E$ & $\mathrm{~F}$ & $\mathrm{G}$ \\
\hline$S-\Delta S$ & 1 & 2 & 3 & 4 & 5 & 6 & 7 \\
\hline S & 2 & 3 & 4 & 5 & 6 & 7 & 1 \\
\hline$S+\Delta S$ & 4 & 5 & 6 & 7 & 1 & 2 & 3 \\
\hline
\end{tabular}

Letters A thru G designate 7 tires while numbers 1 thru 7 identify the 7 lanes comprising the surface [8]. The nominal test speed is $S$, while $\Delta \mathrm{S}$ is an incremental change in the speed. Since $\Delta \mathrm{S}$ is small, the slope over the range $2 \Delta S$ approaches the speed gradient at $S$. Another subdivision of the test plan given in Table 5 consists of a test matrix where the variables are time periods, lanes and speed. 
Table 5 - Tests Planned and Accomplished

\begin{tabular}{|c|c|c|c|c|c|c|c|c|c|c|c|c|}
\hline \multirow[b]{3}{*}{ Surface } & \multirow{3}{*}{$\begin{array}{l}\text { Nominal } \\
\text { Test Speed }\end{array}$} & \multirow{3}{*}{$\begin{array}{l}\text { Number of } \\
\text { Time Periods }\end{array}$} & \multirow{3}{*}{$\begin{array}{l}\text { No. of } \\
\text { Tires }\end{array}$} & \multirow{3}{*}{$\begin{array}{l}\text { No. of } \\
\text { Lanes }\end{array}$} & \multicolumn{8}{|c|}{ Test Matrix } \\
\hline & & & & & \multirow{2}{*}{\multicolumn{3}{|c|}{$\overline{\text { Planned }}$}} & \multicolumn{5}{|c|}{ Accomplished } \\
\hline & & & & & & & & \multicolumn{3}{|c|}{ IRS } & \multicolumn{2}{|c|}{ EARS } \\
\hline 1 & 40 & 1 & 7 & 7 & 3 & $\mathrm{x}$ & 7 & 3 & $\mathrm{x}$ & 7 & & - \\
\hline 2 & 20 & 1 & 7 & 7 & 3 & $\mathrm{x}$ & 7 & & - & & 3 & $\times 3$ \\
\hline 2 & 40 & 1 & 7 & 7 & 3 & $\mathrm{x}$ & 7 & 3 & $\mathrm{x}$ & 7 & 3 & $\times 4$ \\
\hline 2 & 60 & 1 & 7 & 7 & 3 & $\mathrm{x}$ & 7 & & - & & 3 & $\times 4$ \\
\hline 3 & 20 & 1 & 7 & 7 & 3 & $\mathrm{x}$ & 7 & 3 & $\mathrm{x}$ & 7 & 3 & $\times 5$ \\
\hline 3 & 40 & 1 & 7 & 7 & 3 & $\mathrm{x}$ & 7 & 3 & $\mathrm{x}$ & 7 & & - \\
\hline 3 & 60 & 1 & 7 & 7 & 3 & $\mathrm{x}$ & 7 & 3 & $x$ & 7 & & - \\
\hline 1 & 40 & 7 & 1 & 7 & 3 & $\mathrm{x}$ & 7 & 3 & $\mathrm{x}$ & 6 & 3 & $\times 5$ \\
\hline 2 & 40 & 7 & 1 & 7 & 3 & $\mathrm{x}$ & 7 & 3 & $\mathrm{x}$ & 5 & 3 & $\times .5$ \\
\hline 3 & 40 & 7 & 1 & 7 & & $\mathrm{x}$ & 7 & 3 & $\mathrm{x}$ & 5 & 3 & $\times 5$ \\
\hline & Total & easurements & & & & 210 & & & 153 & & & 93 \\
\hline & $\begin{array}{c}\text { Accomp } \\
\text { of }\end{array}$ & $\begin{array}{l}\text { ished as a } \mathrm{Pe} \\
\text { lanned }\end{array}$ & cent & & & & & & $73 \%$ & & & $44 \%$ \\
\hline
\end{tabular}


Table 6 - Test Plan Sequence

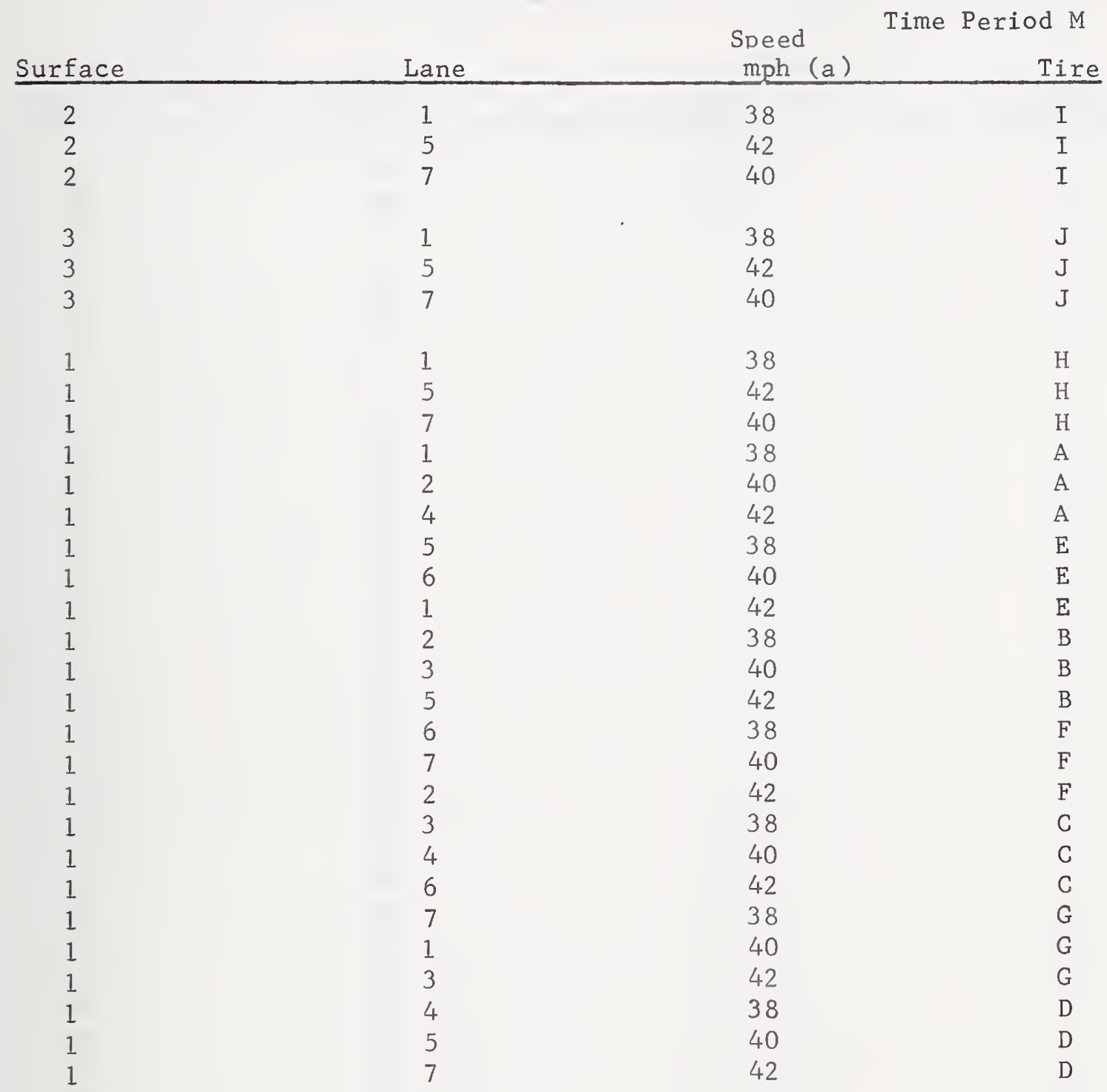


Table 6 - Test Plan Sequence (Continued)

\begin{tabular}{|c|c|c|c|}
\hline Surface & Lane & $\begin{array}{l}\text { Speed } \\
\text { mph (a) }\end{array}$ & $\begin{array}{r}\text { Time Period Tu } \\
\text { Tire } \\
\end{array}$ \\
\hline 1 & 1 & 40 & $\mathrm{H}$ \\
\hline 1 & 2 & 38 & $\mathrm{H}$ \\
\hline 1 & 6 & 42 & $\mathrm{H}$ \\
\hline 3 & 1 & 40 & $\mathrm{~J}$ \\
\hline 3 & 2 & 38 & $\mathrm{~J}$ \\
\hline 3 & 6 & 42 & $\mathrm{~J}$ \\
\hline 2 & 1 & 40 & I \\
\hline 2 & 2 & 38 & I \\
\hline 2 & 6 & 42 & I \\
\hline 2 & 1 & 38 & A \\
\hline 2 & 2 & 40 & A \\
\hline 2 & 4 & 42 & A \\
\hline 2 & 5 & 38 & $E$ \\
\hline 2 & 6 & 40 & $E$ \\
\hline 2 & 1 & 42 & $E$ \\
\hline 2 & 2 & 38 & B \\
\hline 2 & 3 & 40 & B \\
\hline 2 & 5 & 42 & B \\
\hline 2 & 6 & 38 & F \\
\hline 2 & 7 & 40 & F \\
\hline 2 & 2 & 42 & F \\
\hline 2 & 3 & 38 & C \\
\hline 2 & 4 & 40 & C \\
\hline 2 & 6 & 42 & C \\
\hline 2 & 7 & 38 & G \\
\hline 2 & 1 & 40 & G \\
\hline 2 & 3 & 42 & G \\
\hline 2 & 4 & 38 & D \\
\hline 2 & 5 & 40 & $\mathrm{D}$ \\
\hline 2 & 7 & 42 & $\mathrm{D}$ \\
\hline
\end{tabular}


Table 6 - Test Plan Sequence (Continued)

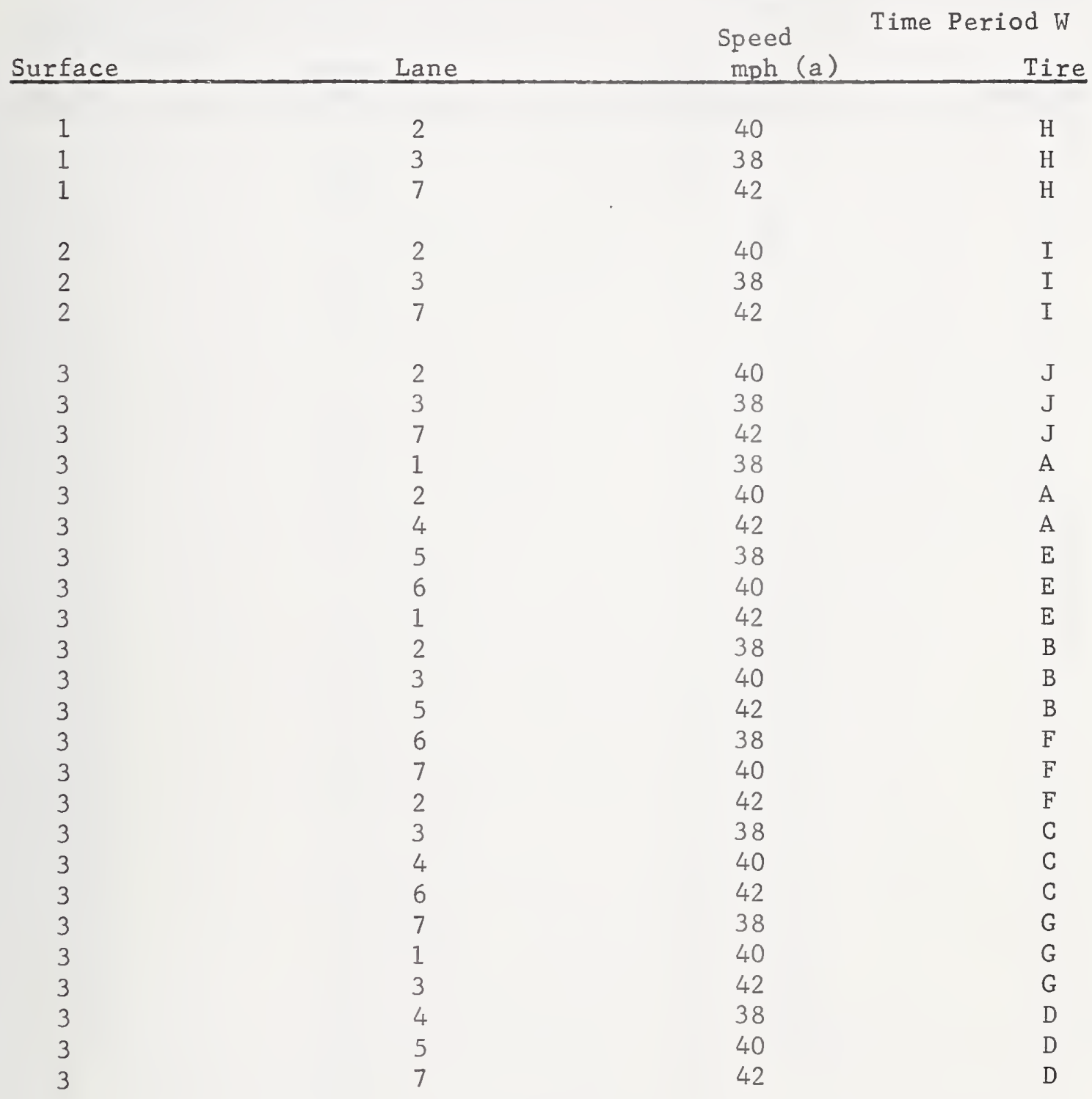


Table 6 - Test Plan Sequence (Continued)

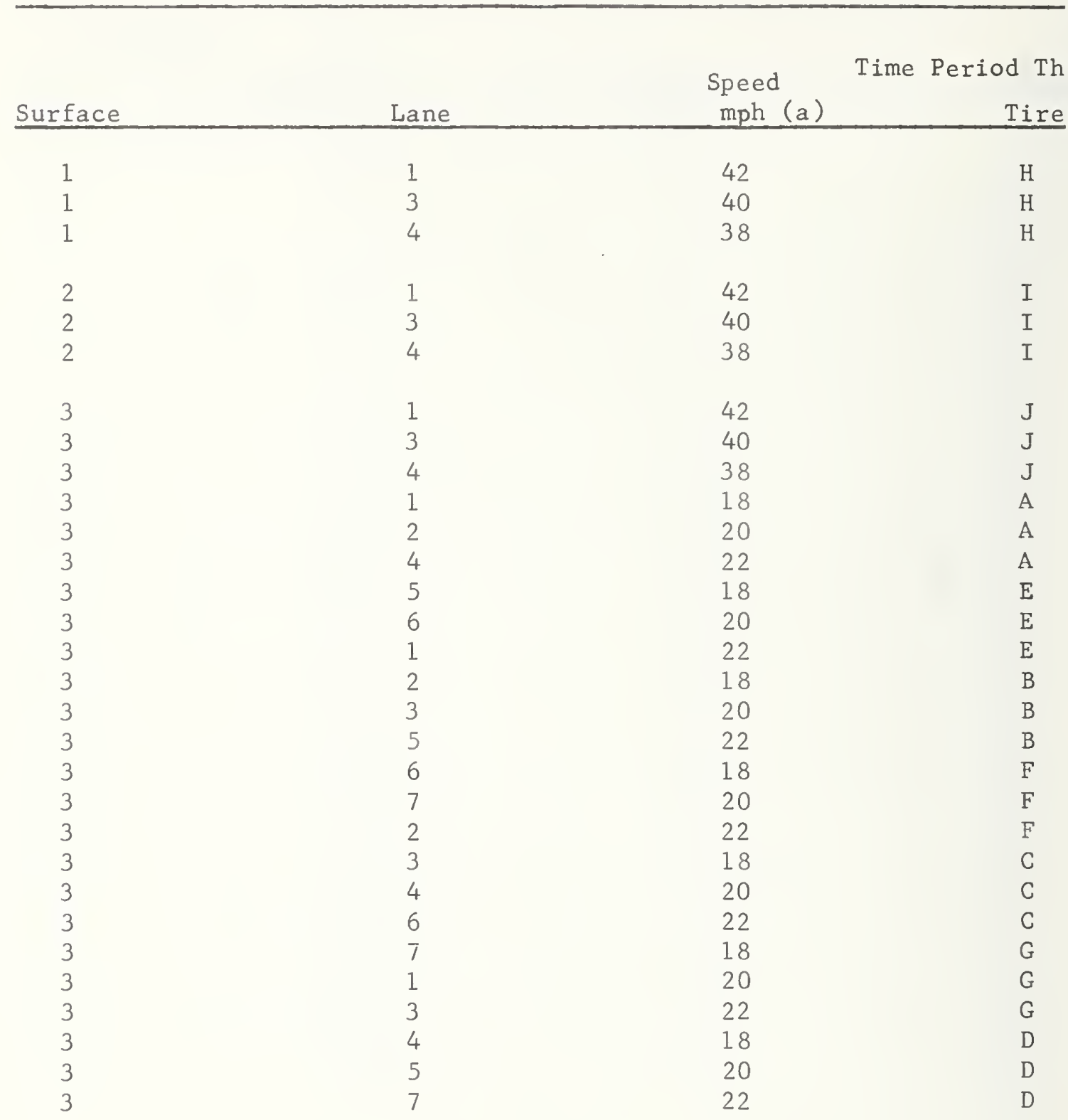


Table 6 - Test Plan Sequence (Continued)

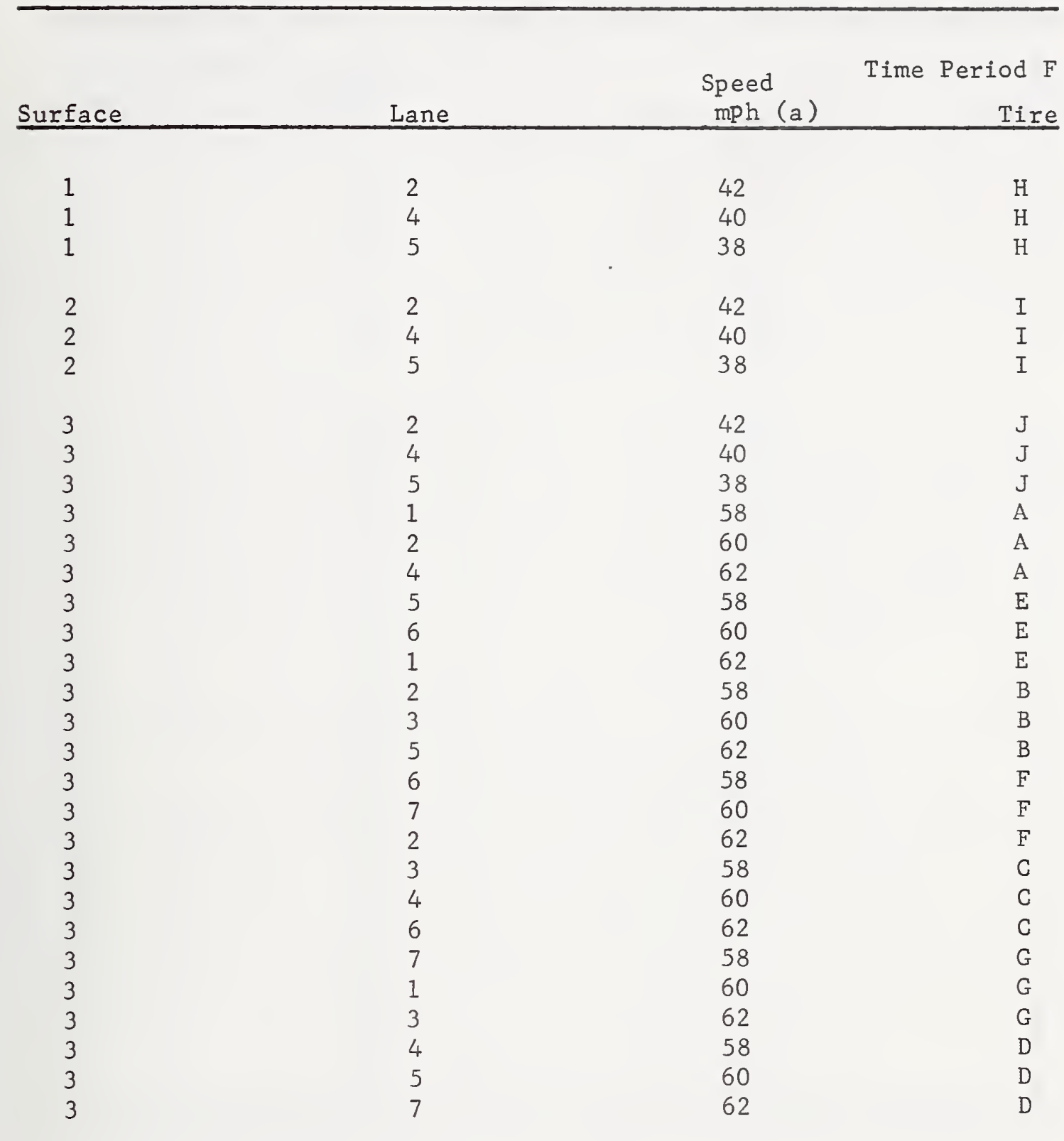


Table 6 - Test Plan Sequence (Continued)

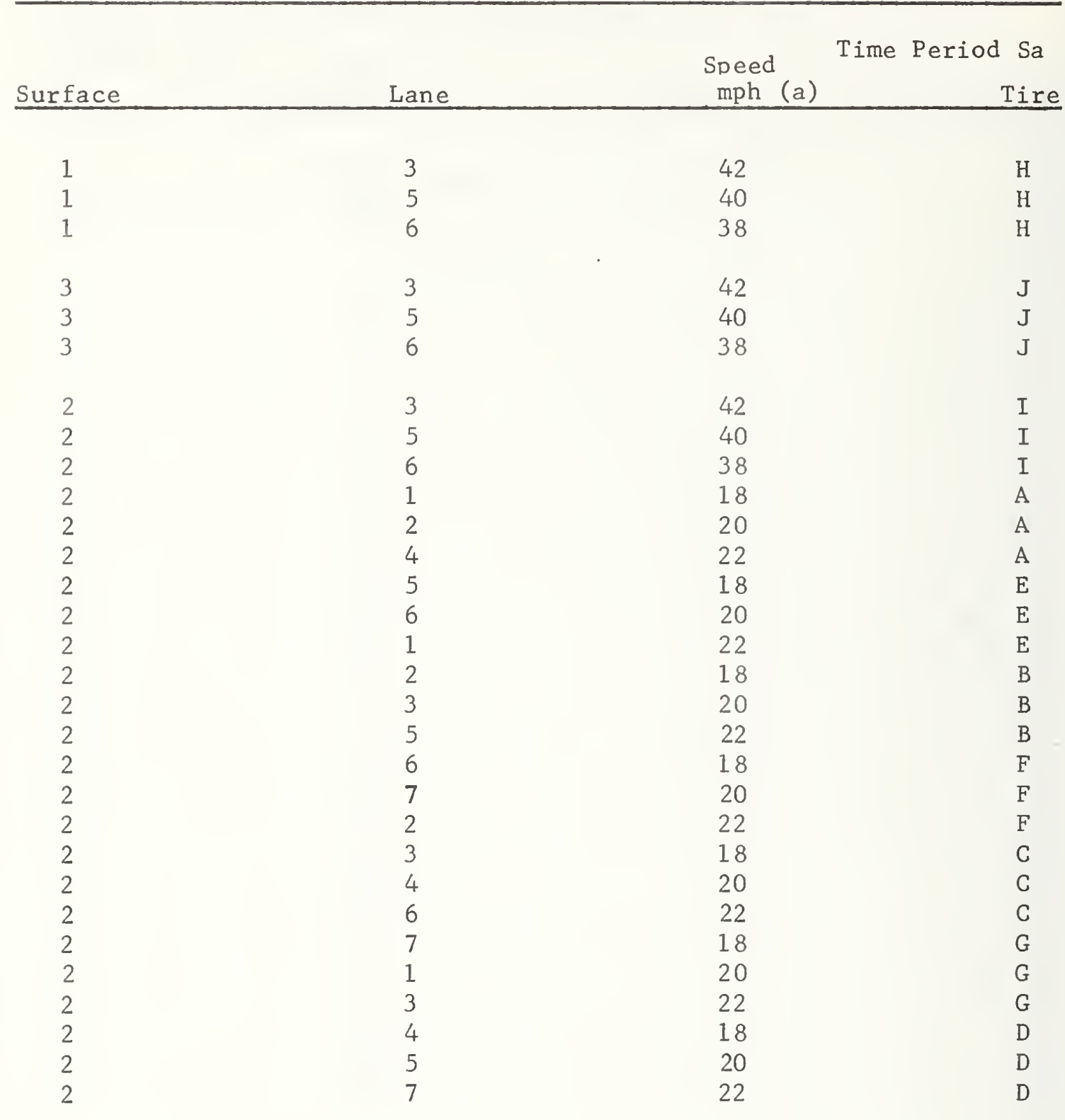


Table 6 - Test Plan Sequence (Continued)

\begin{tabular}{|c|c|c|c|}
\hline Surface & Lane & $\begin{array}{l}\text { Speed } \\
\mathrm{mph} \text { (a) }\end{array}$ & $\begin{array}{r}\text { Time Period Su } \\
\text { Tire }\end{array}$ \\
\hline 1 & 4 & 42 & $\mathrm{H}$ \\
\hline 1 & 6 & 40 & $\mathrm{H}$ \\
\hline 1 & 7 & 38 & $\mathrm{H}$ \\
\hline 3 & 4 & 42 & $\mathrm{~J}$ \\
\hline 3 & 6 & 40 & $\mathrm{~J}$ \\
\hline 3 & 7 & 38 & $\mathrm{~J}$ \\
\hline 2 & 4 & 42 & I \\
\hline 2 & 6 & 40 & I \\
\hline 2 & 7 & 38 & $I$ \\
\hline 2 & 1 & 58 & $\mathrm{~A}$ \\
\hline 2 & 2 & 60 & $\mathrm{~A}$ \\
\hline 2 & 4 & 62 & A \\
\hline 2 & 5 & 58 & $\mathrm{E}$ \\
\hline 2 & 6 & 60 & $\mathrm{E}$ \\
\hline 2 & 1 & 62 & $\mathrm{E}$ \\
\hline 2 & 2 & 58 & B \\
\hline 2 & 3 & 60 & B \\
\hline 2 & 5 & 62 & B \\
\hline 2 & 6 & 58 & $F$ \\
\hline 2 & 7 & 60 & $\mathrm{~F}$ \\
\hline 2 & 2 & 62 & $\mathrm{~F}$ \\
\hline 2 & 3 & 58 & C \\
\hline 2 & 4 & 60 & C \\
\hline 2 & 6 & 62 & $\mathrm{C}$ \\
\hline 2 & 7 & 58 & $G$ \\
\hline 2 & 1 & 60 & $G$ \\
\hline 2 & 3 & 62 & G \\
\hline 2 & 4 & 58 & $D$ \\
\hline 2 & 5 & 60 & $D$ \\
\hline 2 & 7 & 62 & $D$ \\
\hline
\end{tabular}

(a) $1 \mathrm{mph}=1.6 \mathrm{~km} / \mathrm{h}$ 
The mean of the 21 skid number measurements represents the skid number of the surface measured during the time period using the average tire at the nominal test speed. The novelty of the test matrix is that it yields the skid gradient of the surface, as well as a measure of the surface and tire nonuniformities. The test matrix is explained further in Appendix B.

Seven tires were used by each system on the seven lanes of surfaces 1, 2, and 3 for the single time period test matrices ( 14 tires). One tire was used by each system on each surface every testing day for the multiple time period test matrices ( 6 tires). Twenty test tires were used in the program.

\subsection{Tests Accomplished}

The test plan utilized seven time periods, with each time period containing two days. The plan required 14 extended working days of dynamic testing. The weather conditions during the two weeks are given in Table 7. The testing time periods are related to the date and weather conditions in the table. Two days were lost due to rain at the beginning of the week with frost occurring on Saturday, followed by snow that evening. Thursday of the second week was lost due to wet surfaces and a heavy fog. The number of tests completed are shown in Table 5.

\subsection{Control of Test Variables}

Previous experiments with the IRS had shown that the operating variables listed in Section 3.2 required control.

Variations in hitch height, as expected, change the unloading constant of the test wheel vertical load. Variations in hitch height which also rotate the two-axis force transducer cause a shift in the zero of the traction channel and change the unloading constant, as measured by the vertical load channel, from the expected value. Two axis force transducers are used on both the EARS and the IRS. The static tests (Section 2.3) had demonstrated that the hitch height depends on occupant and water weight.

Variations in inflation pressure of the test tire have also been found to cause a shift in the zero of the traction force instrumentation and change the area of contact between the test tire and the surface. On dry pavements the variation in contact area changes the $2 \mathrm{mph}(3.2 \mathrm{~km} / \mathrm{h})$ skid resistance of smooth tires approximately one skid number per 2.5 psi $(17 \mathrm{k} \mathrm{Pa})$ in inflation pressure [9]. The $2 \mathrm{mph}(3.2 \mathrm{~km} / \mathrm{h})$ skid resistance is a measure of the first term of the skid resistance functional equation (Section 3.9). Variations in the inflation pressure of the tow vehicle rear tires change the water laying system pump rate with test speed. 


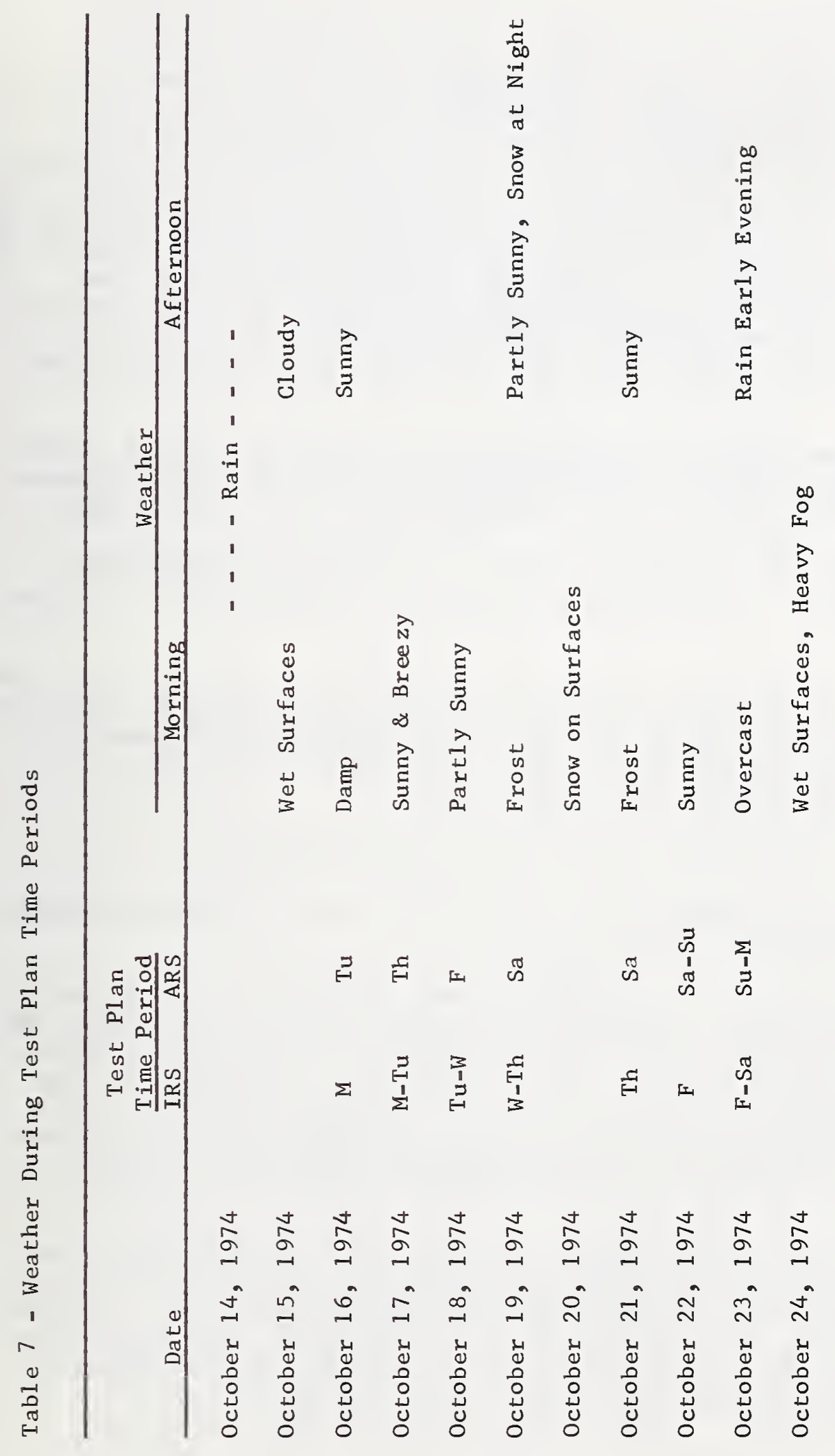


Each of ten tires were used for three tests during a test plan time period. Prior to the set of three tests, the test tire was conditioned with a five-mile drive. Immediately upon return to the test site, the inflation pressure of the test tire was readjusted to $24 \mathrm{ps} 1$ $(165 \mathrm{k} \mathrm{Pa})$. The hitch height was then readjusted to $12-5 / 8$ in $(32.07 \mathrm{~cm})$ for the IRS and to $11-7 / 8$ in $(30.16 \mathrm{~cm})$ for the EARS for the dimension from the surface to under the hitch flange at the same level location on the test site. The inflation pressure of the tow vehicle rear tires of both systems was readjusted to a nominal $45 \mathrm{psi}(310 \mathrm{kPa}$ ) four times per test day. The shock absorber pressure was checked at least once each day. Variations in shock absorber inflation pressure result in a shift in trailer body orientation which changes the static vertical test wheel load.

The surfaces were swept at the beginning of the test program. There is a considerable amount of rubber deposited on the surfaces as evidenced by the tire wear and "black residue" accumulated on the trailer fenders.

To control surface dryness, at least one hour was allowed between tests on any lane. A longer time was allowed if necessary for the surface to dry.

The skid resistance of a surface is recognized to vary with test speed (Section 3.9). A $0.5 \mathrm{mph}(0.8 \mathrm{~km} / \mathrm{h})$ difference in test speed on surface 3 (Fig. 35) changes the measurement result by approximately one percent. Test speed was recorded with a stationary differential radar system. The resolution of the system is $0.1 \mathrm{mph}(0.2 \mathrm{~km} / \mathrm{h})$.

\subsection{Measurement of Uncontrolled Test Variables}

The weather conditions around the surfaces during the dynamic testing time period are given in Table 7 .

The temperature of the surfaces was measured with a sensor located at one end of each surface. The temperature sensitive area of the sensor was placed in contact with the top of the aggregate. A conductive grease was used to provide thermal contact between the sensor and the sides of the protruding aggregates and the binder of the surface. The sensors were read frequently during the testing period. The surface temperatures measured are given versus time of day in Figure 28. The surface temperatures ranged from $40{ }^{\circ} \mathrm{F}$ to $92^{\circ} \mathrm{F}\left(4^{\circ} \mathrm{C}\right.$ to $\left.33^{\circ} \mathrm{C}\right)$ during this period.

The test wheel lock-up position was noted by an observer during each test and the tread depth at each groove across the width of the tire at the lock-up position was measured and recorded after each test. The tire surface temperature was a further guide in locating the lock-up position. Analysis of these data enable the amount of tire wear and the number of tests occurring at that tire location to be determined. 


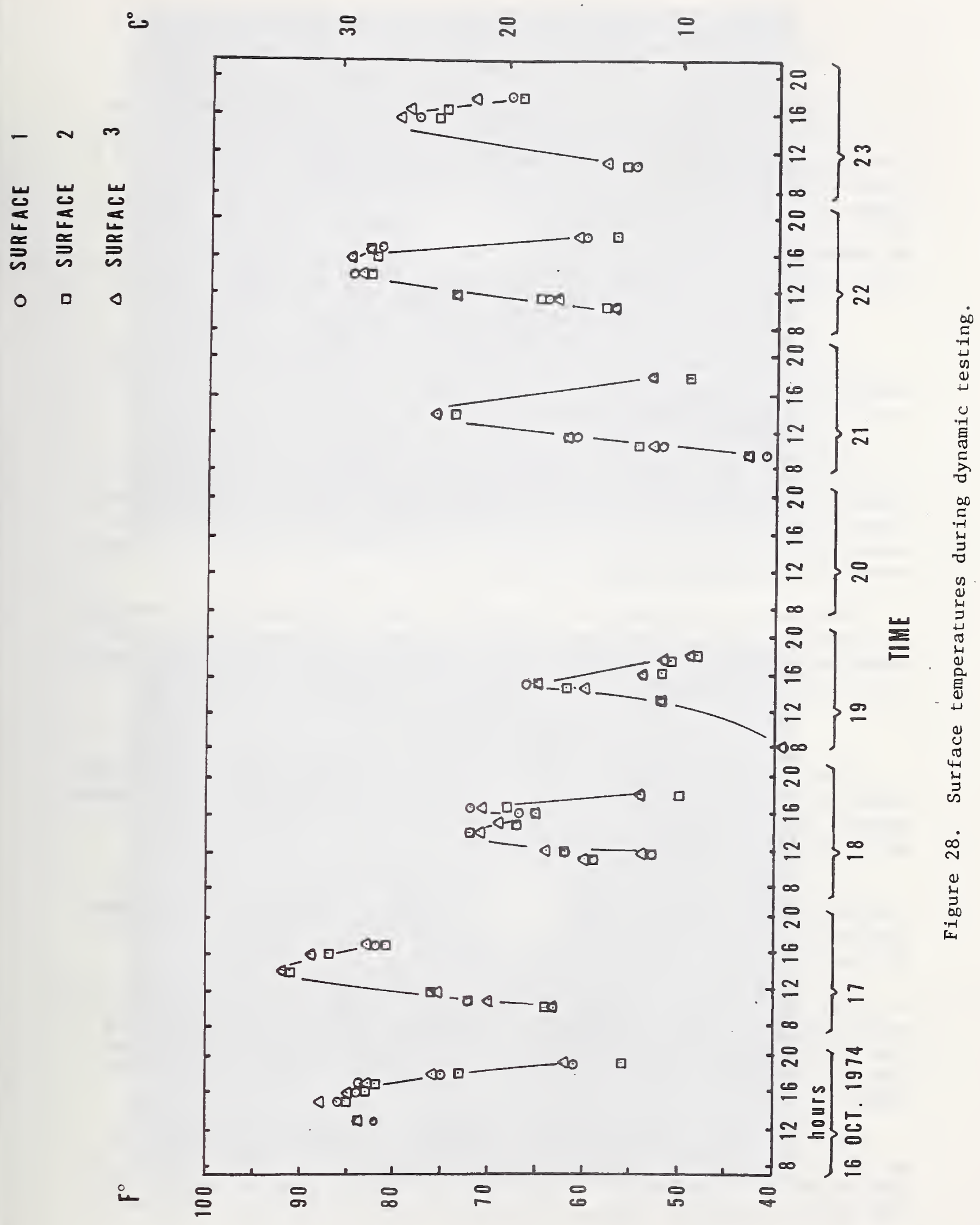


The type of wear varied with the surface. The textures of surfaces 1,2 , and 3 are shown in Figures 29, 30, and 31 respectively. A distinctive type of wear is associated with each surface. The surface of tire $H$, which skidded exclusively on surface 1, was "blistered" as shown in Figure 32. The surface of tire I, which skidded exclusively on surface 2, had 0.12 in $(0.32 \mathrm{~cm})$ diameter by 1 to 3 in $(2.5$ to $7.5 \mathrm{~cm})$ long strands of rubber carved from it as shown in Figure 33. The surface of tire J, which skidded exclusively on surface 3, was "grated" as shown in Figure 34.

\subsection{The Correlation Test Plan}

A purpose of the dynamic skid test program listed previously is to correlate the degree to which results obtained from measurements using the IRS and EARS systems match.

The correlation test plan is designed to separate the sources of dispersion listed in Section 3.2. If their existence can be proven and quantified, the effect on the results can be taken into account to yield a more precise correlation. Eventual knowledge of the bounds of these sources of dispersion will be useful in establishing an uncertainty band around the correlation result.

Statistical confidence in the results can be improved by increasing the number of tests. Confidence in the equipment and measurement is enhanced by finding consistency in the measurement results and the determination of data points within small confidence intervals.

\subsection{Test Matrix Results}

The skid resistance measurement results are given in terms of a mean value at the nominal test speed, the measured skid resistance - test speed gradient through that mean value, and a 99 percent confidence interval about the mean value.

The results from measurements made at the EFTC during single time periods are shown in Figure 35 for the IRS and in Figure 36 for the EARS. The results during multiple time periods are shown in Figure 37 for the IRS and in Figure 38 for the EARS.

The deviation from the mean calculated for the test tires at 20, 40, and $60 \mathrm{mph}(32,64$, and $97 \mathrm{~km} / \mathrm{h})$ on surface 3 from measurements made by the IRS are shown in Figure 39. The deviation from the mean calculated for the test tires at $40 \mathrm{mph}(64 \mathrm{~km} / \mathrm{h})$ on surfaces 1 and 2 are shown in Figure 40 .

The deviation from the mean calculated for the lanes of surface 3 at 20,40 , and $60 \mathrm{mph}(32,64$, and $97 \mathrm{~km} / \mathrm{h})$ from measurements made by the IRS are shown in Figure 41. The deviation from the mean calculated for the lanes of surfaces 1 and 2 at $40 \mathrm{mph}(64 \mathrm{~km} / \mathrm{h})$ are shown in Figure 42 . 


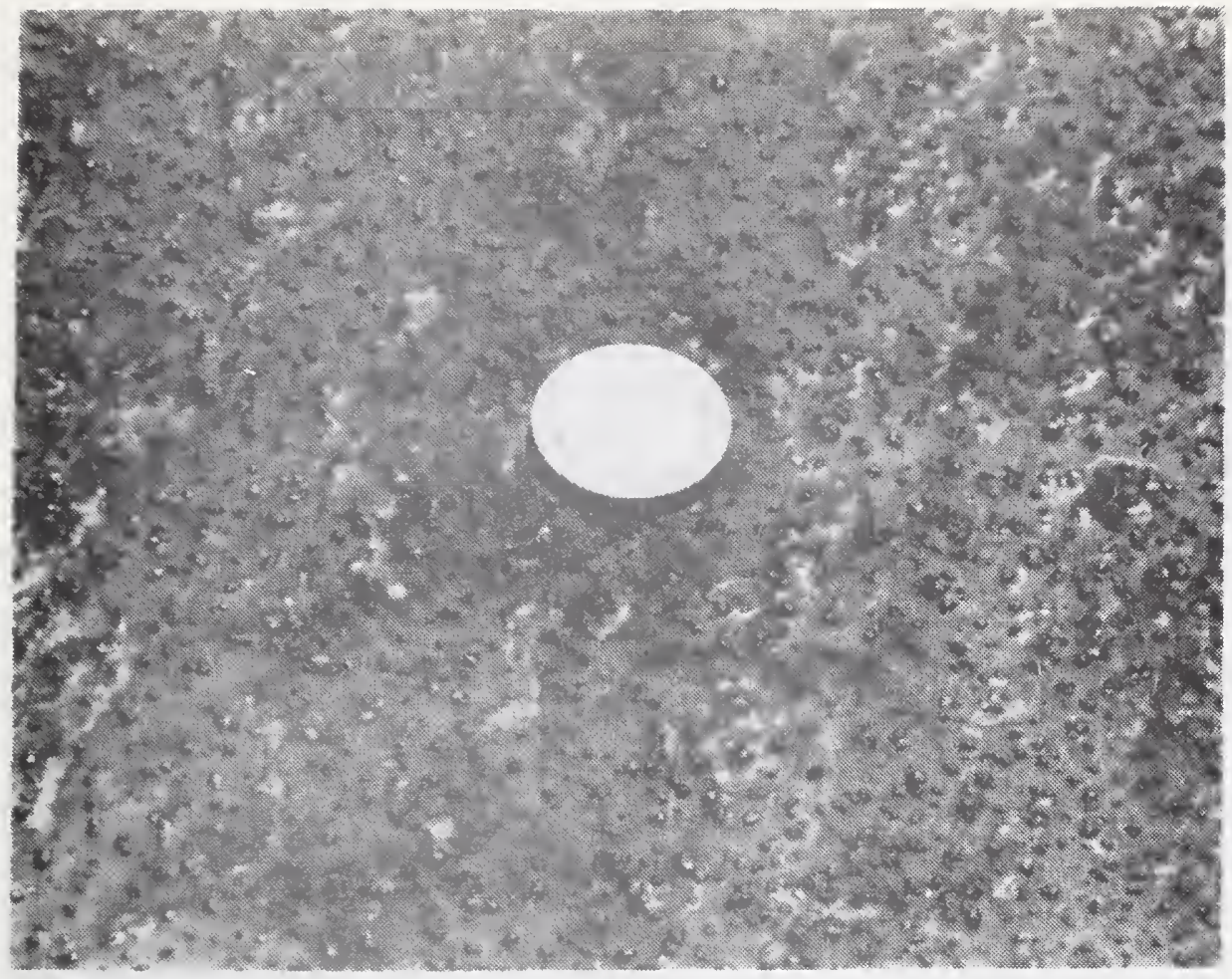

Figure 29. Texture of skid resistance surface number 1

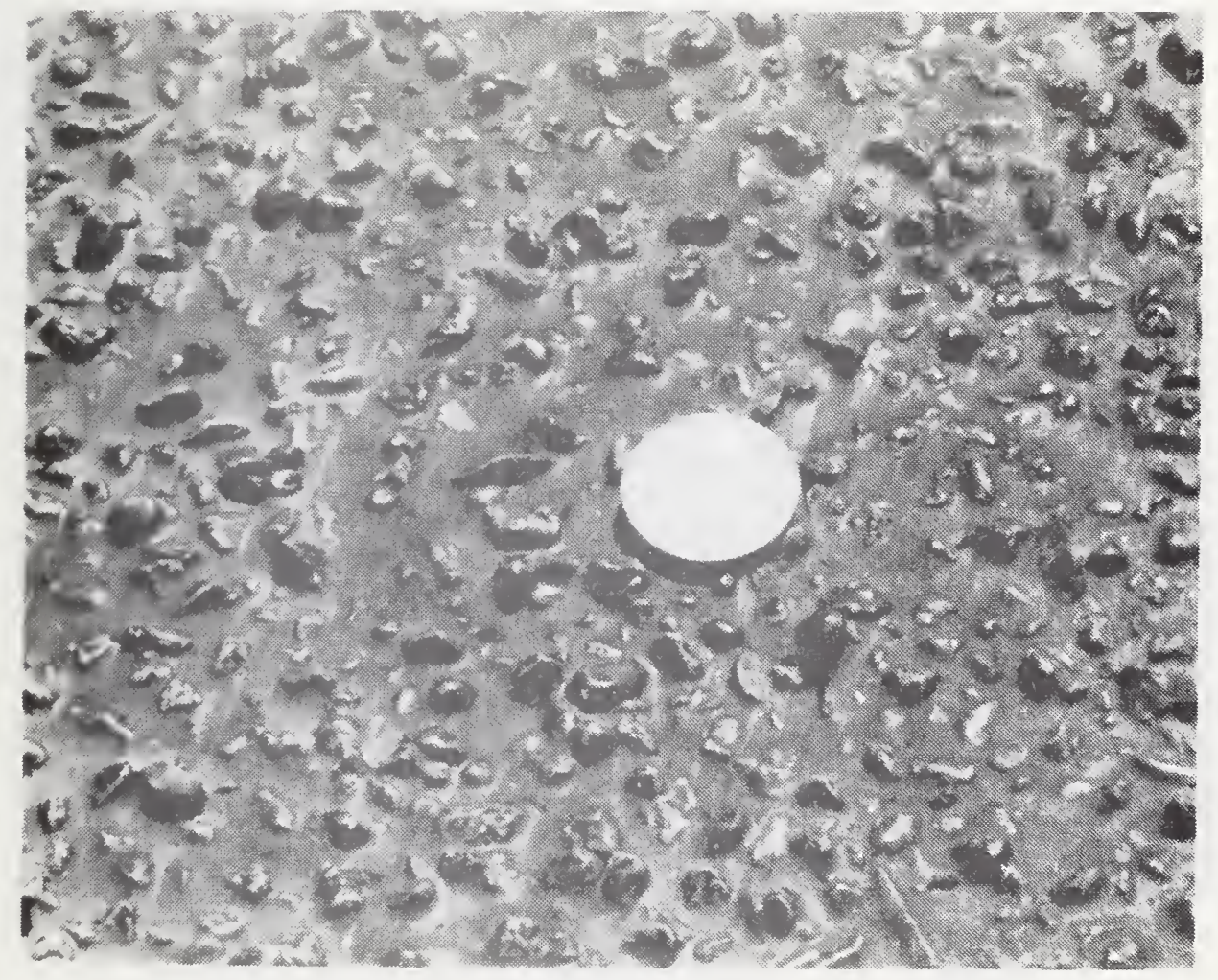

Figure 30. Texture of skid resistance surface number 2. 


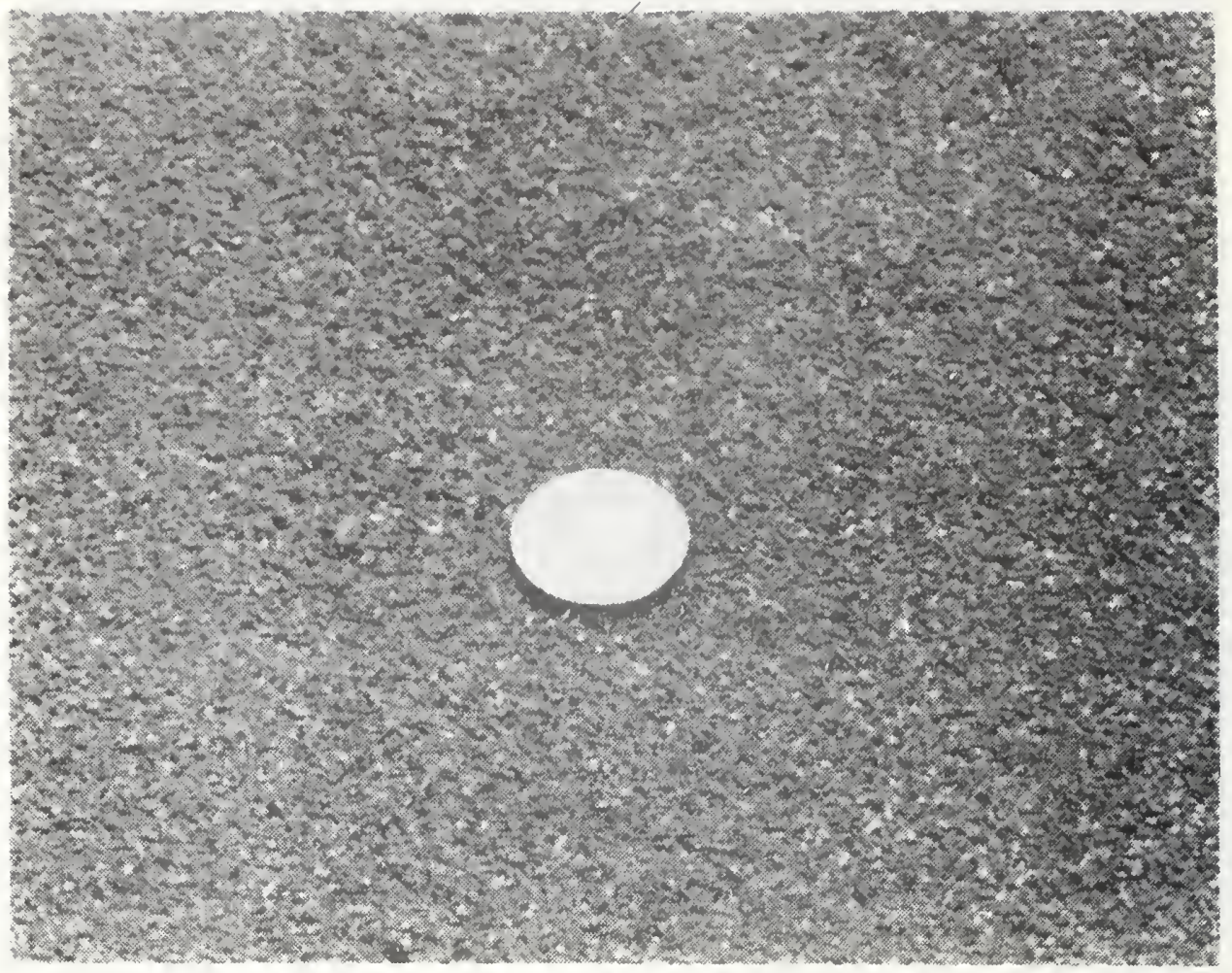

Figure 31. Texture of skid resistance surface number 3 .

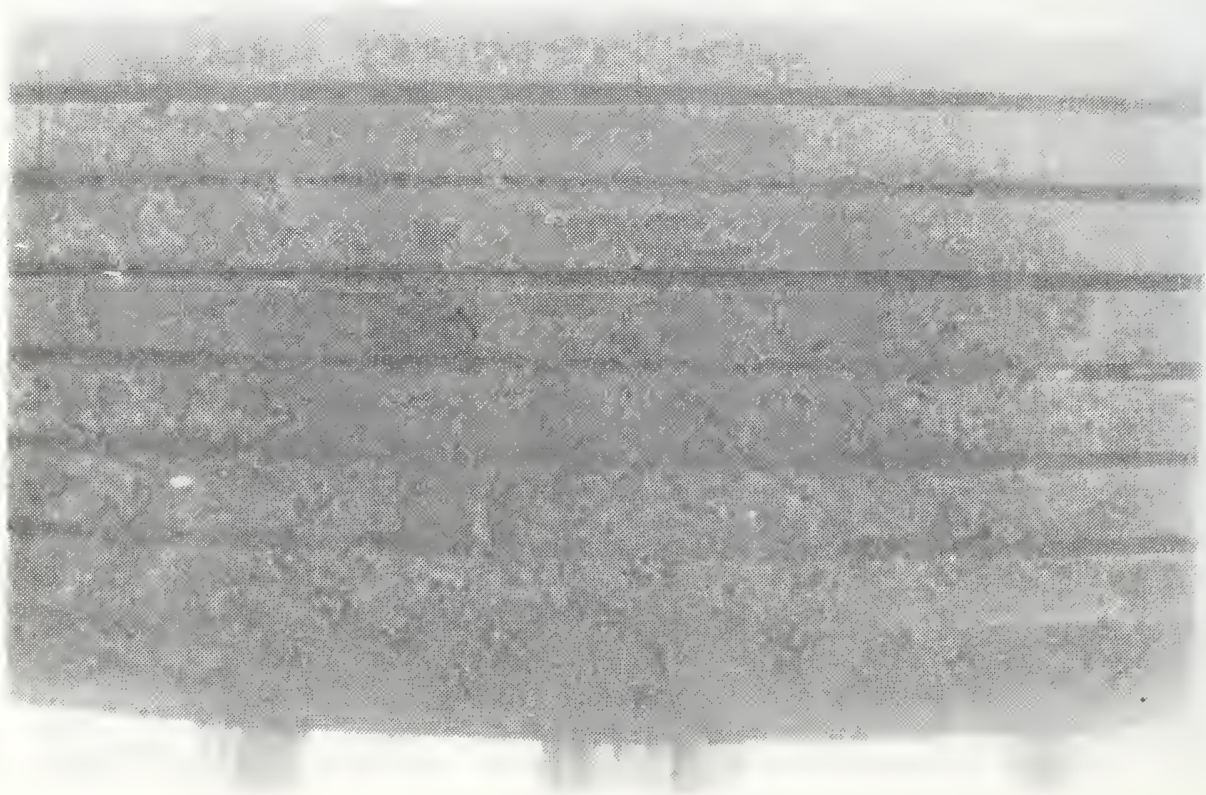

Figure 32. Texture of tire wear on surface number 1. 


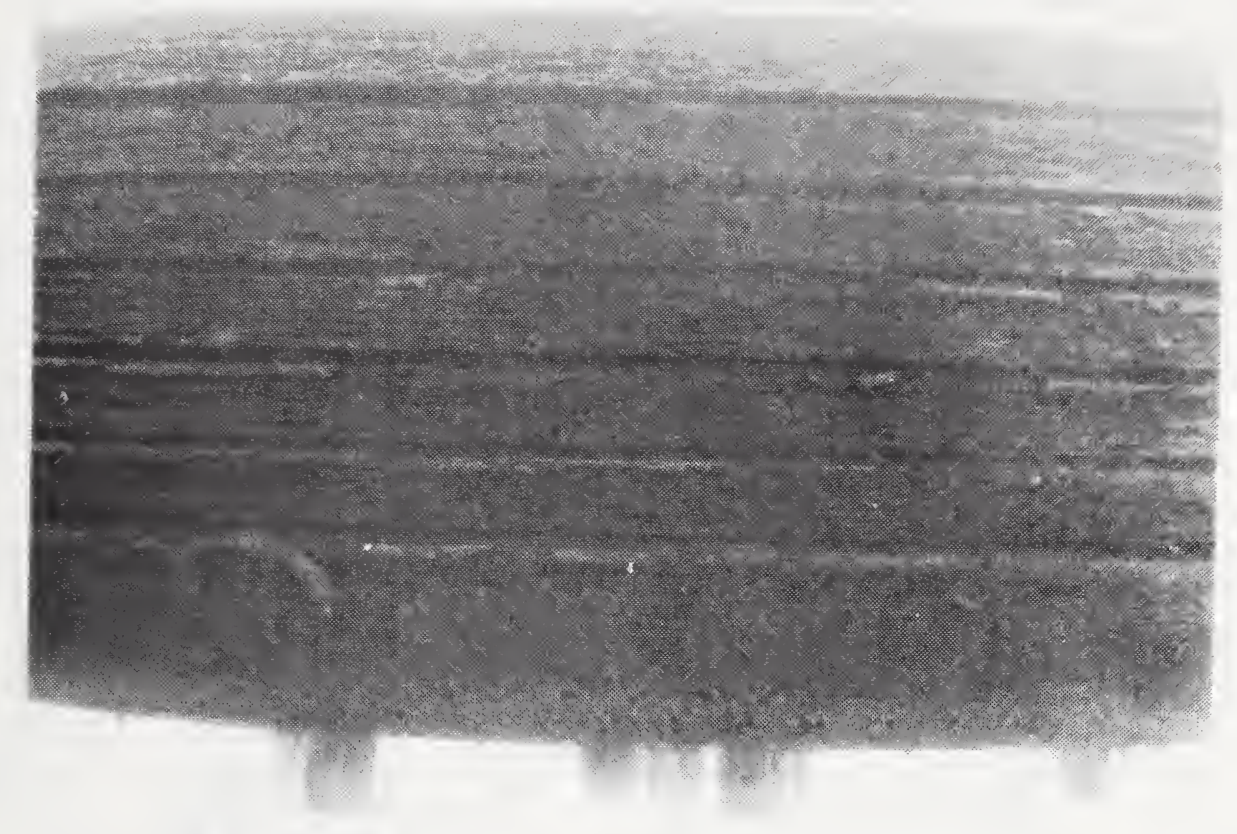

Figure 33. Texture of tire wear on surface number 2.

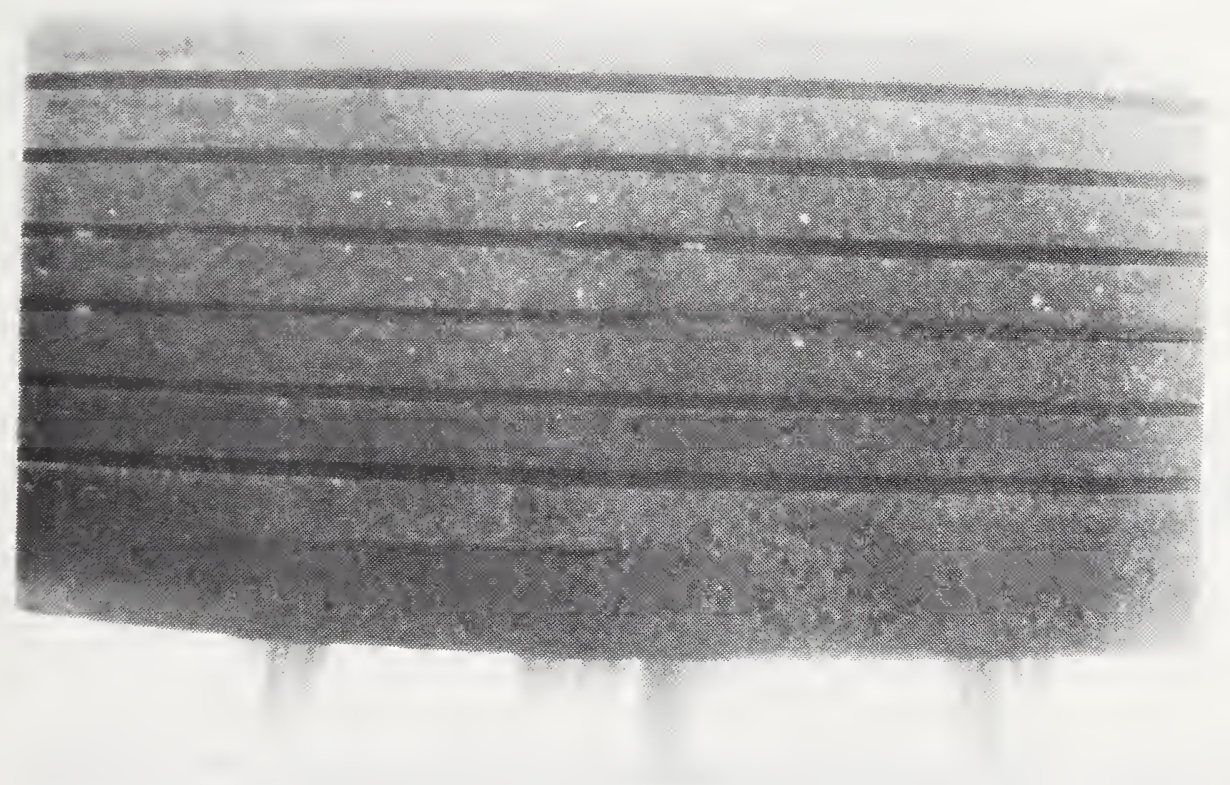

Figure 34. Texture of tire wear on surface number 3. 


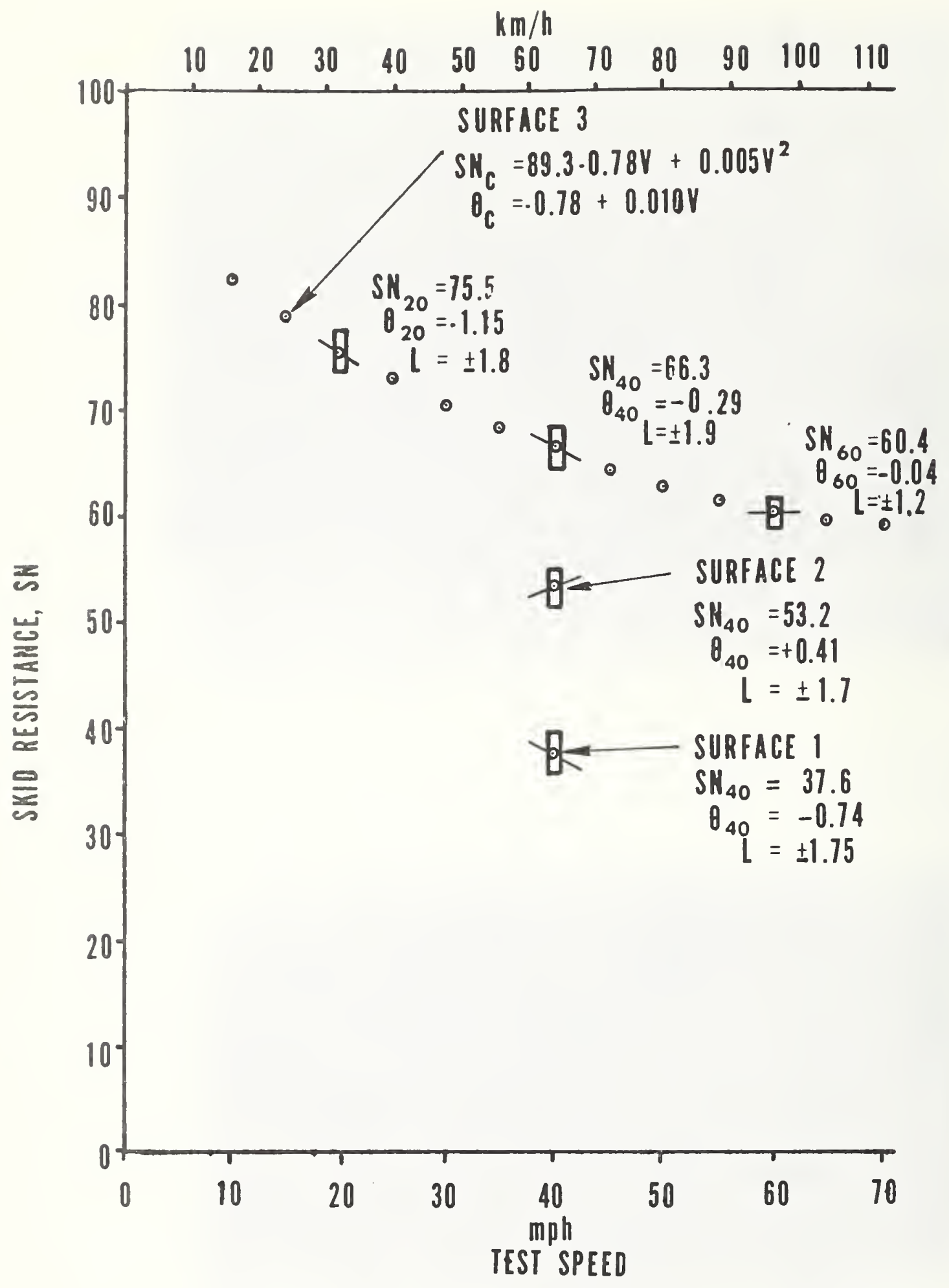

Figure 35. IRS results from measurements made at EFTC during single time periods. 


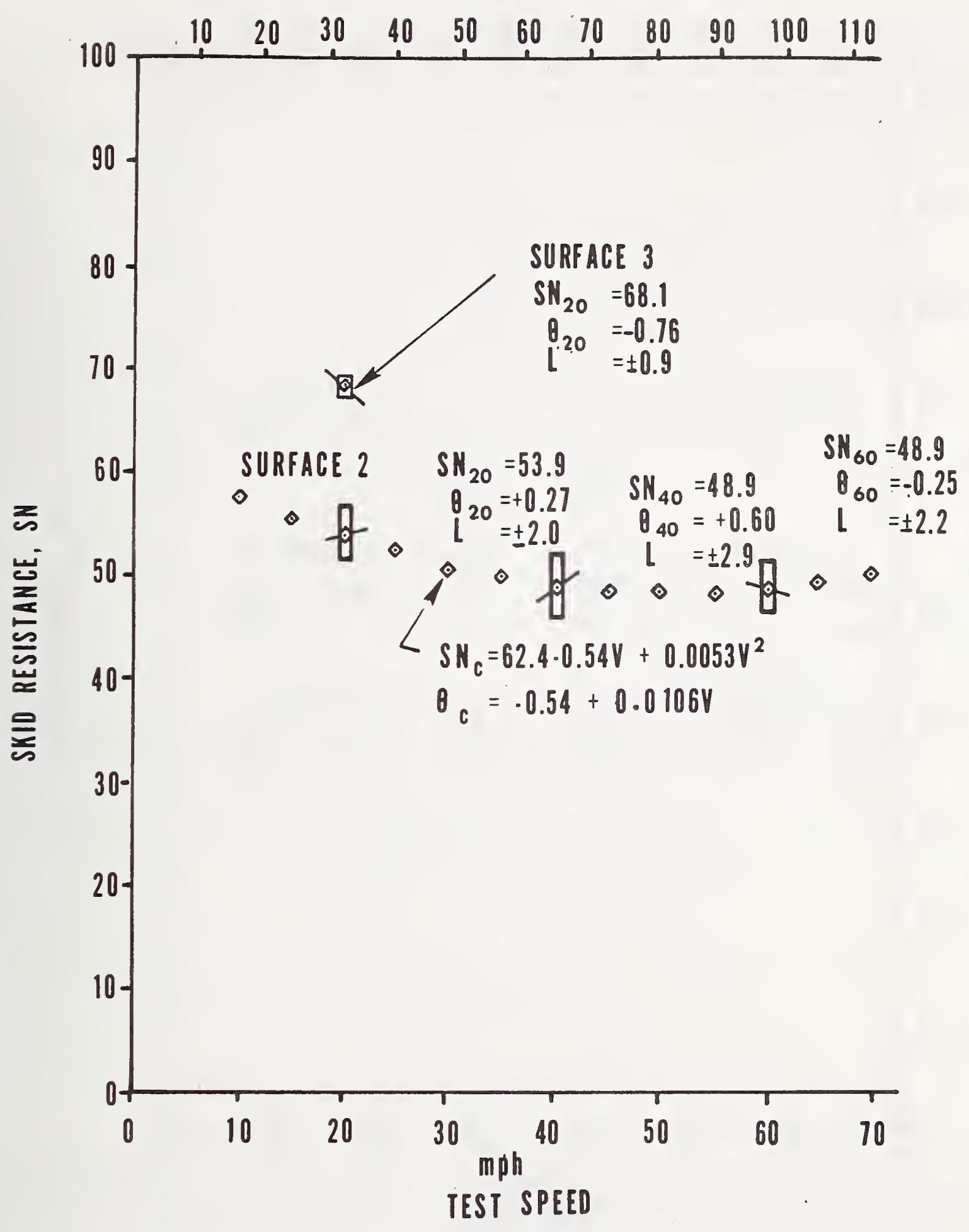

Figure 36. EARS results from measurements made at EFTC during single time periods. 


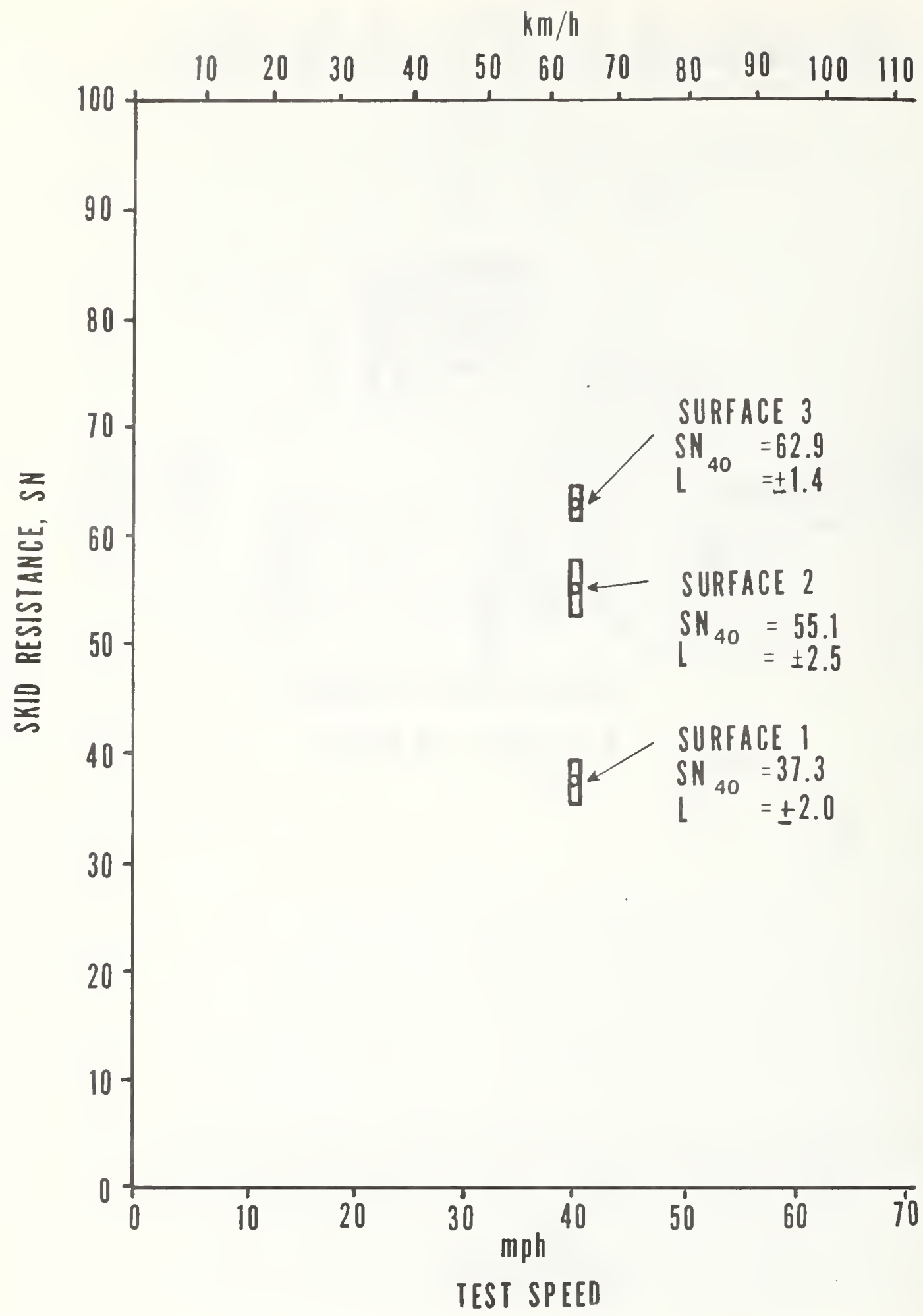

Figure 37. IRS results from measurecients made at EFTC during multiple time periods. 


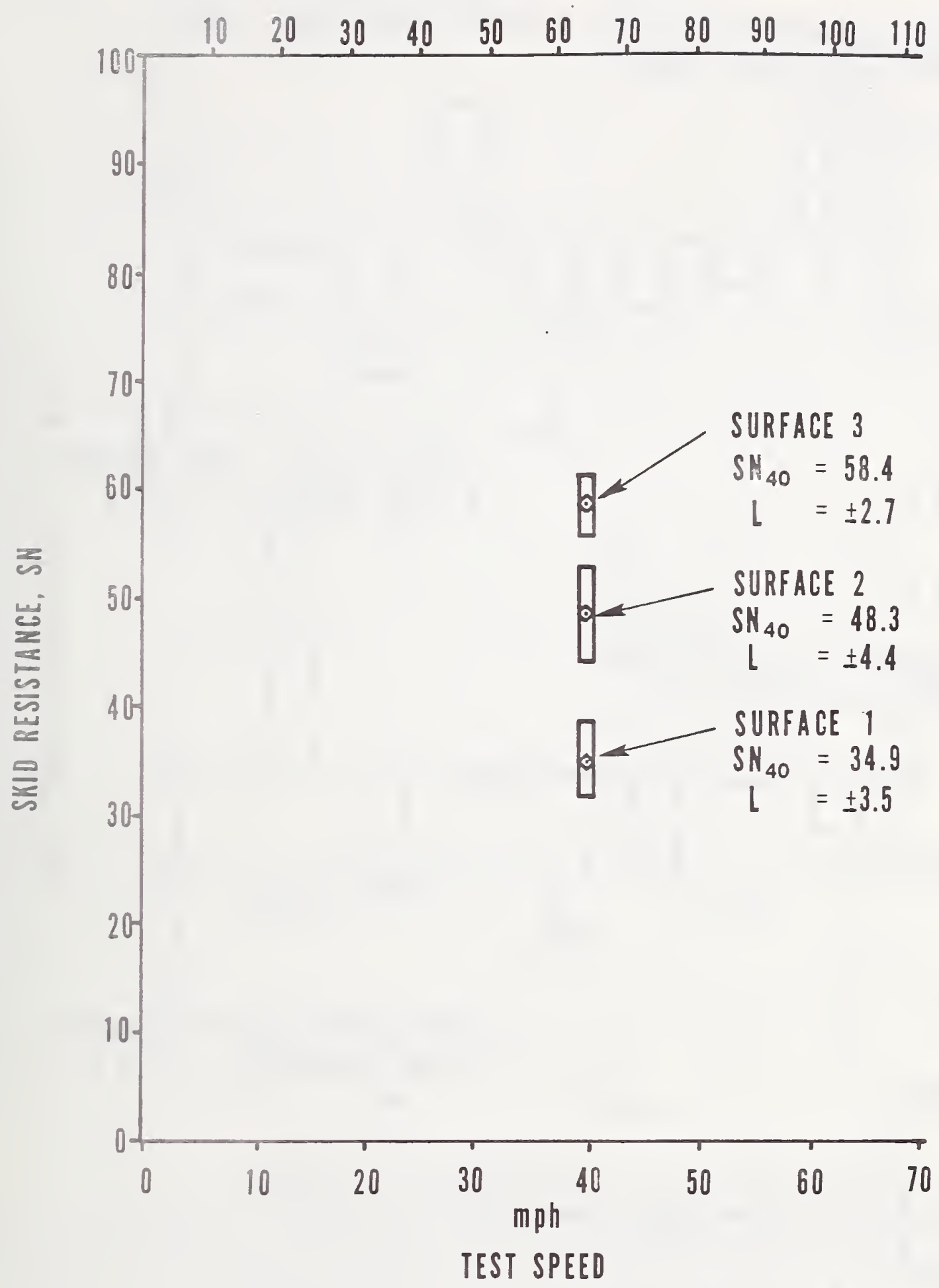

Figure 38. EARS results from measurements made at EFTC during multiple time periods. 


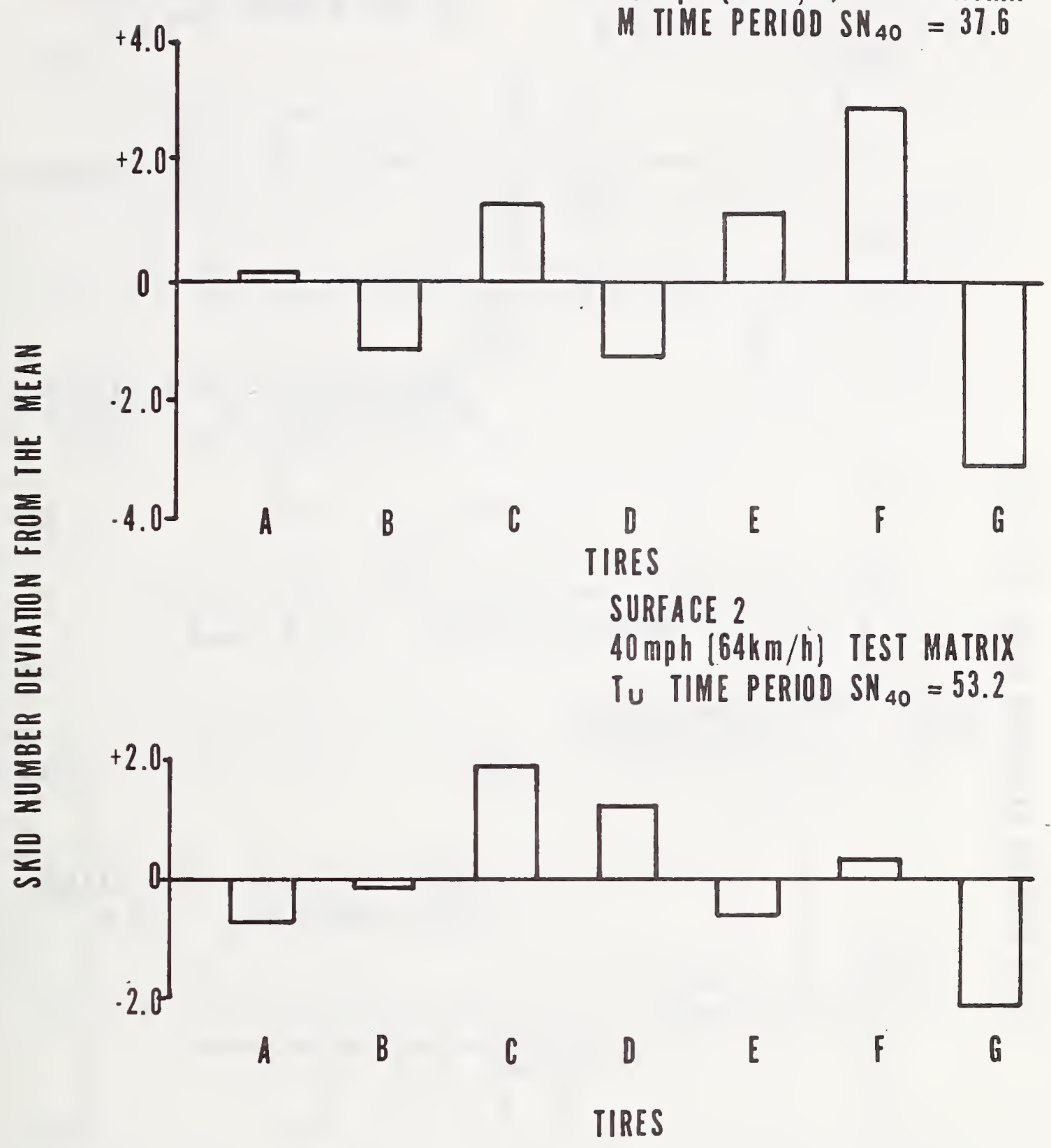

Figure 40. Possible tire dispersion calculated from IRS measurements on surfaces 1 and 2 at the EFTC. 
TH TIME PERIOD SH $_{20}=75.5$

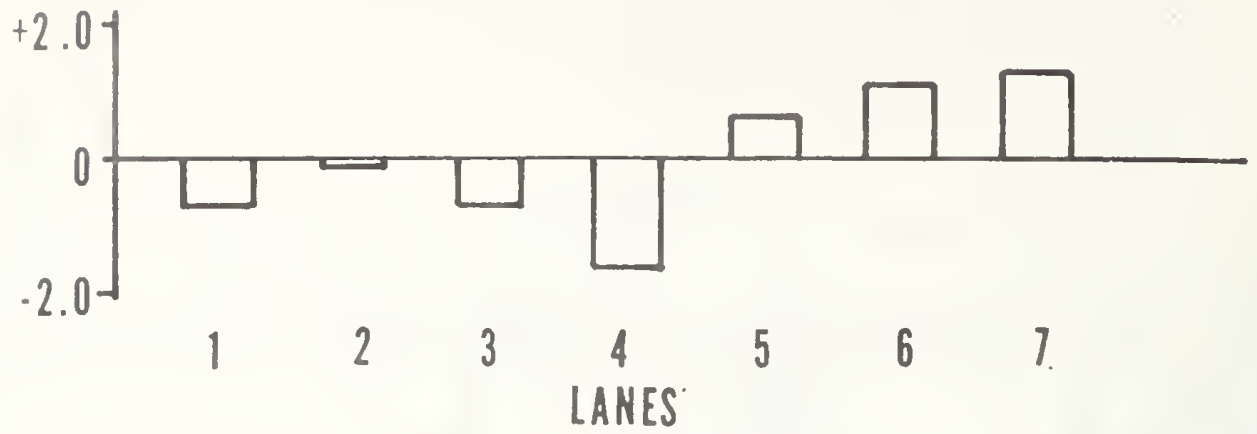

$40 \mathrm{mph}(64 \mathrm{~km} / \mathrm{h})$ TEST IIAT:IK

W TIME PERIOD $\mathrm{SN}_{40}=66.3$

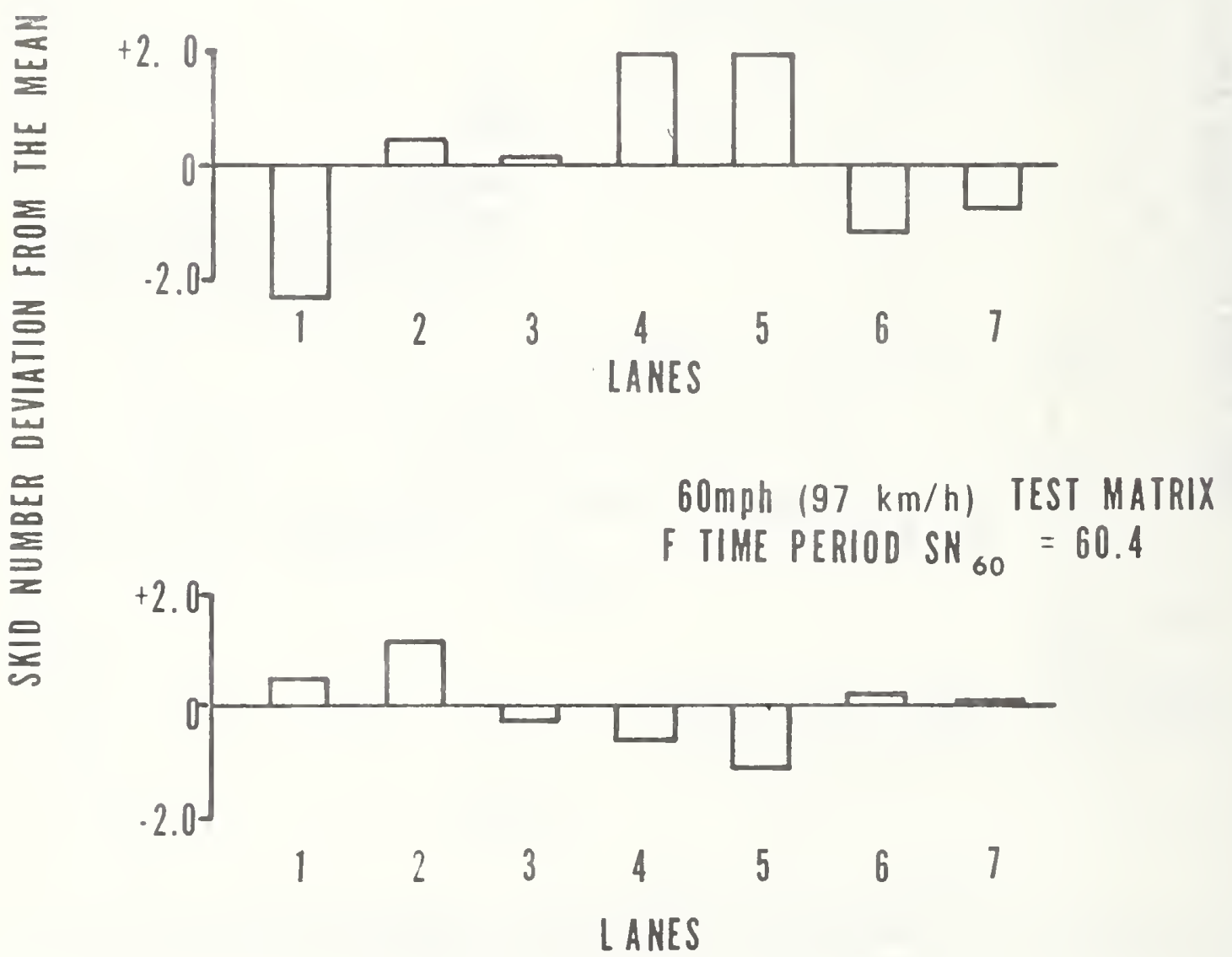

Figure 41. Possible lane dispersion calculated from IRS measurements on surface 3 at the EFTC. 


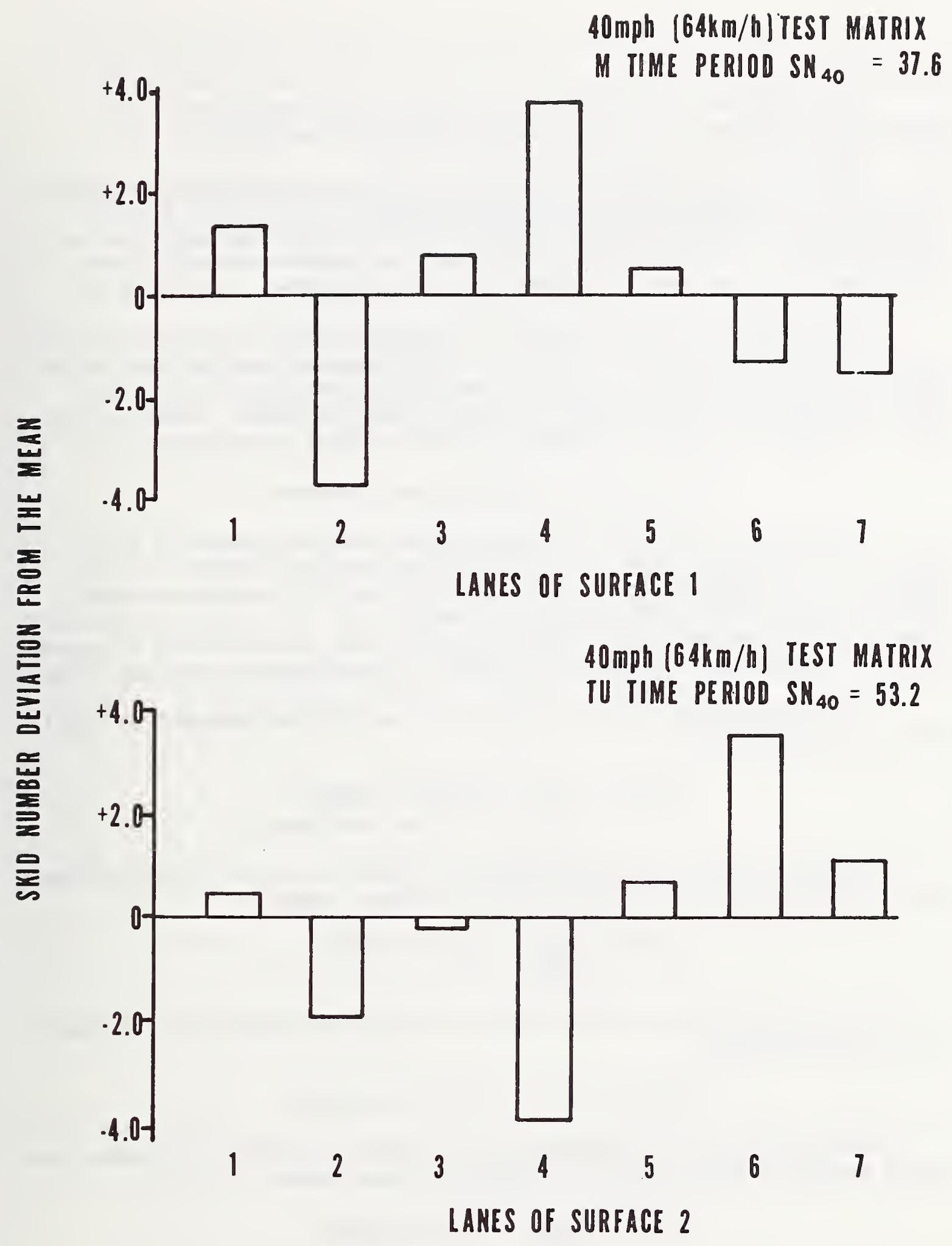

Figure 42. Possible lane dispersion calculated from IRS measurements on surfaces 1 and 2 at the EFTC. 
The deviation from the mean calculated for the multiple time periods on surfaces 1,2 , and 3 are shown in Figure 43.

There was not a sufficient number of tests conducted by the EARS to calculate surface and tire nonuniformities from the test matrices. Consequently, there is no verification of the pattern or magnitude of these sources of dispersion at this time. As additional data becomes available on these surfaces, more definitive statements may be made.

The ranking of these sources of dispersion calculated from the IRS test matrices are given in Table 8 . The dispersion associated with the choice of time period for the test was the largest source calculated while the choice of lane within a surface was the least. Special care had been taken to make each surface uniform during construction.

\subsection{Skid Resistance Speed Gradient}

It is known from test data generated at largely different test speeds that pavement skid resistance varies with test speed. In this section it is shown that, for one surface, the skid resistance speed gradients measured using incremental speeds, $\Delta S$, of $2 \mathrm{mph}$ are consistent with a continuous polynomial expression for skid resistance as a function of test speed, while for another surface this consistency was not found.

The skid resistance for surface 3 at the EFTC as measured by the IRS can be expressed as:

$$
\begin{aligned}
\mathrm{SN}_{\mathrm{C}}(\mathrm{V})= & 89.3-0.78 \mathrm{~V}+0.005 \mathrm{~V}^{2} \\
& \text { where } \mathrm{V} \text { is the test speed. }
\end{aligned}
$$

Differentiation of this expression results in a skid resistance-test speed gradient which is also a function of test speed

$$
\theta_{c}(\mathrm{~V})=\frac{\mathrm{d}(\mathrm{SN})}{\mathrm{dV}}=-0.78+0.010 \mathrm{~V}
$$

The skid resistance for surface 2 at the EFTC measured by the EARS can be expressed as:

$$
\mathrm{SN}_{\mathrm{C}}(\mathrm{V})=62.4-0.54 \mathrm{~V}+0.0053 \mathrm{~V}^{2}
$$

Differentiation of this expression results in a skid resistance-test speed gradient which is also a function of test speed

$$
\theta_{c}(V)=\frac{d(S N)}{d V}=-0.54+0.0106 \mathrm{~V}
$$


Table 8 - Ranking of Possible Sources of Dispersion

\begin{tabular}{|c|c|c|c|c|c|c|}
\hline Rank & $\begin{array}{c}\text { Possible } \\
\text { Source } \\
\text { of } \\
\text { Dispersion } \\
\end{array}$ & $\begin{array}{l}\text { Sample } \\
\text { Std. } \\
\text { Dev. }\end{array}$ & Sub-Rank & Surface & $\begin{array}{l}\text { Speed, } \\
\text { mph (a) }\end{array}$ & $\begin{array}{c}\text { Sample } \\
\text { Std. } \\
\text { Dev. } \\
\end{array}$ \\
\hline 1 & $\begin{array}{l}\text { Multiple } \\
\text { Time-Period }\end{array}$ & 2.63 & $\begin{array}{l}\mathrm{A} \\
\mathrm{B} \\
\mathrm{C}\end{array}$ & $\begin{array}{l}1 \\
3 \\
2\end{array}$ & $\begin{array}{l}40 \\
40 \\
40\end{array}$ & $\begin{array}{l}2.8 \\
1.8 \\
1.6\end{array}$ \\
\hline 2 & 7 Tires & 2.43 & $\begin{array}{l}A \\
B \\
C \\
D \\
E\end{array}$ & $\begin{array}{l}3 \\
3 \\
1 \\
2 \\
3\end{array}$ & $\begin{array}{l}40 \\
20 \\
40 \\
40 \\
60\end{array}$ & $\begin{array}{l}2.9 \\
2.8 \\
2.0 \\
1.3 \\
1.0\end{array}$ \\
\hline 3 & 7 Lanes & 2.0 & $\begin{array}{l}A \\
B \\
C \\
D \\
E\end{array}$ & $\begin{array}{l}1 \\
2 \\
3 \\
3 \\
3\end{array}$ & $\begin{array}{l}40 \\
40 \\
40 \\
20 \\
60\end{array}$ & $\begin{array}{l}2.4 \\
2.3 \\
1.5 \\
1.2 \\
0.8\end{array}$ \\
\hline
\end{tabular}

(a) $1 \mathrm{mph}=1.609 \mathrm{~km} / \mathrm{h}$. 


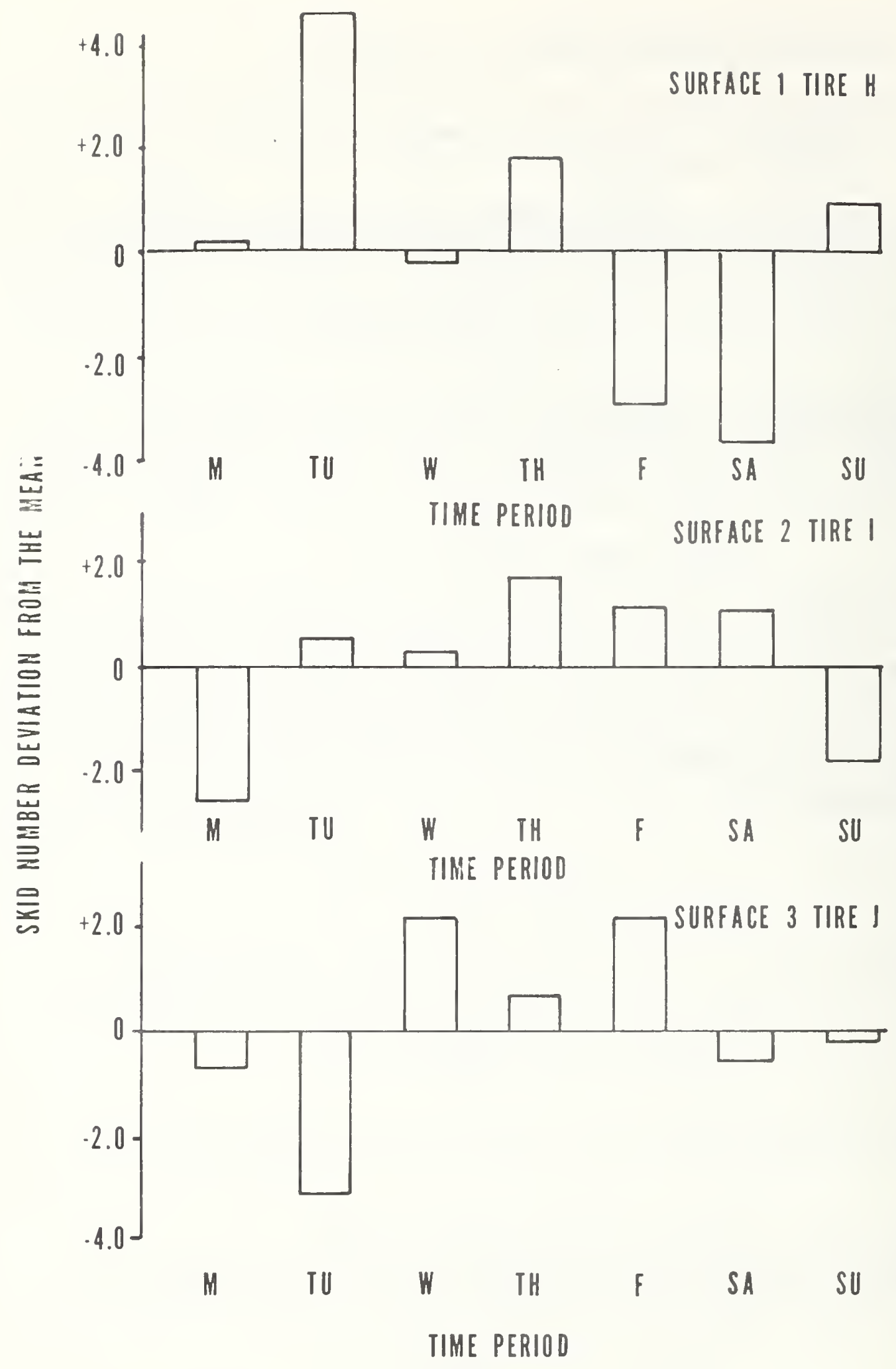

Figure 43. Possible time period dispersion calculated from IRS measurements on surfaces 1,2 , and 3 at the EFTC. 
The values computed from the above equations can be compared to values obtained from the slopes of stralght lines through average values taken over small speed increments, $\Delta \mathrm{S}$, about $\pm 2 \mathrm{mph}(3.2 \mathrm{~km} / \mathrm{h})$. When this is done for measurements on surface 3 reasonably consistent values are found. These are:

\begin{tabular}{lcrr}
$\mathrm{V}$ & ${ }^{{ }_{\text {Calc }}}$ & ${ }$ IRS & ${ }_{\text {EARS }}$ \\
\hline 20 & -.58 & -1.15 & -.79 \\
40 & -.38 & -0.29 & -- \\
60 & -.18 & -0.04 & --
\end{tabular}

when $\theta_{\text {calc }}$ is calculated from the above equation and $\epsilon_{\text {IRS }}$ and $\theta_{\text {EARS }}$ are the values measured over a small speed range. However, when similar comparisons are made for surface 2, the results are not consistent and the measured and calculated values are of opposite sign. The results for surface 2 are:

\begin{tabular}{lccc}
$\mathrm{V}$ & ${ }_{\text {calc }}$ & ${ }_{\text {IRS }}$ & ${ }_{\text {EARS }}$ \\
\hline 20 & -.34 & -- & +.27 \\
40 &.- .14 & +.41 & +.60 \\
60 & +.06 & -- & -.25
\end{tabular}

\subsection{The Correlation Equation}

The correlation equation between the EARS and the IRS from the unrounded test data is:

$$
\mathrm{SN}_{\text {EARS }}=1.40+0.886 \mathrm{SN}_{\text {IRS }}
$$

The equation has a correlation coefficient of 0.996. A two-sigma band about the calibration line is about 2.5 skid numbers .

A plot of the data points is shown in Figure 44. The lengths of the crosses are equal to the 99 percent confidence interval, L.

The results of the dynamic skid resistance measurement test program conducted on the three surfaces at the EFTC are rounded and summarized in Table 9.

\subsection{Use of the Correlation Equation}

Based on the five pairs of values given in Table 9, a straight line fitted to the data yields:

$$
\mathrm{SN}_{\text {EARS }}=1.59+0.883 \mathrm{SN}_{\text {IRS }}
$$

Residual standard deviation

1.37

Standard deviation of intercept

Standard deviation of slope

Standard deviation of predicted value

(a point on the line)
2.86

0.049

1.14 (SN 40)

0.65 (SN 50-60)

$1.10(\mathrm{SN} 70)$ 


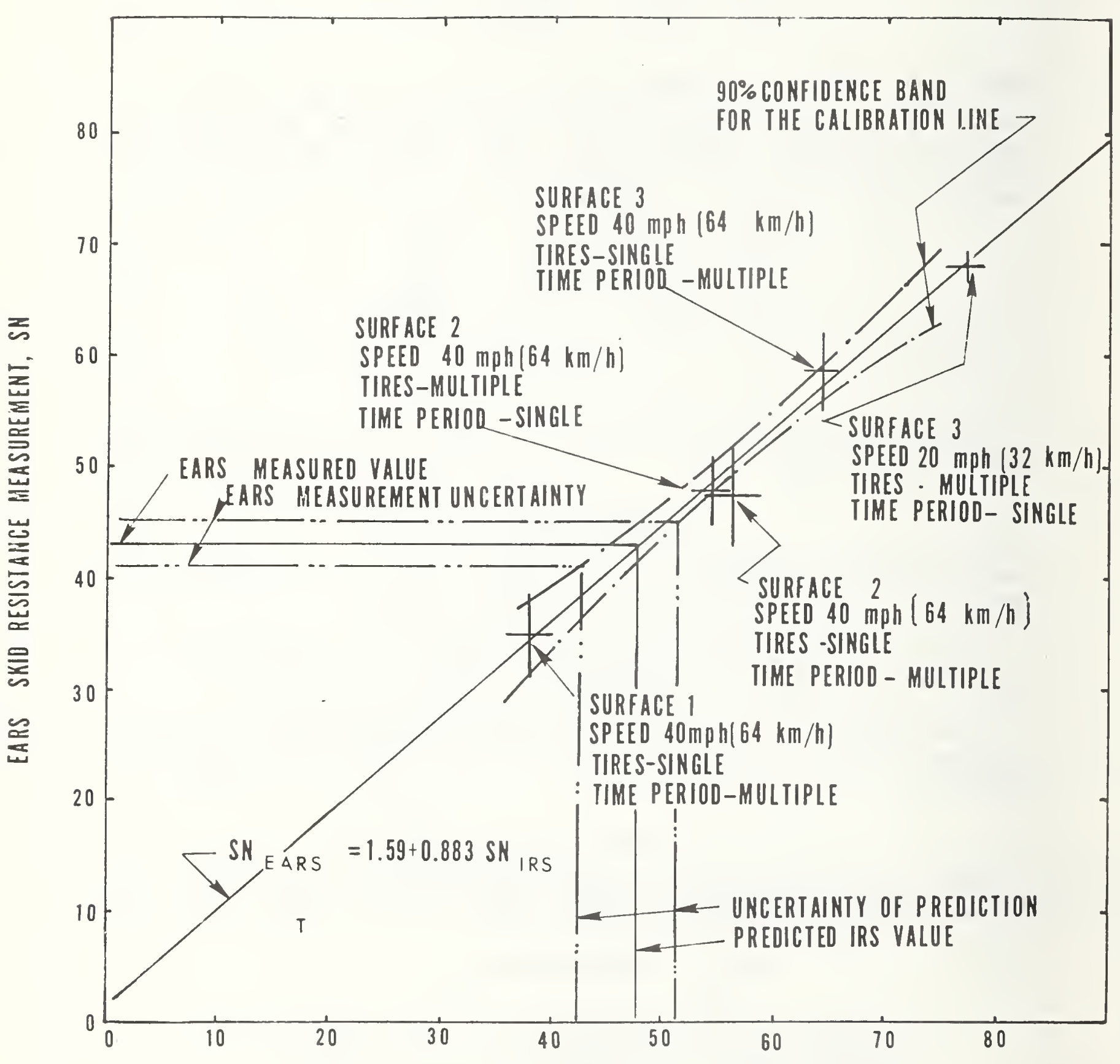

IRS SKID RESISTANCE MEASUREMENT, SN

Figure 44. EARS-IRS correlation. 


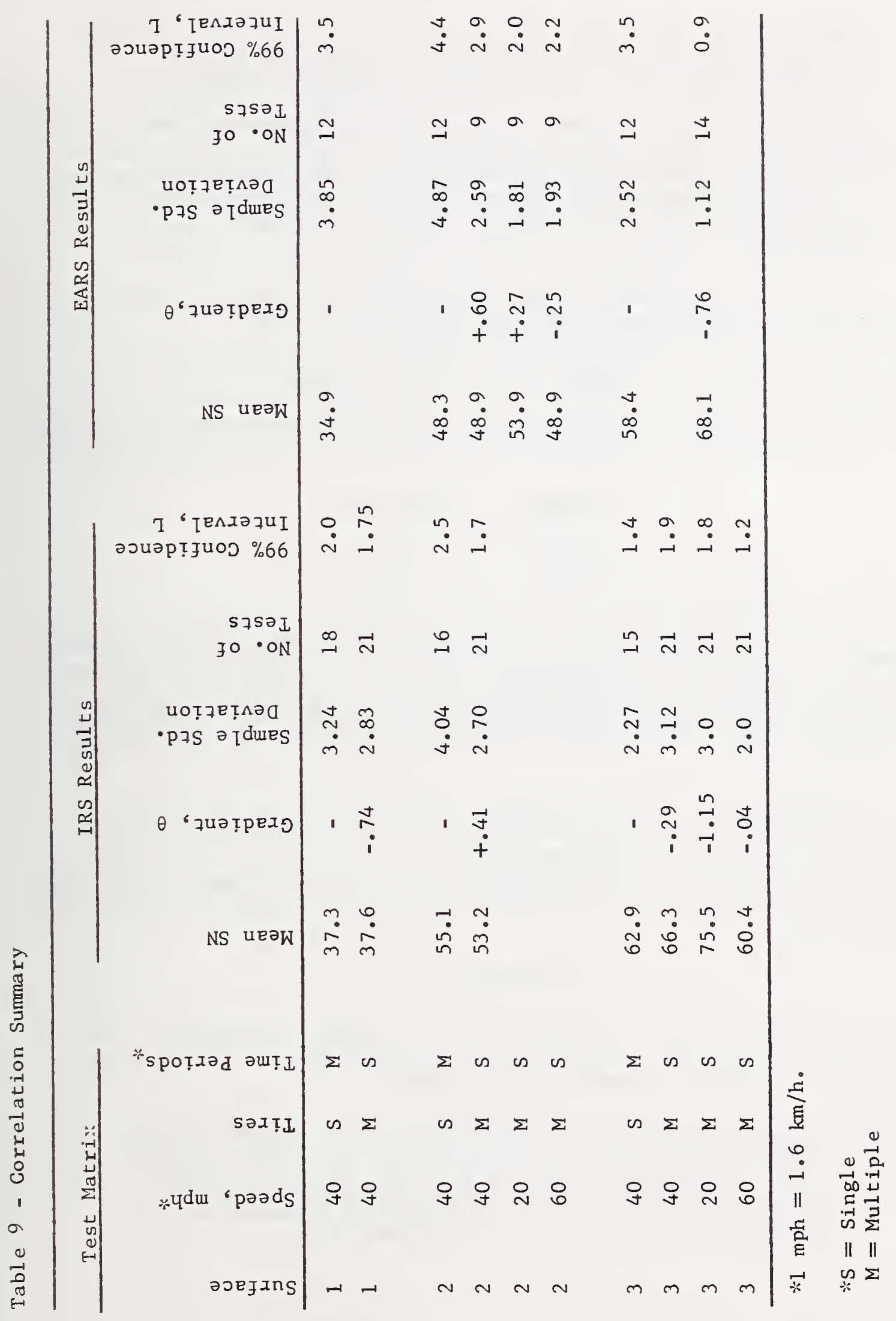


For 90 percent confidence limits, multiply the standard deviation of predicted values by 2.353. For 95 percent confidence limits, multiply the standard deviation of the predicted values by 3.182 .

The above information may be interpreted as follows for 90 percent confidence limits: "In repeated calibration of EARS using the same general procedure, the results are not expected to differ from the present calibration by more than $2.7 \mathrm{SN}$ at the two ends of the calibration line ( $\mathrm{SN} 40$ and 70), and by more than $1.5 \mathrm{SN}$ in the middle range (SN 50-60)."

In using the calibration line, presumably EFTC personnel would like to predict IRS values from their own measurements, using

$$
\mathrm{SN}_{\text {IRS }}=-1.27+1.123 \mathrm{SN}_{\text {EARS }}
$$

The uncertainty of a predicted IRS value for a given value of (EARS) is:

$\begin{array}{cc}\text { SN Number } & \text { Uncertainty } \\ 40 & 3.0 \\ 50-60 & 2.0 \\ 70 & 3.0\end{array}$

computed as before for 90 percent confidence limits. In addition, the random error component of $\mathrm{SN}_{\text {EARS }}$ must also be taken into consideration. A graphical procedure is perhaps the easiest way to estimate the total uncertainty. The example shown in Figure 44 is drawn for a 90 percent confidence band.

The uncertainty given for the calibration line itself is, in a sense, systematic in nature from EARS point of view, i.e., if EARS is comparing the SN of two different surfaces, this systematic uncertainty cancels out. However, if EARS compares its result with another ARS, then the uncertainty of the two calibration lines will have to be taken into consideration.

\section{RECOMENDATIONS}

In order to improve the reliability of subsystem evaluation, skid measurement correlation results and the convenience of conducting the tests, the following recommendations are made:

1. A measured distance for adjusting the fifth wheel system should be established at a place more convenient to the skid test surfaces, where it would be possible to make test runs in both directions, and where extended driving distance would not be required between runs. 
2. The EARS speed measuring system should be modified so that the recorded speed and drivers aid are derived from the same fifth wheel source.

3. The DDG and its method of use should be thoroughly studied and modified as necessary to improve its reliability.

4. A photographic method should be developed for determining the width of the water trace at the point that the tire enters it.

The EARS evaluations and correlation results reported here are valid only if no modifications are made, if no changes occur in mechanical and electrical components, and if the system is operated in the same manner as it was at the time of these tests. Appendix $C$ describes the EARS and contains a listing of the values of recognized EARS variables in effect during these tests.

\section{Acknowledgement}

It is a pleasure to acknowledge the helpful discussions and assistance of $\mathrm{Dr}$. Hsien $\mathrm{H}$. Ku concerning the statistical analysis of the test results, of $\mathrm{Mr}$. W. H. Appleton and Mr. R. G. Russell in the conduct of the tests and other members of the NBS staff, of Mr. W. Goff of the Transportation Research Center of Ohio for the operation of the high speed camera, of personnel of the FHWA Western, Central and Eastern Field Test Centers, and the Federal Highway Administration for their cooperative efforts. 


\section{REFERENCES}

[1] "Standard Method of Test for Skid Resistance of Paved Surfaces Using a Full Scale Tire" Designation E274-70. Annual Book of ASTM Standards, Part II. American Society for Testing and Materials, Philadelphia, Pa. (1973).

[2] Watson, John R. and Cook, Larry M. "A National Program to Standardize Skid Resistance Measurements" Public Roads, A Journal of Highway Research, Vol. 37, No. 3, pp 70-80 (December 1972).

[3] Smith, L. L. and Fuller, S. L., "Florida Skid Correlation Study of 1967 - Skid Testing with Trailers", Highway Skid Resistance, STP 456 American Society for Testing and Materials (1969).

[4] Kearns, R. W. and Ward, J. F., "A Method and Means of Calibrating an Air-Bearing Force Plate for Use with a Towed Pavement Friction Test Trailer", National Bureau of Standards (U.S.), NBSIR 75-738 (December 1974).

[5] "Procedure for Speed and Distance Calibration of a Fifth Wheel Equipped with Either Analog or Digital Instrumentation" Designation F457, American Society of Testing and Materials, Philadelphia, Pa. (1975).

[6] Federal Highway Administration Procedures for Evaluating the Skid Measurement Process at Field Test and Evaluation Centers, Department of Transportation, Federal Highway Administration, Washington, D.C. (December 1973 ).

[7] Mortimer, T. P. and Ludema, K. C. (University of Michigan) "The Effects of Salts on Road Drying Rates, Tire Friction and Invisible Wetness", Pavement Friction Characteristics and Water Depth, Paper 396, Highway Research Record, (1972).

[8] Garfinkel, Mann and Youden, "Design and Statistical Procedures for the Evaluation of an Automatic Gamma-Ray Point-Source Calibrator", National Bureau of Standards (U.S.), Spec. Publ. 300, Vol. 1, 436 pages (February 1969).

[9] Horne, W. B. "Traction Performance of New (E524) and O1d (E249) ASTM Smooth Tread Test Tires on Several Wet and Dry Pavements" presented at the ASTM Committee E-17 Meeting in Montreal, Canada (June 24-25, 1975).

[10] Chestnut, $H_{0}$ and Mayer, R. W., Solution of Linear Differential Equations, Chapter 3, Servomechanisms and Regulating System Design, Vo1. 1, p 62, John Wiley \& Sons, Inc., N.Y. (1951). 


\section{APPENDIX A \\ Exploratory Tests of the Dynamic Distribution Gage}

Measurements made by NBS personnel using the DDG (Section 2.5.3) showed that there is more water collected than is pumped by the EARS as it travels the length of the collecting basin. Since a large quantity of water enters the gage by uncertain paths, the results of this test cannot be considered a valid measurement of the water distribution.

The following exploratory tests were conducted to help identify the source of the problem. NBS personnel performed DDG runs removing all accumulated water from the basin before each run to minimize splash. The IRS was used at 20, 40, and $60 \mathrm{mph}(32,64$, and $97 \mathrm{~km} / \mathrm{h}$ ). Table A-1 shows the continuing discrepancy between the water distributed and the water collected. The distributions are shown in Figure A-1. For one $40 \mathrm{mph}(64 \mathrm{~km} / \mathrm{h}$ ) run (Fig. A-ld), a wheel extender was used so that the test wheel was out of the path of the distributed water. The fender of the test wheel was also removed for this run.

Photographs were made of IRS runs with and without the wheel extender. High speed cameras were located on the skid trailer and on the ground near the DDG. Figure A-2 is a typical view showing fog and splash.

It was apparent from these films that more than one cause of splash existed. Accumulated water splashed during the passage of the test vehicle. Motion of the grate and gage under the vehicle tires contributed to this splash. Heavy splashes also occurred when water issuing from the pavement wetting system encountered the grate and gage structures. Figure A-3 shows the smooth deposit of water over solid pavement ahead of the grate. while Figure A-4, taken later in the same run, shows heavy splashing over the gage. Splashing of the streams may be caused by such mechanisms as airflow through the grate or collision of the stream with the crossbars of the grate. The latter mechanism, considered in terms of relative motion, may occur because the vertical faces of the crossbars act as swatters. A smooth pavement may not exhibit this splashing mechanism. 
Table A-1 - DDG DATA: Comparison of Water Collected with Water Pumped, Dry Basin

\begin{tabular}{lcccc}
\hline $\begin{array}{l}\text { Speed, } \\
\text { mph (a) }\end{array}$ & Unit & $\begin{array}{c}\text { Collected, } \\
\text { grams }\end{array}$ & $\begin{array}{c}\text { Pumped, } \\
\text { grams }\end{array}$ & $\frac{\text { Collected }}{\text { pumped }}$ \\
\hline 20 & IRS & 91.38 & 68.7 (b) & 1.33 \\
40 & IRS & 182.43 & 66.4 (b) & 2.75 \\
40 & IRS & 125.44 & 68.7 (b) & 1.83 \\
40 & IRS (c) & 173.79 & 73.2 (b) & 2.37 \\
60 & & 176.65 & 73.2 (b) & \\
\hline
\end{tabular}

(a) $1 \mathrm{mph}=1.609 \mathrm{~km} / \mathrm{h}$.

(b) Computed.

(c) Wheel extender used. 

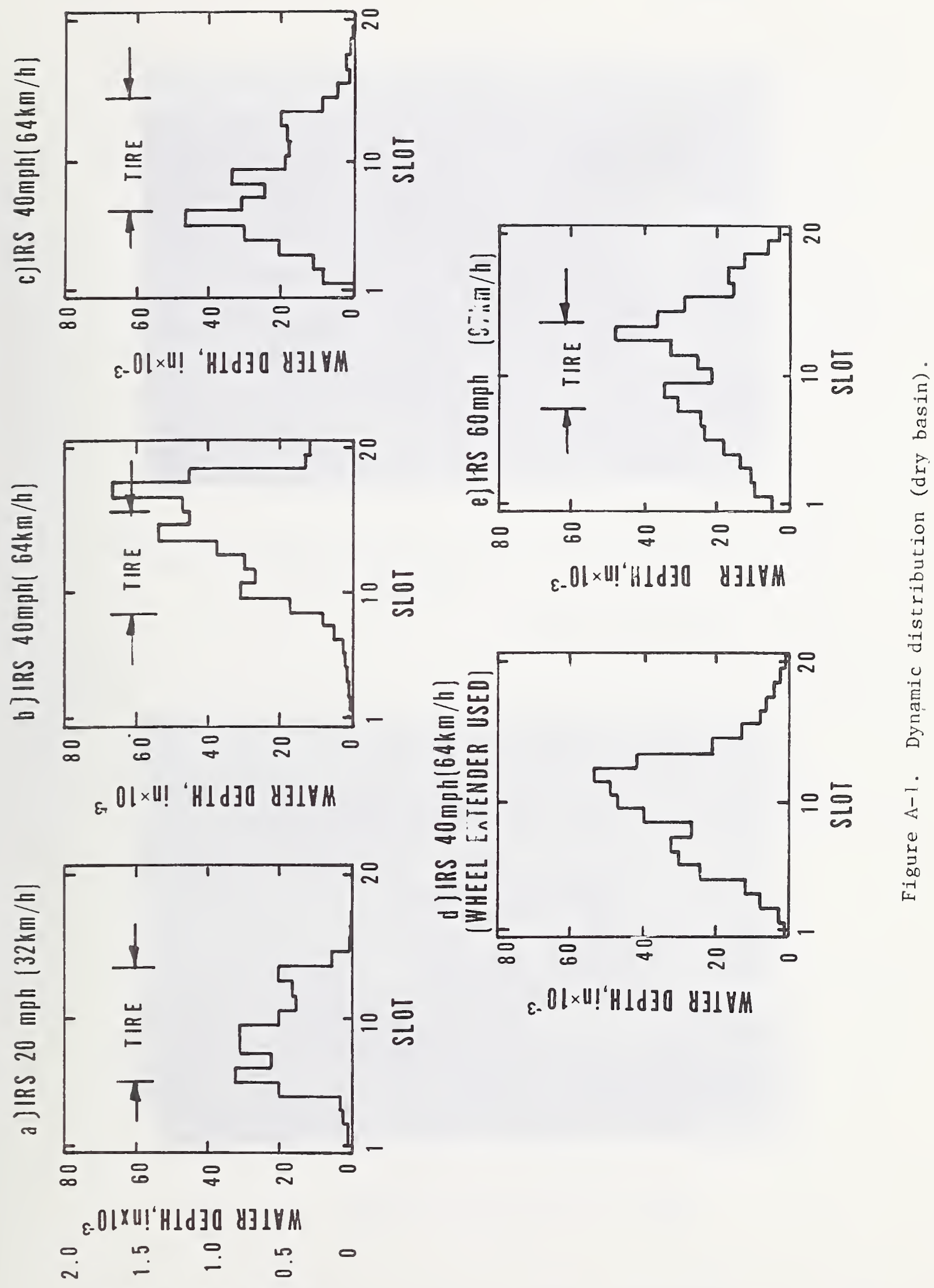

WW'HId]O Y JIVM 
a) Norma 1

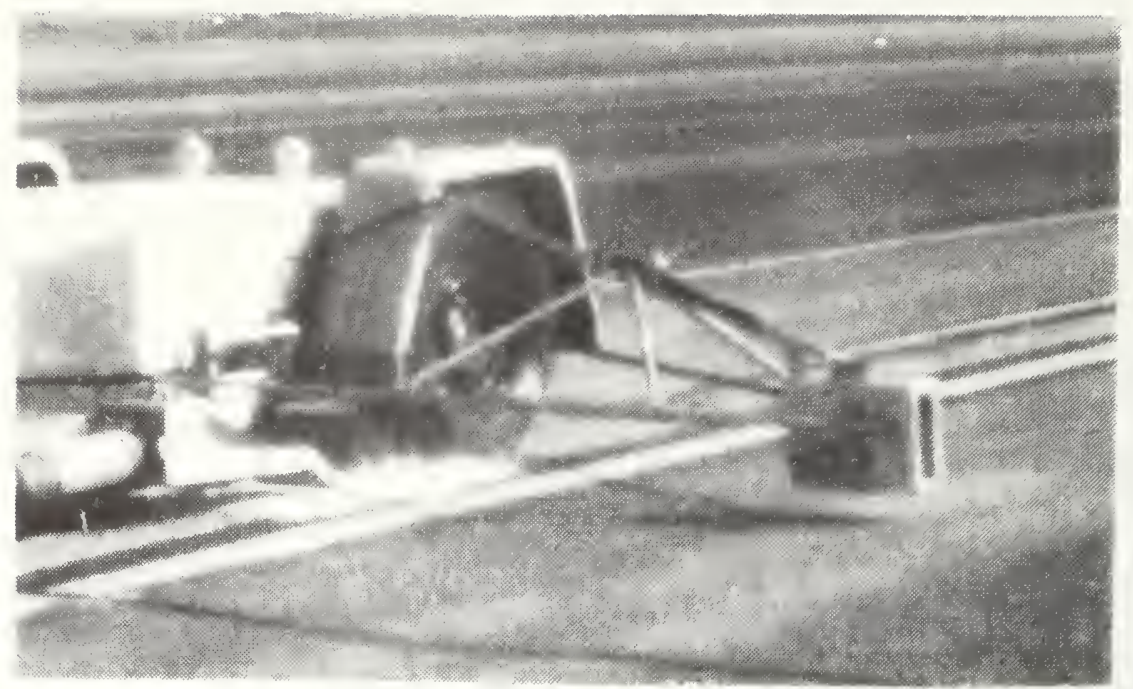

b) With wheel extender

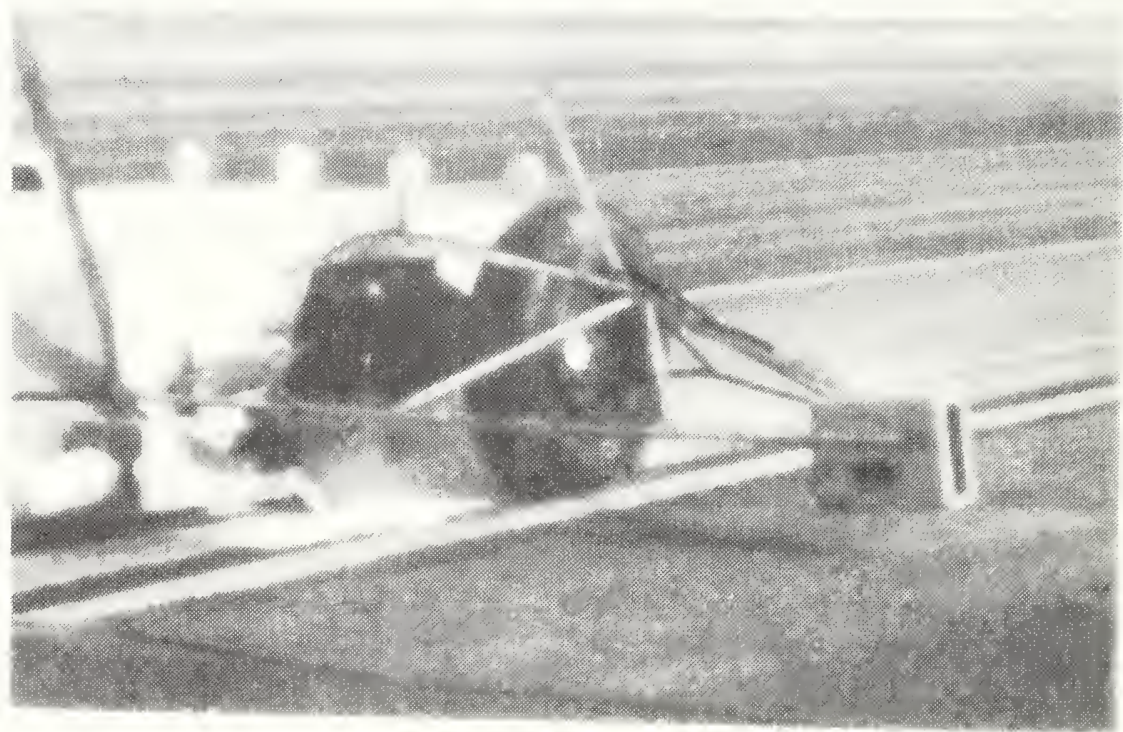

Figure A-2. IRS operating on the DDG. $40 \mathrm{mph}$ test. 


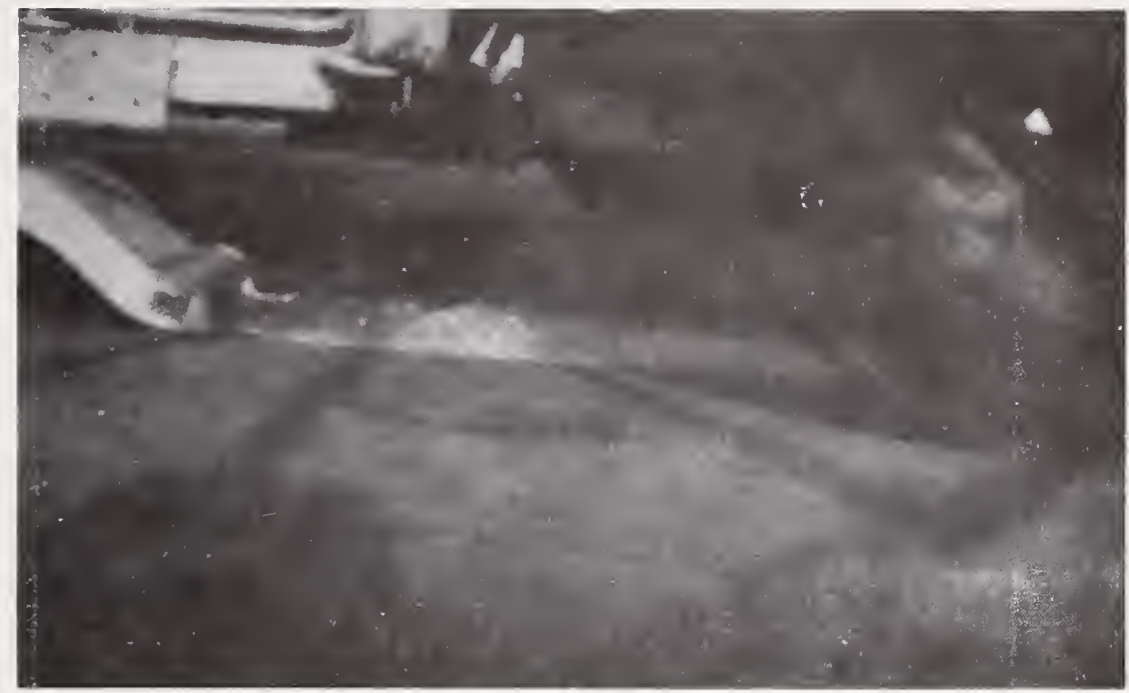

Figure A-3. IRS pavement wetting on solid pavement ahead of the DDG grate.

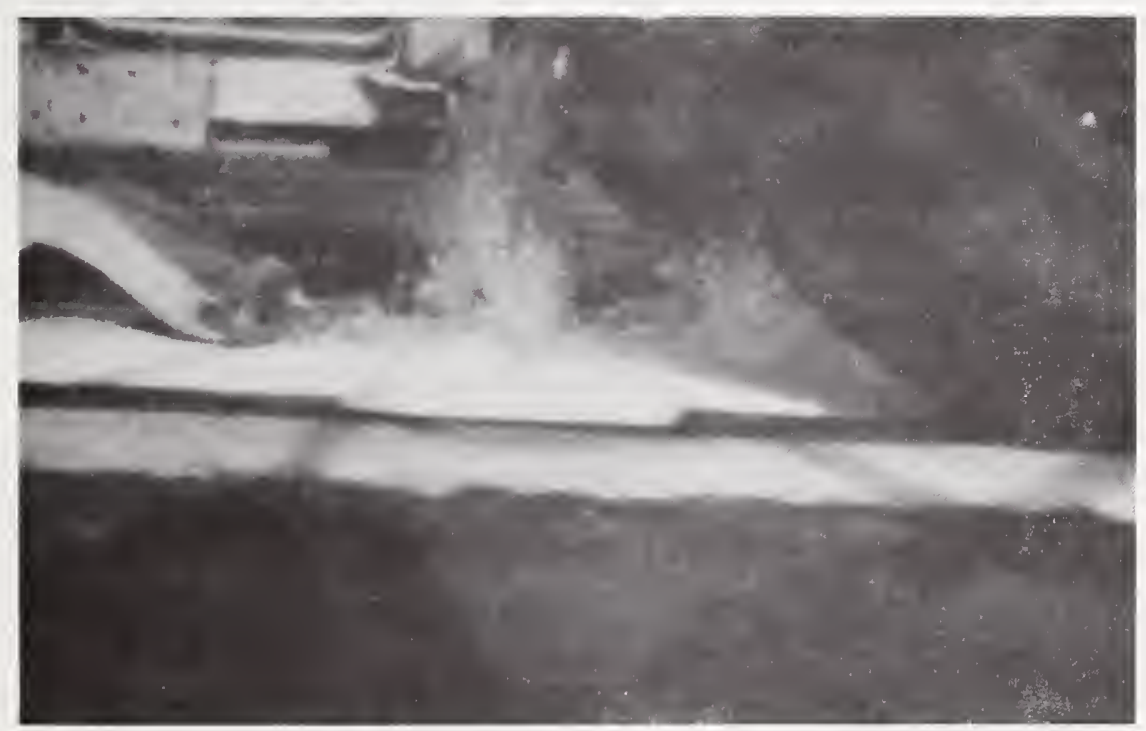

Figure A-4. Severe splashing over the DDG. 
The Test Matrix

A subdivision of the test plan consists of the following test matrix:

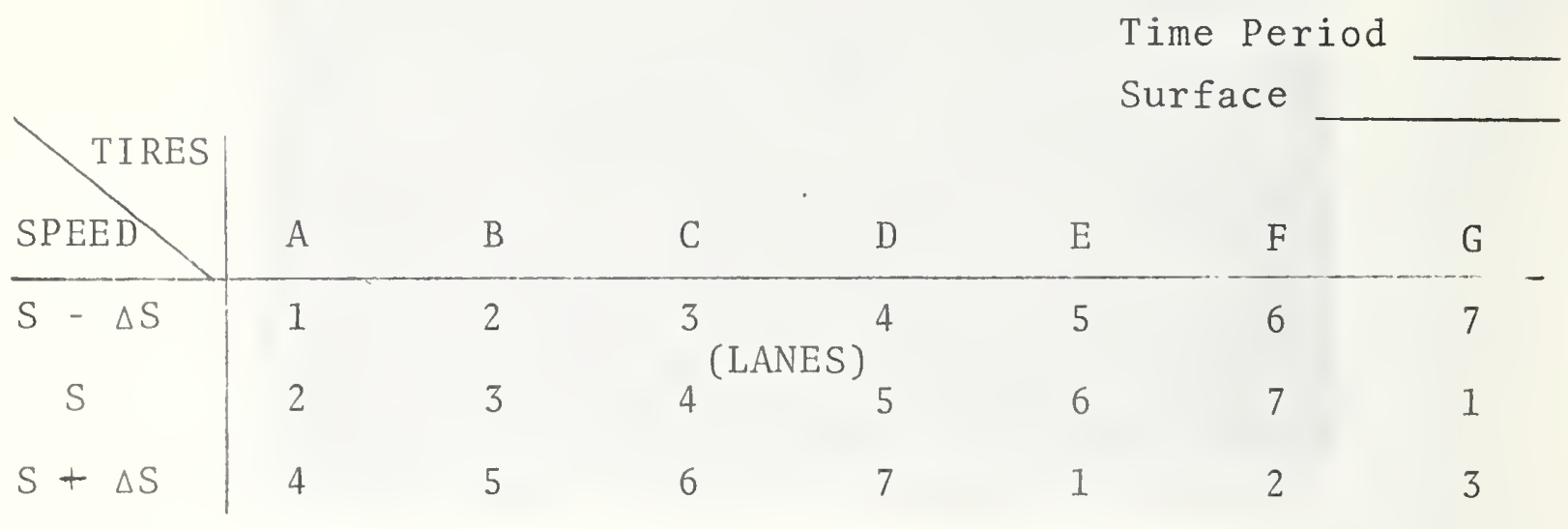

Letters A thru G designate 7 tires while numbers 1 thru 7 identify the 7 lanes comprising the surface. The nominal test speed is $\mathrm{S}$, while $\Delta \mathrm{S}$ is an incremental change in the speed.

The mean of the 21 skid number measurements represents the skid number of the surface measured during the time period using the average tire at the nominal test speed. The novelty of the test matrix is that it yields the skid gradient of the surface, as well as a measure of the surface and tire nonuniformities.

Suppose, we want to compare the effect of making a measurement with tire A with all the other tires. To do this effectively, we want to elimieliminate any measurement deviations due to skidding in different lanes and at different speeds.

Let a measurement result be represented by the notation

$$
(\mathrm{SN}+\varepsilon) \operatorname{LT}(\mathrm{S}-\Delta \mathrm{S})
$$

where:

$$
\begin{aligned}
\mathrm{SN}= & \text { a nominal skid number measured value, } \\
+\varepsilon= & \text { an increase in the } \mathrm{SN} \text { value due to testing at } \\
& \text { lower than the nominal test speed by the } \\
& \text { increment } \Delta \mathrm{S}, \\
\mathrm{L}= & \text { lane identification of the test measurement, and } \\
\mathrm{T}= & \text { the tire identification of the test measurement. }
\end{aligned}
$$


From the test matrix, tire $A$ was used in lanes 1, 2, and 4 at three different speeds. Lane 1 was used with tires $A, G$, and $E$ at three different speeds, while lane 2 was used with tires $B, A$, and $F$ at the three different speeds, while lane 4 was used with tires D, C, and A at three different speeds.

Let us write an equation for the measurement results made in each lane

$$
\begin{aligned}
& 2(\mathrm{SN}+\varepsilon)_{1 A(S-\Delta S)}-(\mathrm{SN})_{1 G(S)}-(\mathrm{SN}-\varepsilon)_{1 E(S+\Delta S)}=\Delta_{\mathrm{AGE}}+3 \varepsilon
\end{aligned}
$$

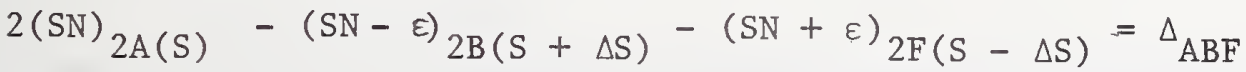

$$
\begin{aligned}
& 2(S N-\varepsilon)_{4 A}(S+\Delta S)-(S N)_{4 C(S)}-(S N+\varepsilon)_{4 D(S-\Delta S)}=\Delta_{A C D}-3 \varepsilon
\end{aligned}
$$

where $\Delta_{\mathrm{AGE}}=$ twice the difference between using tire $\mathrm{A}$ and the average of using tires $G$ and $E$ in lane 1 ,

${ }_{\mathrm{ABF}}=$ twice the difference between using tire $\mathrm{A}$ and the average of using tires $B$ and $F$ in lane 2,

$\Delta_{A C D}=$ twice the difference between using tire $\mathrm{A}$ and the average of using tires $C$ and $D$ in lane 4.

Note that Equations 1, 2, and 3 are each independent of lane effects. Note also that the sum of the three equations is independent of any speed effects (assuming $\Delta \mathrm{S}$ is small). Consequently, the sum is free of both lane and speed effects. To simplify the notation, eliminate the lane and speed variations from the sum, and we get

$$
6(\mathrm{SN})_{\mathrm{A}}-(\mathrm{SN})_{\mathrm{B}}-(\mathrm{SN})_{\mathrm{C}}-(\mathrm{SN})_{\mathrm{D}}-(\mathrm{SN})_{\mathrm{E}}-(\mathrm{SN})_{\mathrm{F}}-(\mathrm{SN})_{\mathrm{G}}=\sum \Delta
$$

We may add to this equation (8), the equation

$$
(\mathrm{SN})_{\mathrm{A}}-(\mathrm{SN})_{\mathrm{A}}=0
$$

which simply says that the skid number without lane and speed dispersion is equal to the skid number measurement using tire A without lane and speed dispersion with no measurement error. Then

$$
7(\mathrm{SN})_{\mathrm{A}}-\left\{\mathrm{SN}_{\mathrm{A}}+\mathrm{SN}_{\mathrm{B}}+\mathrm{SN}_{\mathrm{C}}+\mathrm{SN}_{\mathrm{D}}+\mathrm{SN}_{\mathrm{E}}+\mathrm{SN}_{\mathrm{F}}+\mathrm{SN}_{\mathrm{G}}\right\}=\sum \Delta
$$


Now, the measurement performance with tire A can be compared with the performance of all the other tires by writing

$$
\begin{aligned}
\mathrm{SN}_{\mathrm{A}} & =\sum_{i=\mathrm{A}}^{\mathrm{G}} \frac{\mathrm{SN}_{i}}{7}+\frac{\sum \Delta}{7} \\
& =\quad \begin{array}{l}
\text { mean of all } \\
\text { measurements }
\end{array}+\sum \frac{\Delta \Delta}{7}
\end{aligned}
$$

In a similar manner, the test matrix can be rearranged to yield, for example, the measurement performance on lane 1 compared with the performance on all the other lanes. The results are then a measure of surface uniformity. 


\section{APPENDIX C}

General Description of the Eastern Area Reference System (Tow Vehicle and Trailer)

1. System Identification

1.1 System manufactured by: K. J. Law.

1.2 Model : 1270 .

1.3 Tow vehicle ID number: DOT 40444 .

1.4 Trailer ID number: DOT 40409.

2. Tow Vehicle

2.1 Make: Chevrolet.

2.2 Model year: 1973

2.3 Body style: C30 series "Camper Special" pickup. 10,100 IbGVW rating.

2.4 Engine: 454-4/SE V8.

2.5 Fuel tank capacity: main 20 gallons, auxiliary 16 gallons.

2.6 Seating: bucket seats, 2 front, 2 rear.

2.7 Normal occupancy: front seats only.

2.8 Air conditioning: yes.

2.9 Wheel base: 164-1/2 inches.

2.10 Track: front 66 inches, rear dual 64 inches inside, 84 inches outside.

2.11 Tire size: front 8.75-16.5C(6 PR)(TL), rear 8.75-16.5C(6PR(TL).

2.12 Rear wheels: dual.

3. Trailer

3.1 Construction: welded box section chassis with angular sheet metal body.

3.2 Length: center of hitch to center of axle 120 inches.

3.3 Track 64-5/16 inches (E501 tires).

3.4 Suspension: coil springs, "parallelogram" trailing arms, sway bar. One air spring shock absorber at each wheel. Air springs operated at 50 psi.

3.5 Test brakes: hydraulic disk with hydraulic actuator, selectable for left or right wheel tests.

3.6 Skid measurement transducers: left and right wheels instrumented. Strain gaged beams between axle and brake backing plate. Outputs for traction force and normal force.

4. Pavement Wetting

4.1 Water tank capacity: 290 gallons.

4.2 Pumps: gear type, one for left wheel tests, one for right wheel tests, powered by drive shaft.

4.3 Flow rate control: approximately proportional to speed. Adjusts by changing drive pulleys.

4.4 Nozzles: Penn State type, mounting adjustable for pitch angle and height. 
5. Instrumentation

5.1 Speed: Labeco Tracktest fifth wheel and full scale digital driver aid readout. Independent tachometer generator on trailer wheel for full scale analog data recording readout.

5.2 Water supply: gage readout in cab.

5.3 Flow rate: no gage.

5.4 Inflation: Common tire gage referenced to precision gage.

5.5 Data recorder: Brush Model 440, strip chart, four channels side by side, pressure ink pens.

5.6 Signal amplifiers: (2) Brush 13-4215-12 for vertical load and traction force; (4) Brush 13-4215-32, one for speed, one for SN, and two for pen position of force signals.

5.7 Channel assignments: Ch 1, traction force; Ch 2, normal force; Ch 3, speed; Ch 4 skid number.

Comments: signal recorded on $\mathrm{Ch} 4$ is the instantaneous ratio of the traction force signal to the normal force signal. One second time marks are also recorded. Chart rate is $5 \mathrm{~cm} / \mathrm{sec}$. Channels are $4 \mathrm{~cm}$ wide with 50 divisions.

5.8 Transducer excitation: $10.02 \mathrm{Vdc}$.

6. Trailer suspension:

Tire radial spring rate

Effective spring rate: test wheel-to-body body-to-pavement

Effective Coulomb friction (without shocks)

Natural frequency, high:

Natural frequency, low:

Natural frequency, tire:

Effective viscous damping factor:
$12801 \mathrm{bf} / \mathrm{in}$

$350 \mathrm{lbf} / \mathrm{in}$

$275 \mathrm{lbf} / \mathrm{in}$

$9.41 \mathrm{bf}$

$12.7 \mathrm{~Hz}$

$1.3 \mathrm{~Hz}$

$3.1 \mathrm{~Hz}$

0.2

Operating Parameters of the Eastern Area Reference System

The information below represents the values of recognized EARS variables in effect during this comparison with the IRS.

1. Test tires: standard pavement test tires, G 78-15, ASTM Designation E501.

2. Test tire inflation: 24 psi, maintained during testing.

3. Hitch height: 11-7/8 inches from level pavement to bottom of trailer hitch flange, maintained during testing.

4. Test side of trailer: left only.

5. Calibration signals: left traction 501 lbf, left normal 1081 lbf; speed, none.

6. Test Sequence: Figure $\mathrm{C}-1$

7. Consumable cargo: pavement wetting tank refilled frequently, nominally after 10 runs at $60 \mathrm{mph}$. 

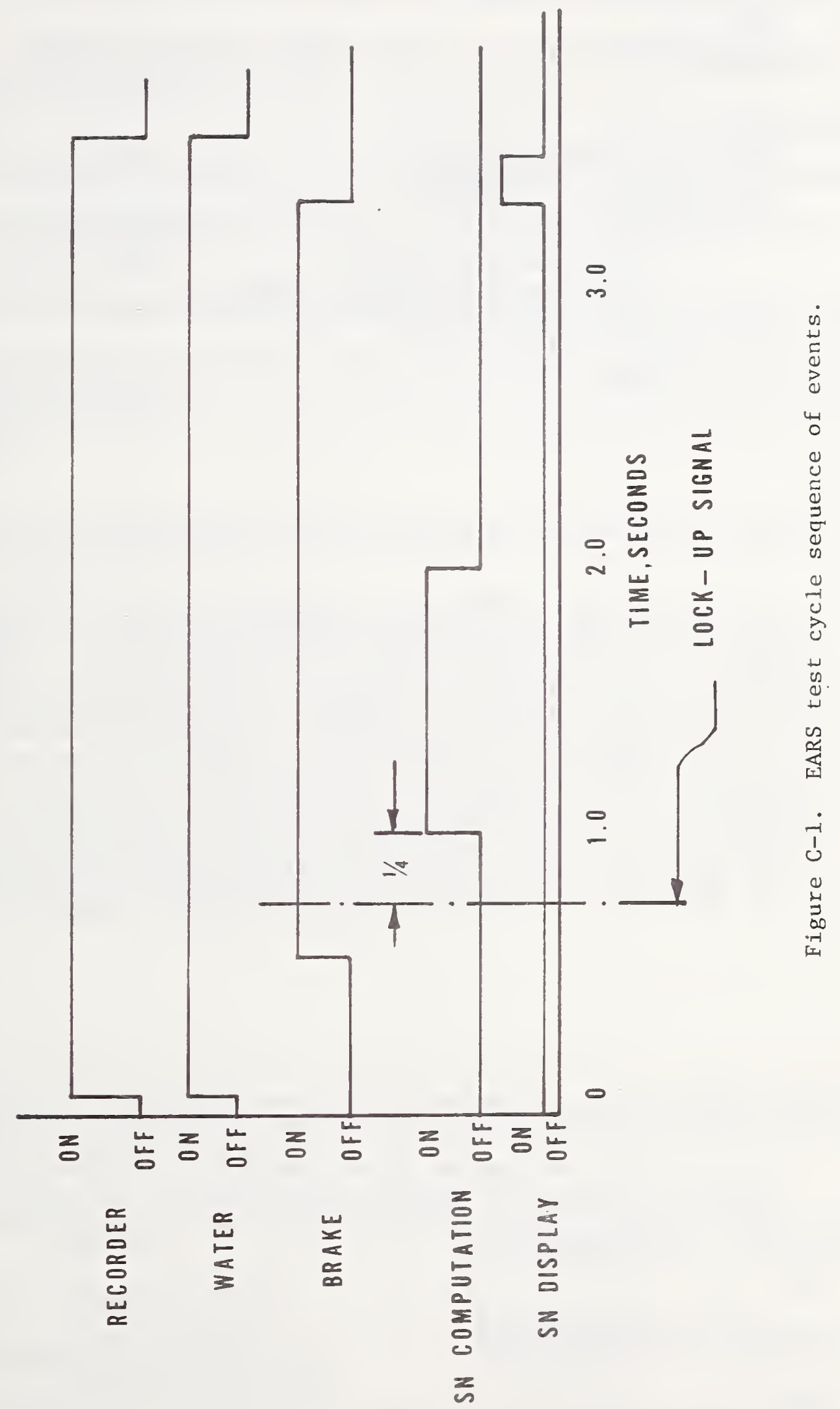
8. Condition of test pavements: dry before each test.

9. Flow rates: $20 \mathrm{mph}, 13.5 \mathrm{gpm} ; 40 \mathrm{mph}, 27.2 \mathrm{gpm} ; 60 \mathrm{mph}$, 40.2 gpm.

10. Crew

7.1 Driver: Herb Litteral.

7.2 Operator: Bill Edwards.

7.3 For further information, contact:

E. A. Whitehurst

Principal Investigator

Field Test and Evaluation Center

for Eastern States

Post Office Box 249

East Liberty, Ohio 43319 
NBS-114A (REV. 7-73)

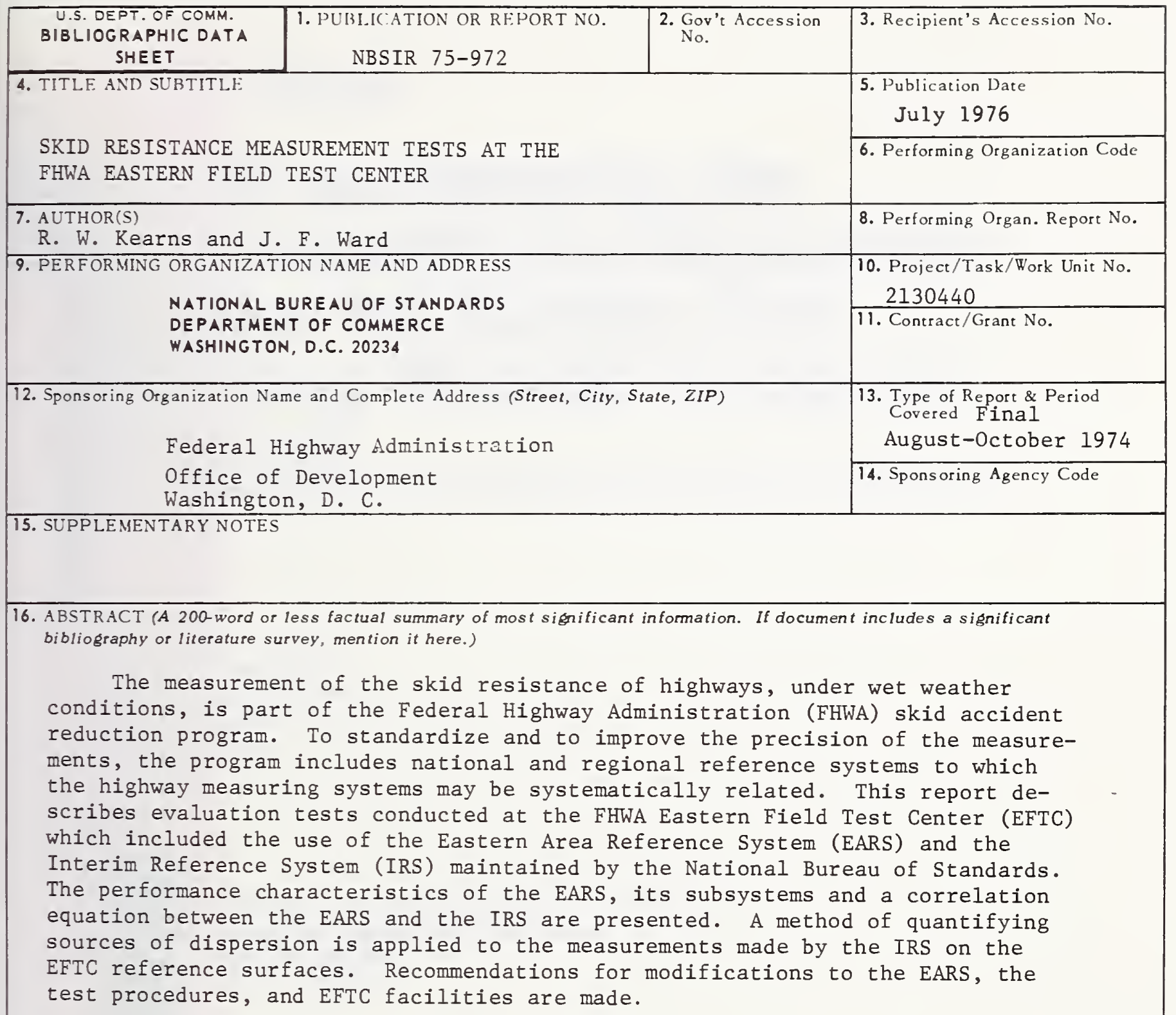

17. KEY W'ORDS (six to twelve entries; alphabetical order; capitalize only the first letter of the first key word unless a proper name; separated by semicolons)

Accident reduction, skidding; correlation, skid resistance; highway safety; pavement, skid resistance; pavement wetting system; tire-pavement interface forces; wet pavement.

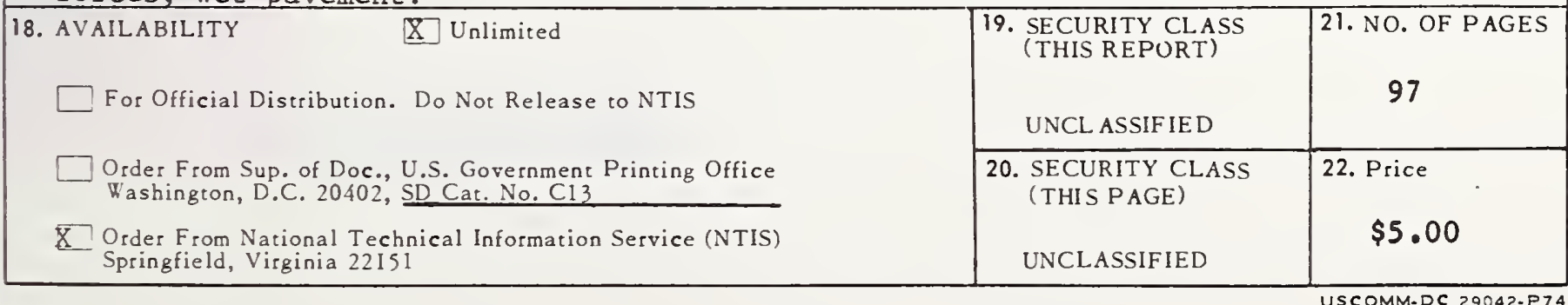


